FOR-001.003

Formal Operations Requirements

LA-UR-93-3831 (Revised)

RECEIVED

JARI 209995

OSTI

\title{
Integrated Formal Operations Plan
}

prepared by the

Configuration Management Office

January 5, 1994

\section{DISCLAIMER}

This report was prepared as an account of work sponsored by an agency of the United States Government. Neither the United States Government nor any agency thereof, nor any of their employees, makes any warranty, express or implied, or assumes any legal liability or responsibility for the accuracy, completeness, or usefulness of any information, apparatus, product, or process disclosed, or represents that its use would not infringe privately owned rights. Reference herein to any specific commercial product, process, or service by trade name, trademark, manufacturer, or otherwise does not necessarily constitute or imply its endorsement, recommendation, or favoring by the United States Government or any agency thereof. The views and opinions of authors expressed herein do not necessarily state or reflect those of the United States Government or any agency thereof. 
This document was produced by the Los Alamos Configuration Management Office.

Authors:

Gary Cort

Will Dearholt

Steve Donahue

Joe Frank

Brad Perkins

Ray Tyler

Jon Wrye

Editing:

Alison Caughran

Geana Garrett

Design Credit:

Gloria Sharp 


\section{DISCLAIMER}

Portions of this document may be illegible in electronic image products. Images are produced from the best available original document. 


Oonfiguration
Management
offoe

1.0 INTRODUCTION

1.1 Goals for the Integrated Formal Operations Plan $\ldots \ldots \ldots \ldots \ldots \ldots \ldots \ldots$

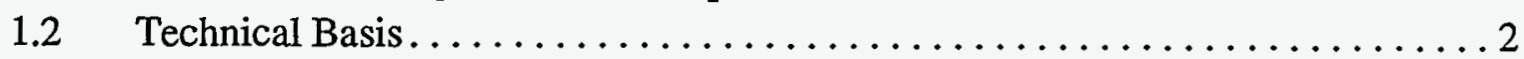

1.3 Relationship to Conduct of Operations. . . . . . . . . . . . . . . 2

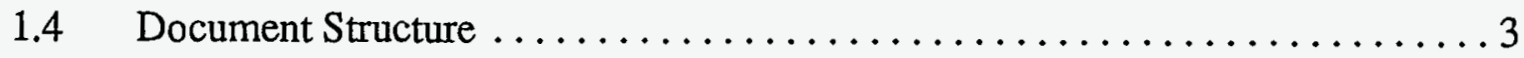

1.5 Application of the Integrated Formal Operations Plan. . . . . . . . . . 3

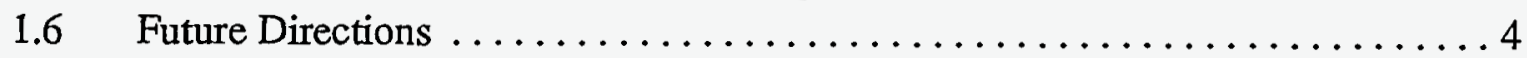

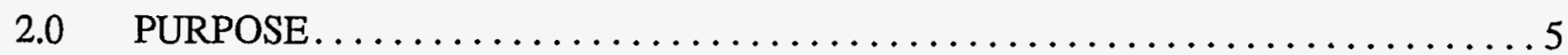

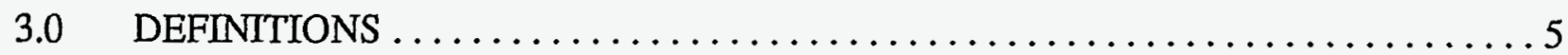

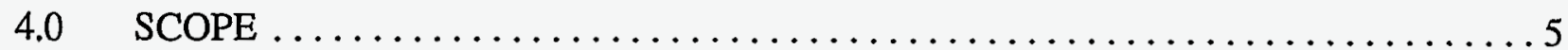

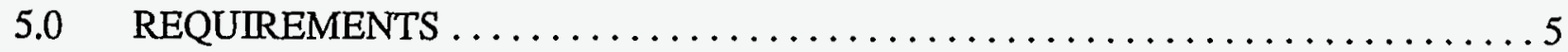

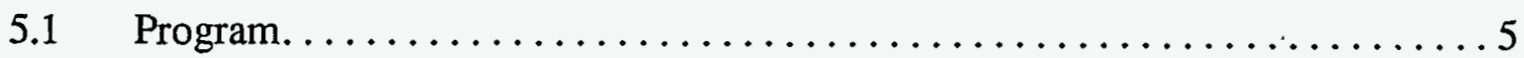

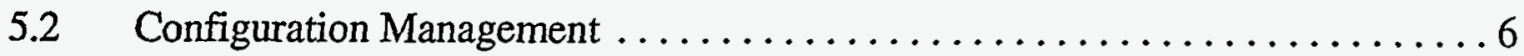

5.3 Personnel Qualification and Training . . . . . . . . . . . . . . . 12

5.4 Deficiencies, Occurrences, and Process Improvement. . . . . . . . . . 14

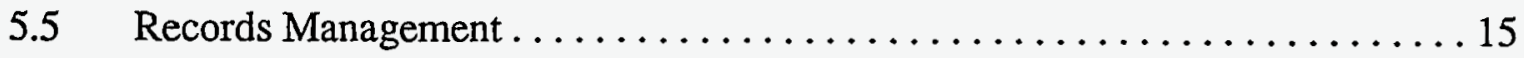

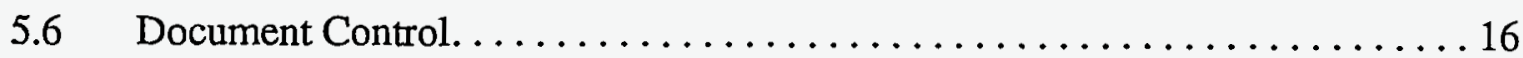

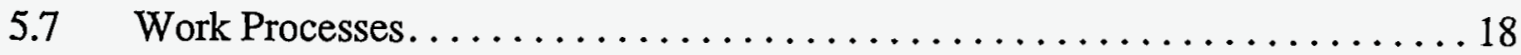

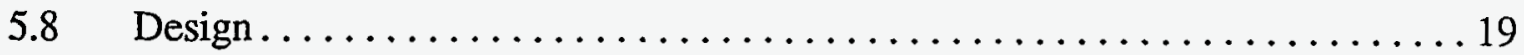

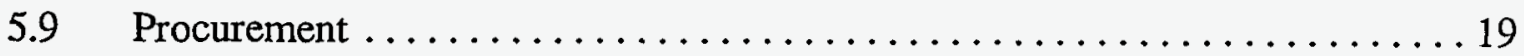

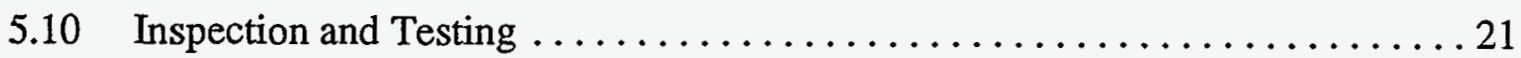

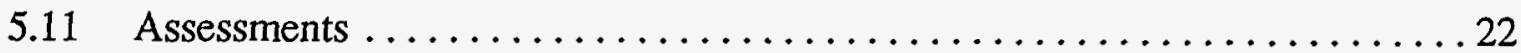

$6.0 \quad$ RESPONSIBILITIES . . . . . . . . . . . . . . . . . . . . . . . 23

6.1 Accountable Line Manager. . . . . . . . . . . . . . . . . . . 23

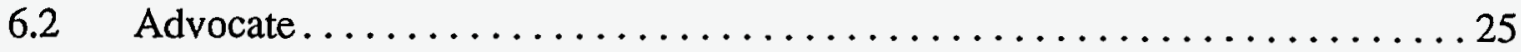

6.3 Assessment Sponsor . . . . . . . . . . . . . . . . . . . . . . 25

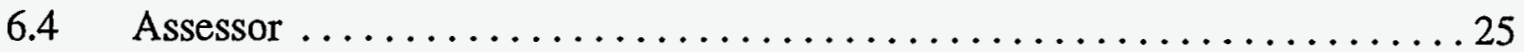

6.5 Candidate for Qualification. . . . . . . . . . . . . . . . . . . . 25

6.6 Change Agent . . . . . . . . . . . . . . . . . . . . . . . 26

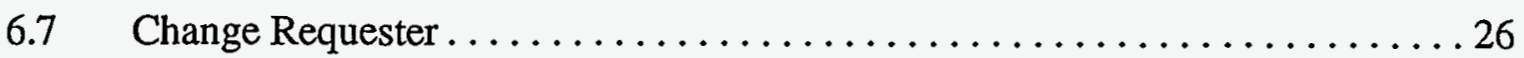

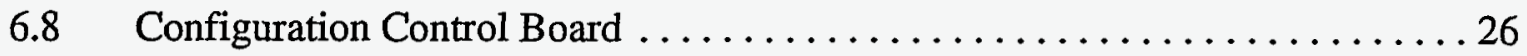

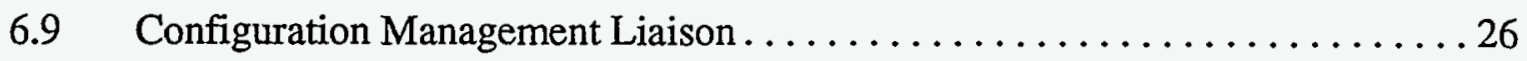

6.10 Configuration Manager. . . . . . . . . . . . . . . . . . . . 27

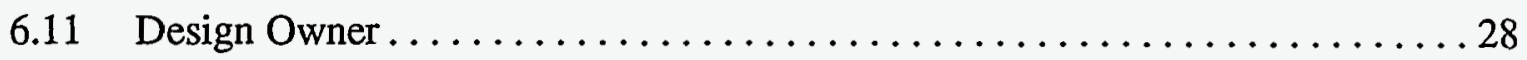

6.12 Document Custodian. . . . . . . . . . . . . . . . . . . . . . 29

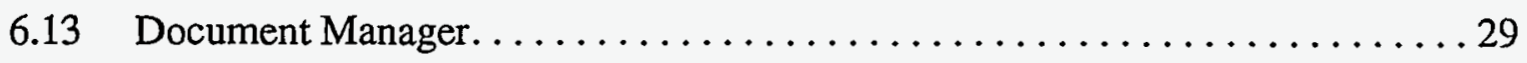

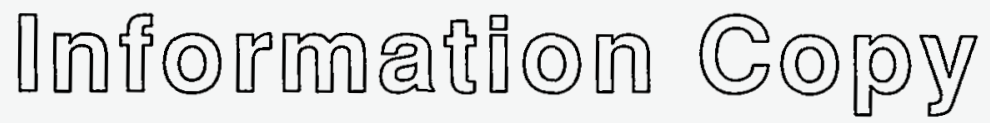




\begin{tabular}{|c|c|c|}
\hline $\begin{array}{l}\text { FOR-001.003 } \\
\text { Table of Contents } \\
\text { Page } 2 \text { of } 2\end{array}$ & $\begin{array}{l}\text { Integrated Formal Operations } \\
\text { Plan }\end{array}$ & $\begin{array}{l}\text { Configuration } \\
\text { Management } \\
\text { Office }\end{array}$ \\
\hline
\end{tabular}

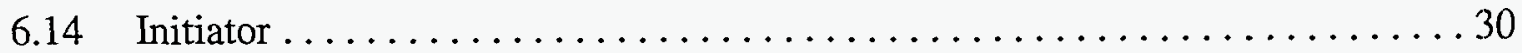

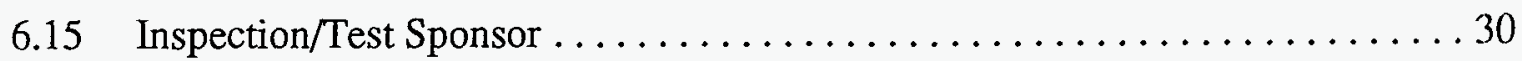

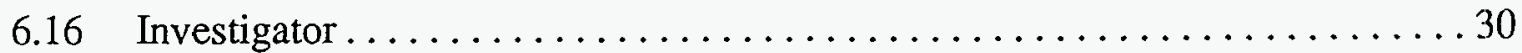

6.17 Procurement Authority . . . . . . . . . . . . . . . . . . . . . . . 30

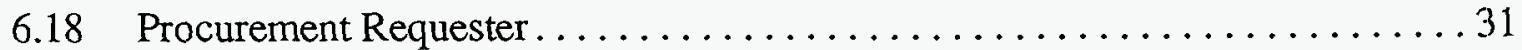

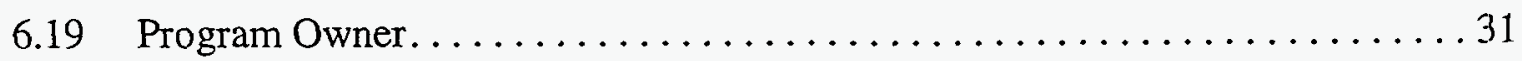

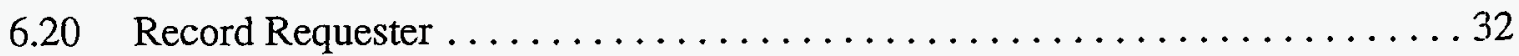

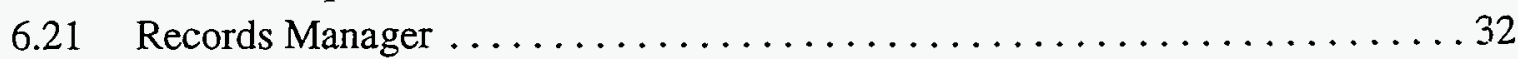

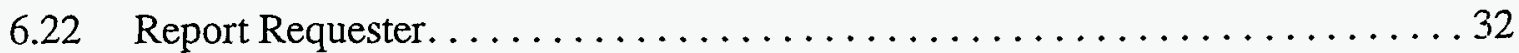

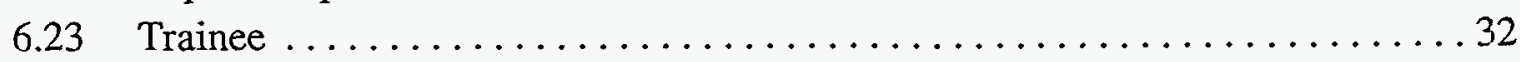

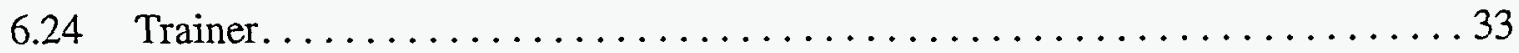

6.25 Training Course Developer. .............................. 33

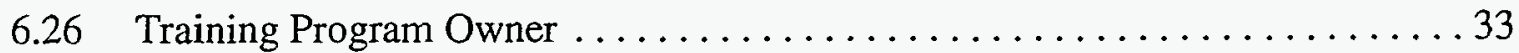

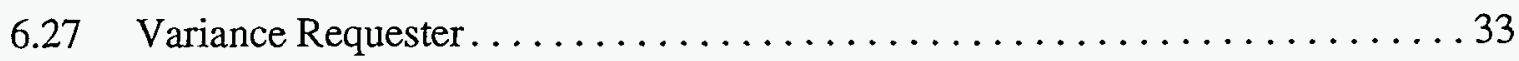

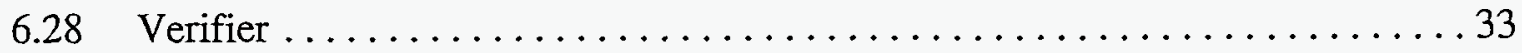

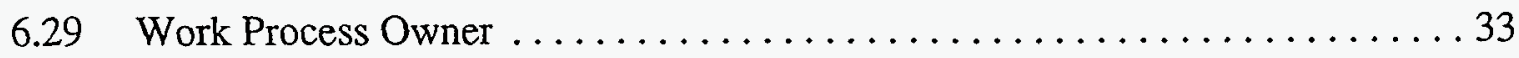

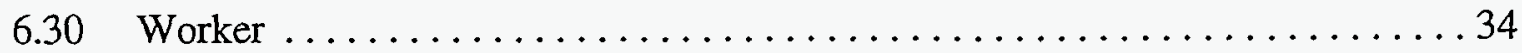

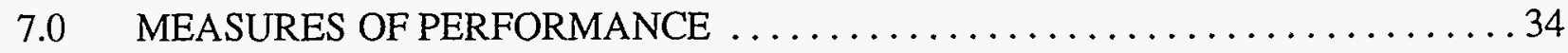

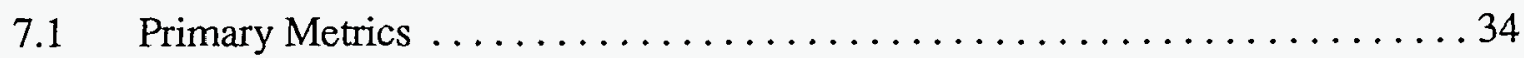

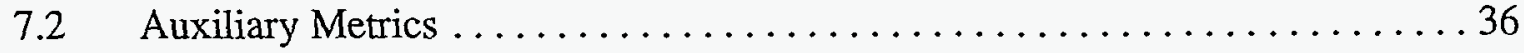

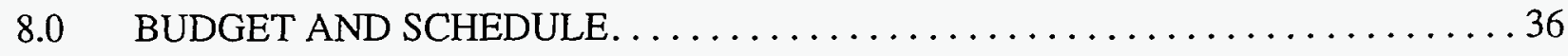

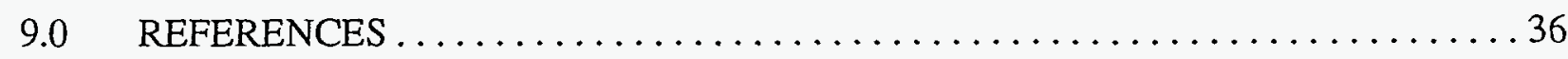

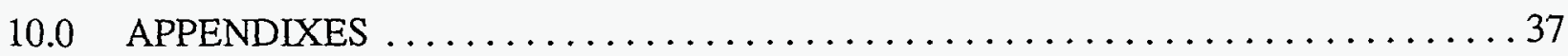

$11.0 \quad$ ATTACHMENTS. . . . . . . . . . . . . . . . . . . . . . . . . . 37 


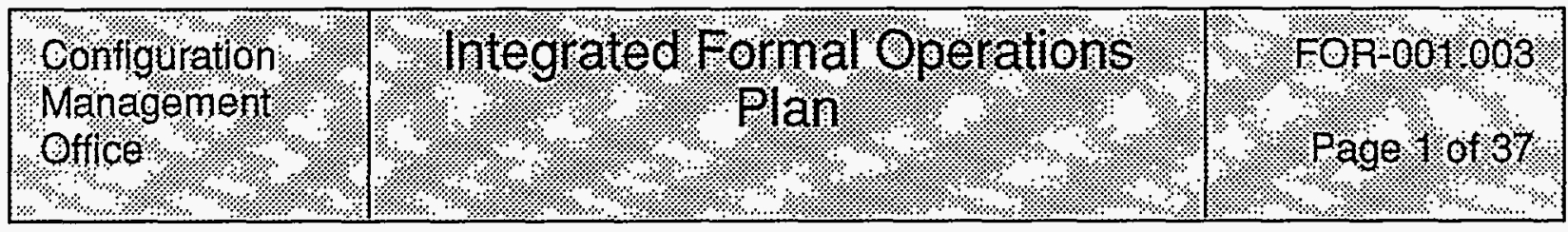

\subsection{INTRODUCTION}

The concept of formal operations (that is, a collection of business practices to assure effective, accountable operations) has vexed the Laboratory for many years. Although conceptually simple, developing practical formal operations programs has proven exceedingly difficult, and there are few examples of success. There are many reasons for this.

To date most attempts at developing such programs have been based upon rigid, compliancebased interpretations of a veritable mountain of Department of Energy (DOE) orders, directives, notices, and standards. These DOE dictates seldom take the broad view but focus on highly specialized programs isolated from the overall context of formal operations. The result is a confusing array of specific, and often contradictory, requirements that produce a patchwork of overlapping niche programs.

The resulting formal operations programs are equally confusing. Boundaries between the various formal operations elements are vague or nonexistent. Each formal operations element tends to re-invent and incorporate all of the others resulting in inconsistent, expensive, redundant programs.

For example, virtually every DOE order specifies requirements for a training program, a formal operations element. There are other orders dedicated specifically to training. Consequently, Laboratory organizations have developed multiple, parallel training programs working to different, often conflicting, requirements. This unnecessary duplication of effort wastes precious resources, dramatically increases the complexity of our work processes, and communicates a sense of confusion to our customers and regulators.

Coupled with the artificial divisions that have historically existed among the Laboratory's formal operations organizations (quality assurance, configuration management, records management, training, etc.), this approach has produced layers of increasingly vague and complex formal operations plans, each of which interprets its parent and adds additional requirements of its own. Organizational gridlock ensues whenever an activity attempts to implement these bureaucratic monstrosities.

The Laboratory needs a new formal operations strategy to break the tyranny of this dysfunctional mode of operation. We need an overall vision of what a Laboratory formal operations program should be. We need carefully defined formal operations elements that are consistent with this vision, understandable to the user, and deal with all of the relevant issues, rather than bundled-together, isolated, disembodied requirements. Most of all we need a formal operations program that can be rapidly and directly implemented without layers of intermediate interpretation, extensive customization, or hordes of implementation experts. The integrated formal operations plan presented in the succeeding sections was born of these needs.

\subsection{Goals for the Integrated Formal Operations Plan}

We wrote this plan with very specific goals in mind. First and foremost, we wanted to develop a plan that could serve as the basis for an overall Laboratory program of formal operations. To meet this goal the plan must be comprehensive; that is, it must incorporate all of the formal operations elements and provide a complete set of requirements for each such element.

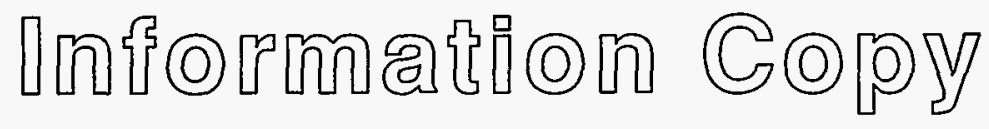




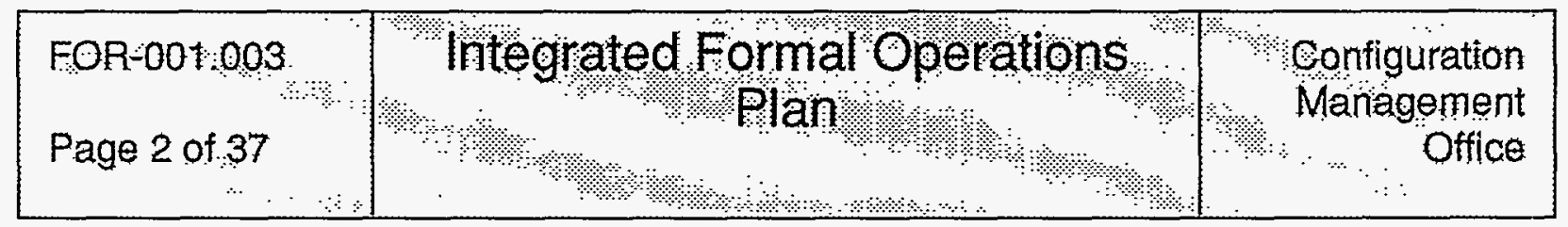

Furthermore, it must do this in a manner that ensures that each formal operations element is internally consistent and consistent with all of the other formal operations elements of the program.

We further wanted to focus and clarify each of the formal operations elements by concentrating all of the relevant requirements within the corresponding element and then creating unambiguous interfaces to other formal operations elements. This enables each such element to draw support from all of the others without contributing to the confusing jumble of largely irrelevant or inappropriate requirements that characterize the Laboratory's (and the Department's) previous failed formal operations approaches.

Finally, we made it our goal to develop a plan from which implementing procedures can be derived directly, without the need for intermediate interpreting plans, guidance, or implementation manuals. A subsidiary goal was to make sure that the plan maintains a truly Laboratory-wide scope and perspective: that it apply equally well to any Laboratory organization and at any level from the Director's Office down to individual sections.

\subsection{Technical Basis}

We chose the program elements of DOE Order 5700.6c Quality Assurance as the framework for the integrated plan. We then augmented these elements with an additional formal operations element for configuration management. We took some liberties in the process, on occasion dividing a single program element in the Order into multiple formal operations elements (for example, the integrated plan has records management and document control as two separate formal operations elements, whereas the Order has a single program element that encompasses both). In other instances we combined multiple program elements from the Order into one formal operations element in the integrated plan (as we did with assessments.)

But the development of the integrated plan went far beyond these superficial organizational changes. We performed a detailed analysis of requirements for each formal operations element to determine the minimum set of requirements necessary to unambiguously characterize that element. In the process we eliminated the implicit overlaps among the program elements of the Order, identified missing requirements, and specified formal interfaces among the various elements. This had the overall effect of decoupling the elements, simplifying the formal operations model, and clarifying the definition of each formal operations element.

We conducted the analysis using a formal technique called structured analysis. The result of this effort was a graphical depiction of the process requirements, the related input and output information, inter-element interfaces, and the responsible work functions for each formal operations element. These diagrams are included in Appendix A and provide an excellent summary view of each formal operations element. We derived the detailed specification of each formal operations element (see Section 5.0) directly from this analysis.

\subsection{Relationship to Conduct of Operations}

There continues to be great confusion at the Laboratory regarding the roles and purpose of formal operations versus conduct of operations. In many cases they are considered (erroneously) as synonyms. In other instances they are represented as competitors.

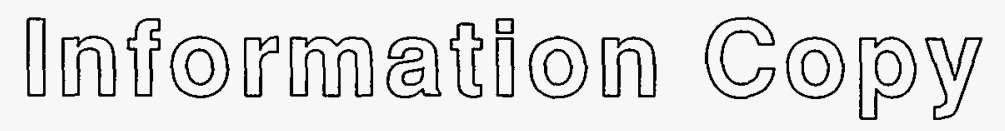




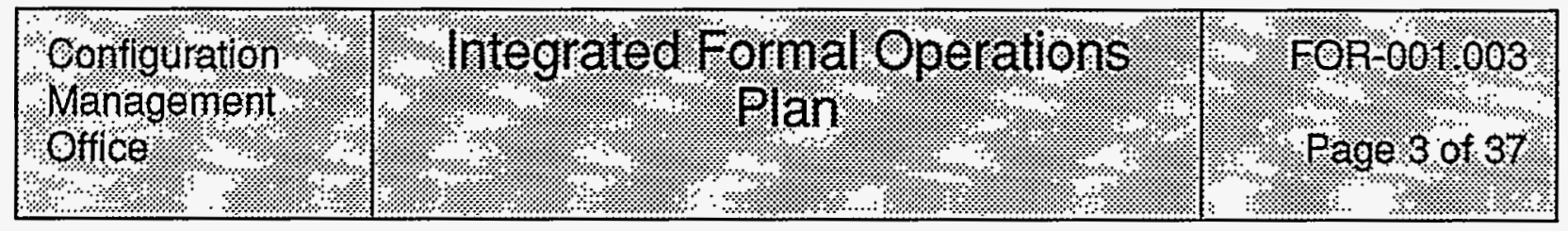

In fact they are very different concepts with unique, but complementary, goals. Conduct of operations, as defined in DOE Order 5480.19, encompasses the requirements for a set of 18 specific work processes (shift changeover, lockout/tagout, log keeping, etc.) that are essential to the responsible operation of a nuclear facility (and are applicable to many other aspects of Laboratory operations).

Formal operations, on the other hand, specifies a collection of fundamental, supporting activities that are the essential foundation upon which a program of conduct of operations (or any other crucial work processes) must be built. For example, all of the elements of conduct of operations require effective records management, document control, and training support. Design, procurement, and process improvement are basic capabilities that cut across all of our work processes. In this sense, the formal operations program provides the enabling technologies that are the essential support infrastructure for specific primary work processes like those in conduct of operations.

Establishing an effective formal operations program does not eliminate the need for effective conduct of operations. However, a credible conduct of operations program must be rooted in an effective program of formal operations.

\subsection{Document Structure}

We have organized this document into eight sections and three appendixes. This section (Section 1.0) places the integrated management plan in context with respect to existing Laboratory and DOE programs, provides background information about the philosophy, goals, and technical approach used to develop the plan, and summarizes some application information.

Sections 2.0 through 4.0 specify the purpose of the integrated formal operations plan, provide a reference to definitions of terms used throughout the document, and specify its scope. Section 5.0 identifies the formal operations elements and provides a detailed specification of requirements for each. Section 6.0 is a summary of roles and responsibilities.

Section 7.0 details specific measurements that can be used to characterize the performance of a formal operations program that is based on this plan. Section 9.0 contains a list of references to relevant documents and other reference works.

Appendix A contains the diagrams that are the formal definition of requirements resulting from the structured analysis decomposition of each formal operations element. Appendix $B$ contains recommendations for tailoring this program to your particular organization.

Appendix $C$ provides an alphabetical index of key words, terms, and concepts. Attachment 1 contains a questionnaire that can be completed by the reader and returned to the Configuration Management Office to help us improve this and all future documents.

\subsection{Application of the Integrated Formal Operations Plan}

We have published this plan to provide Laboratory organizations with a viable alternative to the tedious, time-intensive, and exceedingly expensive process of developing custom formal operations programs. Applied under the guidance of a sensible graded approach, we believe

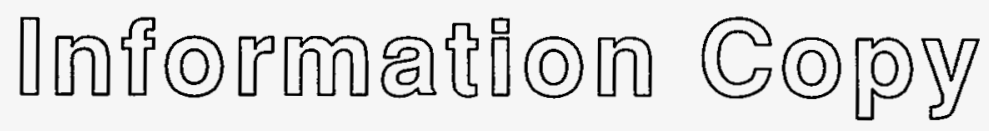




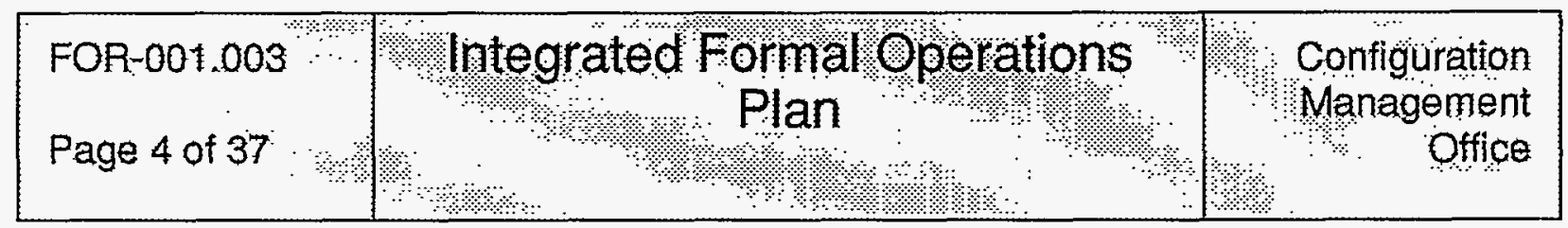

that this plan is applicable without customization to virtually any Laboratory organization at any level in the management hierarchy.

To accomplish this we carefully crafted each requirement to be as objective as possible, without specifying any implementation details. Hence we specified only the information content for the various plans, procedures, requests, and reports that are required by the integrated plan. This gives the implementing organization the flexibility to satisfy these requirements in myriad ways based upon the nature and associated risk of the subject activity.

For example, a test plan is required only to provide the information specified in Section 5.10.1.2. It may be implemented as a simple memo for low intensity activities or may be a detailed, highly structured document for activities for which the stakes are higher. It is the responsibility and prerogative of the accountable line manager to decide which of these (or some other intermediate) implementations is most appropriate.

To ensure the widest applicability of the integrated plan across the Laboratory, we have identified the entities responsible for the various aspects of each formal operations element in terms of work functions rather than specific positions or job titles. This gives each implementing organization the ability to assign responsibilities by mapping the local organizational structure onto the specified work functions. The tailoring guide in Appendix $B$ provides additional information on this and other adaptation issues.

Finally, a note about grading. The integrated plan is very comprehensive. Most organizations will not have need for all of the formal operations elements to assure the success of their operations. In addition, as described above, there is a broad range of implementation flexibility associated with each formal operations element that is adopted. The particular elements that are adopted by any organization depend solely on the character of the organization and the nature of its activities. The level of intensity with which the organization implements the elements it has adopted will be determined by the grading system in use. Ultimately it is the responsibility of the organization's management to articulate and defend that grading system.

\subsection{Future Directions}

This document specifies a non-mandatory program of formal operations that can be adopted by any Laboratory organization. As a principal formal operations support activity, the Configuration Management Office developed and supports this program and makes it available to the Laboratory at no charge.

As part of our continuing commitment to support the Laboratory's formal operations, we will publish a complete implementation for the integrated plan. This implementation will include a complete suite of procedures and technical standards that can be adopted or adapted by an organization to implement each formal operations element of the plan. We will also publish comprehensive training courses (including visual aids, course notes, instructors guides, and proficiency tests) for the various elements.

We intend to furnish a complete and comprehensive program with all of the support necessary for Laboratory organizations to rapidly and cost-effectively establish local

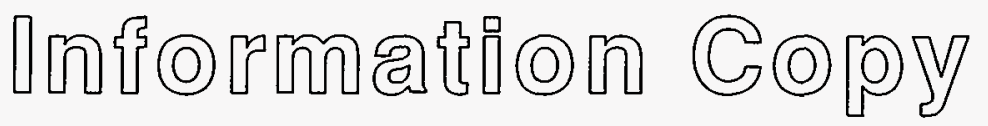




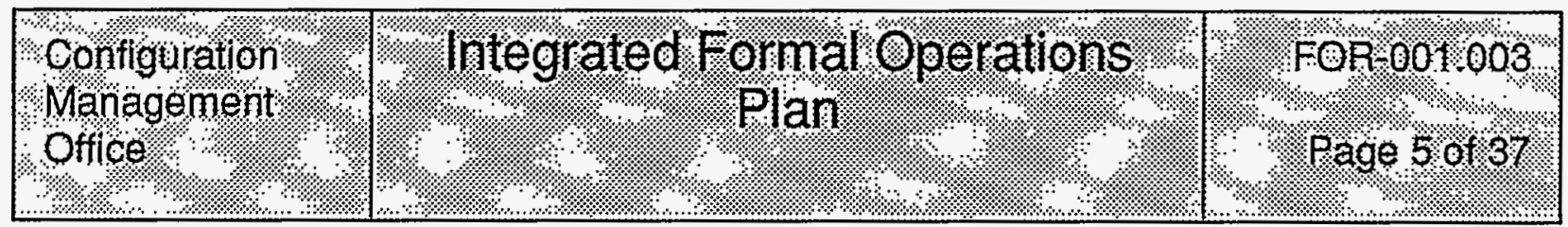

programs of formal operations. We hope to help individual organizations avoid the anguish and upheaval that have so of ten been associated with instituting formal operations, and help the Laboratory as a whole get on with the job of accomplishing its technical mission.

\subsection{PURPOSE}

The purpose of this document is to establish a set of requirements that must be met by an integrated formal operations program, assign responsibilities for implementation and operation of the program, and specify criteria against which the performance of the program will be measured.

\subsection{DEFINITIONS}

Reference 3 in Section 9.0 contains definitions for many of the terms used in this document. The first usage of these terms is italicized.

\subsection{SCOPE}

The accountable line manager specifies the items, processes, and information, i.e., the controlled elements, to which the formal operations program specified in this document applies. These controlled elements may consist of material items such as facility equipment or less tangible items such as programs, processes, and information. The formal operations program is implemented using a graded approach based on the level of importance of the various controlled elements and the scope of the activities in which they are involved.

\subsection{REQUIREMENTS}

\subsection{Program}

This section specifies the requirements for a formal process to establish a new program and to document it with a program plan. A program plan specifies the requirements with which a program must comply. This formal operations plan mandates the creation of many different types of program plans, e.g., for training, design, and assessment. Other aspects of operations may also require a program plan, e.g., a maintenance implementation plan. These additional plans must also comply with the requirements in this section.

\subsubsection{Program Owner}

The program owner will mandate a program's creation and will ensure that a formal plan is developed to describe it.

\subsubsection{Program Plan}

A program plan is a document that includes the program's 1) purpose, 2) scope,

3) requirements, 4) organization and responsibilities, 5) budget, 6) schedule,

7) performance metrics, and 8) references.

A program plan will address the following program-context elements: 1) the mission and goals of the program, 2) known risks and any mitigating factors, 3) known criteria

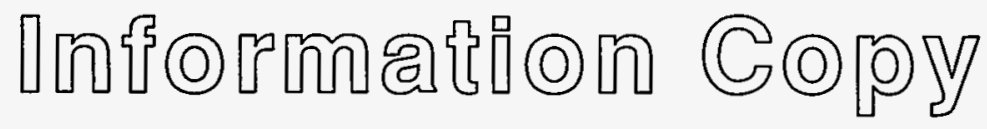




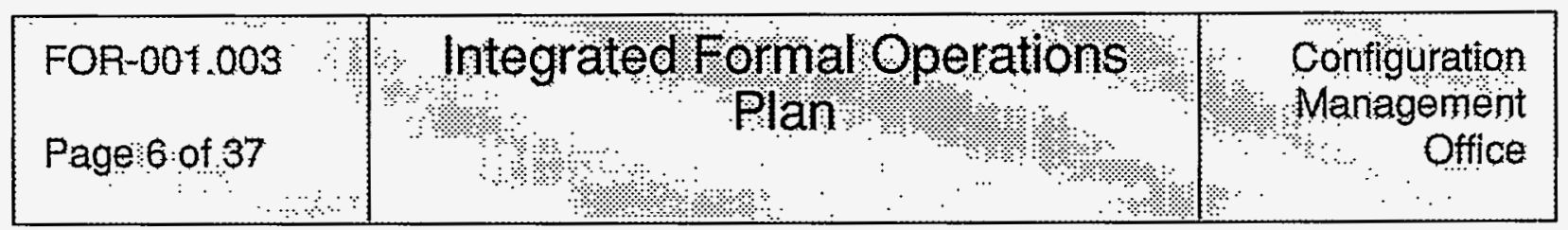

against which the program will be judged, and 4) all explicit requirements that the program must satisfy.

The program owner will initiate program plan development by submitting a change request to, and obtaining an approved work authorization from, configuration management (see Section 5.2.2.2).

\subsubsection{Certifying a Program Plan}

The program owner will ensure that a candidate program plan is compiled into a proposed baseline and is submitted to configuration management for evaluation and certification (see Section 5.2.2.4).

\subsection{Configuration Management}

This section specifies the requirements for identifying the configurations of controlled elements at discrete points in time for the purposes of systematically controlling changes to the configurations and maintaining the integrity and traceability of the configurations throughout the controlled elements' life cycles.

\subsubsection{Configuration Identification}

This section specifies the requirements for describing, labeling, grading, and grouping controlled elements.

5.2.1.1 Describing and Labeling Controlled Elements. The configuration manager will ensure that each controlled element is described and is labeled with a unique identifier that distinguishes it from every other controlled element. The controlled element labels will conform to the labeling strategy specified in the corresponding configuration definition. The configuration manager will develop and maintain a document that lists each controlled element, its description, and its identifier.

5.2.1.2 Grading Controlled Elements. The accountable line manager will ensure that each controlled element receives a distinct grade that indicates its level of importance and, therefore, an indication of the level of configuration management necessary to maintain it.

5.2.1.3 Creating Configuration Definitions. The accountable line manager will develop configuration definitions to specify strategies for grouping related controlled elements into baselines (see Section 5.2.2.1.1). A configuration definition is a document that includes 1) a configuration-definition name, 2) a unique identifier, 3 ) a description of the types of controlled elements included in the configuration definition, 4) a labeling strategy, and 5) a list of related configuration definitions.

The following examples illustrate the flexibility that the accountable line manager has when specifying configuration definitions. These examples describe hypothetical configuration definitions for fire protection systems.

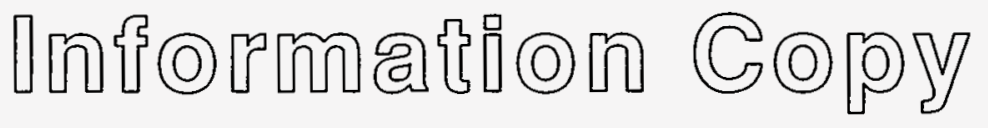




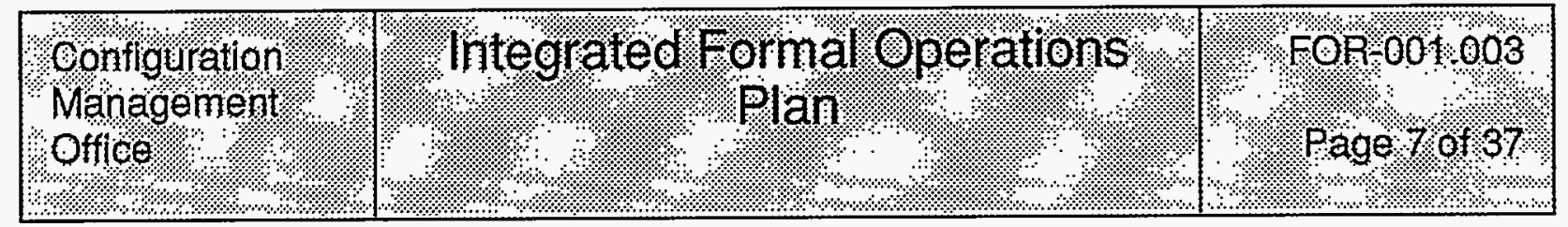

5.2.1.3.1 Example Configuration Definition. In one approach, the accountable line manager may specify the configuration definition to be 1) the physical items that comprise the fire protection sprinkler system (consisting of detectors, alarms, control valves, pipes, and sprinklers);2) the associated design and user documentation; and 3) the maintenance procedures.

5.2.1.3.2 Modular Configuration Definition Example. Alternatively, the line manager may decide to create three configuration definitions for the fire protection sprinkler systems. The first might include only the physical items and design documentation. The second could specify user documentation and the third would then specify the maintenance procedures.

5.2.1.3.3 Kitchen Sink Example Configuration Definition. Many other configuration definitions are possible for these systems depending on the organization's needs and resources. For instance, the line manager may choose to broaden the scope of the definition and incorporate safety interlocks, computer control software, or passive fire protection elements such as movable office partition walls into the definition.

5.2.1.3.4 Building Block Configuration Definition Example. The line manager could specify a configuration definition for a common type of subsystem and reference it in the configuration definitions for the parent systems. One such "building block" definition could specify that all computer software baselines include requirements and design documents, source code, user manuals, test plans, and test reports. The third example above then could reference this software configuration definition for the computer control software, rather than explicitly specify the types of computer software controlled elements that must be included. By using this technique of specifying building block definitions, the line manager will ensure a high level of consistency in baselines for configurations of controlled elements that have common features.

5.2.1.4 Certifying the Configuration Definition. The accountable line manager will ensure that a candidate configuration definition is compiled into a proposed baseline and is submitted to configuration management for evaluation and certification.

\subsubsection{Configuration Control}

This section specifies the requirements to incorporate changes in a controlled manner and ensure that baselines are not changed in an ad hoc fashion.

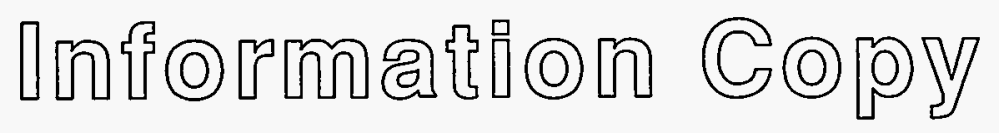




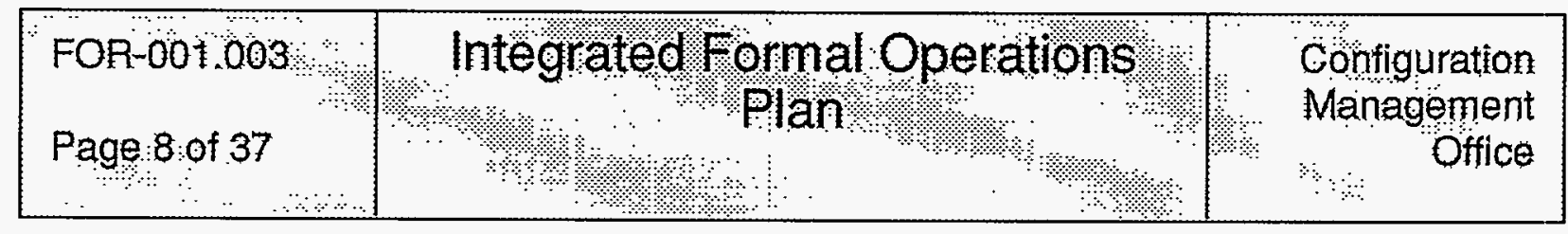

\subsubsection{Configuration Control Environment}

5.2.2.1.1 Baseline. A baseline is a collection of functionally related controlled elements referenced to a designated point in time. A baseline reflects the structure of an associated configuration definition and is maintained under configuration management as a unit. The following examples illustrate how the composition of a baseline is derived from a configuration definition. The baselines in these hypothetical examples are for FP-101, a particular fire protection sprinkler system in a Laboratory facility. They are based on the configuration definitions described in Section 5.2.1.3.2. Baselines for other fire protection sprinkler systems, such as FP-102, FP-103, or FP-104, would be derived in similar fashion from the same configuration definitions.

Example One (Physical Items and Design Documentation). The first FP-101 baseline consists of the following uniquely identified controlled elements that make up a wet pipe sprinkler system:

- $\quad$ smoke detector (ID \#M-46D)

- $\quad$ alarm check valve (ID \#T-27A)

- water main valve (ID \#V-11M)

- $\quad$ sprinklers with detectors at each head (ID \# SV-214 through SV-250, inclusive)

- distribution water piping between mains and sprinklers (ID \#WP-33PT)

- water gong (ID \# WG-4)

- $\quad$ pressure gauges (ID \# PG-145 and PG-177)

- $\quad$ alarm test valve (ID \# ATV-4)

- as-built drawings (Drawing numbers TA-3-35 to TA-3-39)

Example Two (User Documentation). The second FP-101 baseline, conforming to the second configuration definition of Section 5.2.1.3.2, consists of the following uniquely identified controlled elements:

- Fire Protection Personnel User Manual for the Acme Sprinkler System (ID \#FP-UM-503)

Example Three (Maintenance Documentation). The third FP-101 baseline, conforming to the third configuration definition of

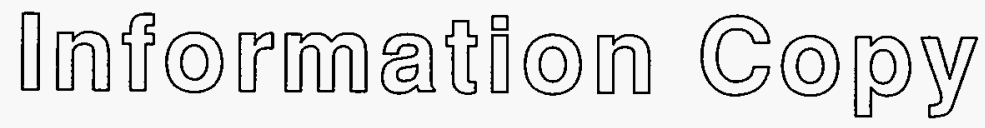




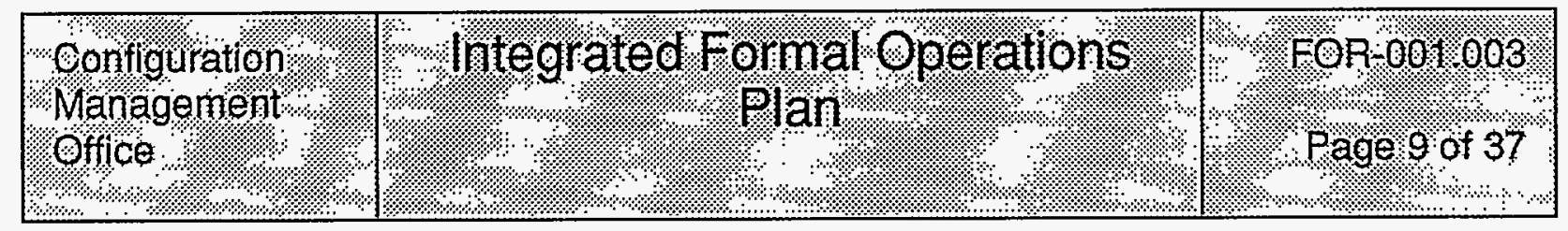

Section 5.2.1.3.2, consists of the following uniquely identified controlled elements:

- Maintenance Manual for the Acme Sprinkler System (ID \#FP-MM-504)

- $\quad$ Fire Protection Group Test Procedures for Sprinkler Systems FP-101 through FP-104 (ID \# FP-MM-100)

5.2.2.1.2 Configuration Manager. The accountable line manager will designate a configuration manager to serve as the line manager's agent in executing configuration management tasks.

5.2.2.1.3 Configuration Management Liaison. The accountable line manager will appoint one or more configuration management liaisons who will serve as an interface between requesters and configuration control boards and will accept requests for configuration status reports.

5.2.2.1.4 Configuration Control Board. A configuration control board analyzes proposed changes, evaluates change implementations, and specifies their disposition. The accountable line manager will establish one or more configuration control boards and will document the scope, authority, and reporting structure of each.

\subsubsection{Initiating Changes}

5.2.2.2.1 Change Request. A change requester submits a change request to the configuration management liaison. A change request is a record that includes 1) the change requester's name, 2) a description of the requested change, 3) an indication of urgency, 4) justification for the change, 5) the configuration-identification labels or descriptions of affected baselines and controlled elements.

5.2.2.2.2 Change Request Verification. The configuration management liaison will verify that the change request is complete (see Section 5.2.2.2.1) before submitting it to the governing configuration control board. Incomplete change requests are rejected.

5.2.2.2.3 Change Request Analysis. The configuration control board will analyze the merit and expected impact of each change request prior to its disposition. During this analysis the configuration control board will amend this request as it deems necessary to ensure that the specified change 1) is technically feasible and appropriate and 2) will not adversely impact existing controlled elements. The configuration control board will approve or reject the analyzed change request and will produce change request documentation to document its decision. 


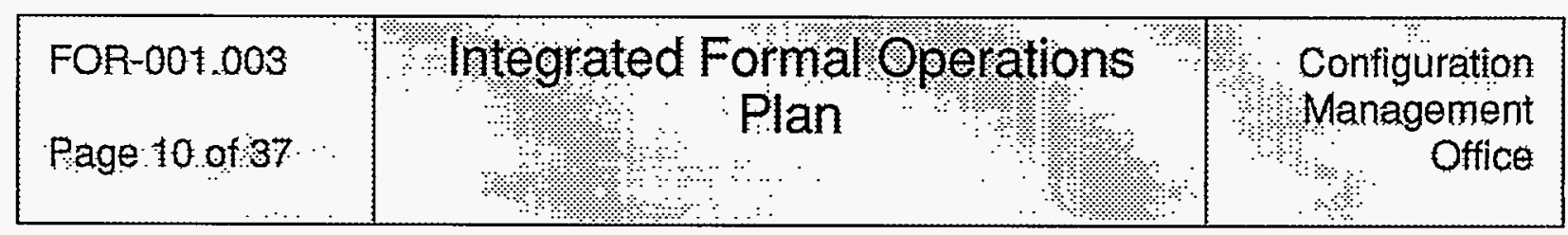

5.2.2.2.4 Change Request Documentation. Change Request documentation is a record that includes the analyzed change request, documentation from the analysis, disposition of the analyzed change request, and configuration control board authentication.

5.2.2.2.5 Work Authorization. After approving a change request, the configuration control board will issue a work authorization to a change agent assigned to implement the change. A work authorization is a record that includes 1 ) the name of the affected baseline; 2 ) the change agent's name; 3) a list of associated change requests; and 4) implementation information including instructions, constraints, required resources, and schedule. The implementation information will be developed in accordance with the assigned grades of the affected controlled elements.

\subsubsection{Implementing Changes}

5.2.2.3.1 Elements Subject to Change. The change agent will change only the controlled elements specified in the work authorization and will not place the changes into service before they are certified by configuration management.

5.2.2.3.2 Proposed Baseline. The change agent will ensure that changes are compiled into a proposed baseline that is submitted to configuration management for evaluation and certification (see Section 5.2.2.4).

\subsubsection{Baselines}

5.2.2.4.1 Validating the Proposed Baseline. Before submitting a proposed baseline to the configuration control board, the configuration management liaison will ensure that 1) a work authorization exists for the proposed baseline and 2) the proposed baseline is consistent with its configuration definition. The configuration management liaison will reject an invalid proposed baseline.

5.2.2.4.2 Evaluating the Proposed Baseline. The configuration control board will 1) evaluate the proposed baseline to ensure that the implemented changes are completed as specified in the work authorization, 2) identify evaluation issues, and 3) specify the disposition of the proposed baseline.

5.2.2.4.3 Evaluation Issues. The configuration control board will ensure that the change agent satisfactorily resolves each evaluation issue and will prepare evaluation issues documentation. Evaluation issues will be documented on records that include 1) the name and/or identification of the proposed baseline, 2) the name and identifier of the controlled element against which the issue is logged, 3) a description of each issue, 4) the location of the issue within the designated controlled element, 5) the evaluator who raised the issue,

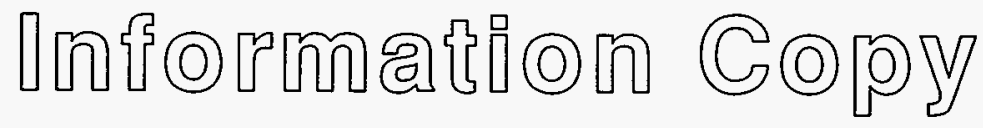




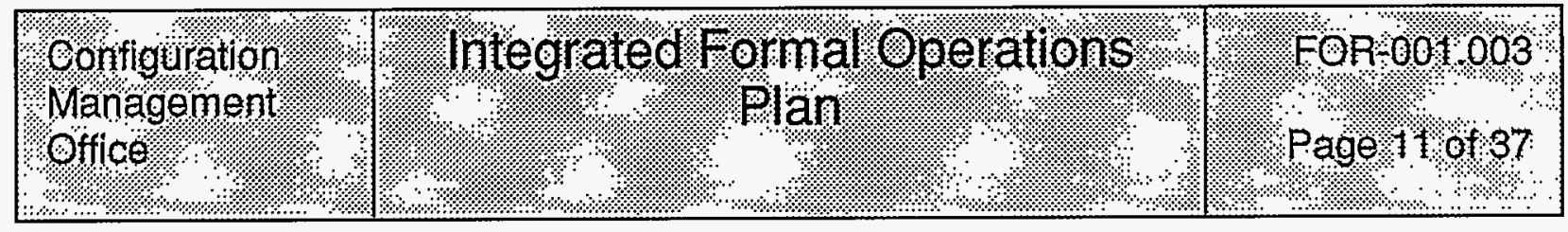

6) the identifier of the controlling work authorization, and 7) how the issue was resolved.

5.2.2.4.4 Certifying the Approved Baseline. When the evaluation is complete and evaluation issues are resolved, the configuration control board will approve the proposed baseline. The configuration manager will 1) assign an identifier to, and document certification of the approved baseline; 2) authenticate the work authorization to confirm task completion; and 3) authenticate all related change requests to confirm change implementation. The baseline certification is a record that includes 1) the name of the certified baseline, 2) its identifier, and 3) the certification date.

5.2.2.4.5 Baseline Catalog. The configuration manager will maintain a catalog of certified baselines. The baseline catalog will include the following information for each certified baseline: 1) the identifier, 2) the certification date, 3) a descriptive title, 4) the accountable line manager's name, and 5) the storage location within the baseline repository.

5.2.2.4.6 Baseline Storage and Maintenance. The configuration manager will store certified baseline documents in the baseline repository. The configuration manager will ensure that the baseline repository provides adequate physical storage, security, protection, and retrievability for certified baseline documents. The configuration manager will periodically audit the baseline catalog to identify obsolete baselines (as defined by the governing configuration control board) and will remove obsolete baselines from the baseline repository and update the baseline catalog.

\subsubsection{Variances}

5.2.2.5.1 Variance Request. A variance requester submits a variance request to the configuration management liaison. A variance request is a record that includes 1) the variance requester's name; 2) a reference to the provision against which the variance is requested;3) a description of the requested variance, including its application limits; 4) a specification of the time during which the variance is valid;5) an indication of urgency; 6) justification for the variance; 7) the configuration-identification labels or descriptions of all affected controlled elements.

5.2.2.5.2 Variance Request Verification. Upon receipt of a variance request, the configuration management liaison will verify that the variance request is complete before submitting it to the configuration control board. Incomplete requests are rejected.

5.2.2.5.3 Variance Request Analysis. The configuration control board will analyze the merit and expected impact of each variance request prior

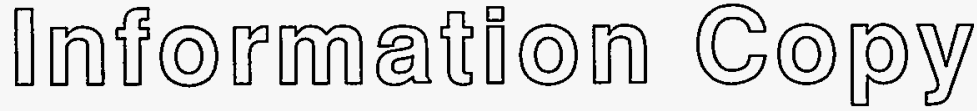




\begin{tabular}{|c|c|c|}
\hline $\begin{array}{l}\text { FOR-001.003 } \\
\text { Page } 12 \text { of } 37\end{array}$ & $\begin{array}{l}\text { Integrated Formall Operations } \\
\text { plan }\end{array}$ & $\begin{array}{r}\text { Gonfiguration } \\
\text { Management } \\
\text { Office }\end{array}$ \\
\hline
\end{tabular}

to its disposition. During this analysis, the configuration control board will amend the variance request as it deems necessary. The configuration control board will approve or reject the analyzed variance request, which includes any amendments, and will produce variance request documentation to document its decision.

5.2.2.5.4 Variance Request Documentation. Variance request documentation is a record that includes the analyzed variance request, documentation from the analysis, disposition of the analyzed variance request, and configuration control board authentication.

5.2.2.5.5 Publishing a Variance. The configuration control board will document the approved variance and request its distribution in accordance with Section 5.6.

\subsubsection{Configuration Status Reports}

5.2.3.1 Report Requester. A report requester will request a configuration status report by completing a report request, a record that includes 1) the requester's name, 2) an indication of urgency, 3) the report title, 4) a description of the report's content and format, 5) a recommended distribution list, and 6) the report-generation schedule. The report requester will submit this request to the configuration management liaison.

5.2.3.2 Report Request Verification. Upon receipt of a report request, the configuration management liaison will verify that the request is complete and reasonable and will reject an incomplete or unreasonable report request.

5.2.3.3 Generating the Report. The configuration manager will, on a best-effort basis, generate the requested report as described in the verified report request.

5.2.3.4 Distributing A Report. The configuration management liaison will distribute the report according to the distribution list in the report request and will submit one copy to records management (see Section 5.5.1).

\subsection{Personnel Qualification and Training}

This section specifies the requirements to ensure that all work processes are executed by properly trained and qualified personnel.

\subsubsection{Personnel Qualification}

This section specifies the requirements for analyzing and certifying the qualifications of workers to perform a specific work process.

5.3.1.1 Candidates for Qualification. The work process owner (see Section 5.7.1.1) will designate candidates for qualification who must meet the qualification criteria required of personnel to perform the work.

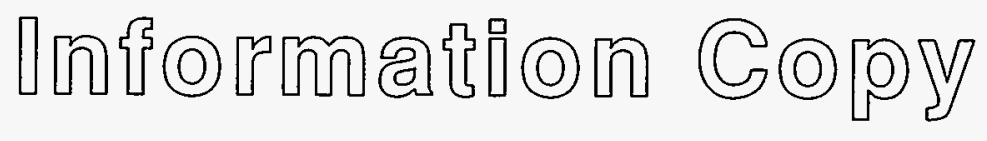




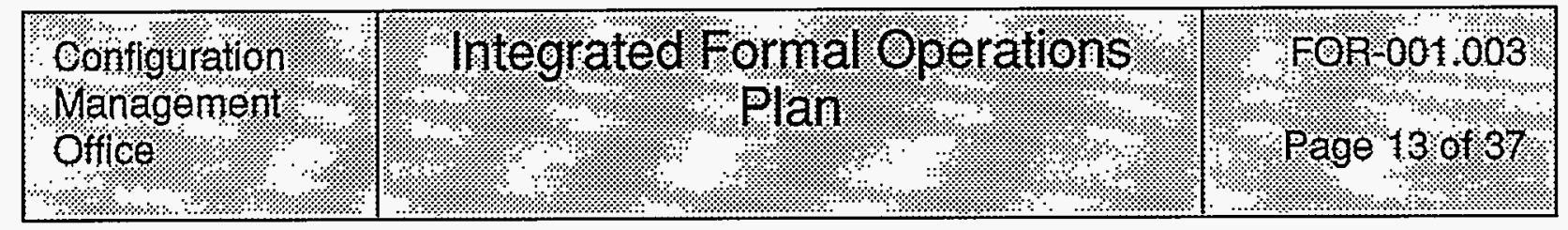

5.3.1.2 Qualification Analysis. The work process owner will compare each candidate's qualifications against the criteria for the work process. Personnel-qualification documentation consists of records that include an individual's 1) name, 2) education, 3) experience, 4) professional certifications, and 5) formal training.

5.3.1.3 Qualification Certification. Based on the qualification analysis, the work process owner will certify each candidate who meets the qualification criteria. A qualification certification is a record that includes 1) the individual's name, 2) the title and identifier of the subject work process, and 3) the qualification's expiration date. Candidates who do not meet the qualification criteria will undergo personnel training.

\subsubsection{Personnel Training}

This section specifies the requirements for establishing a training program to train personnel, and for analyzing and certifying the proficiency of trained personnel.

5.3.2.1 Planning. The accountable line manager will designate a training program owner for every training program. The training program owner will ensure that a formal training plan is developed in accordance with Section 5.1 for the training program.

5.3.2.2 Developing the Training Course. The training program owner will designate a training course developer to create a training course in accordance with the certified training plan. A training course includes the following: 1) a unique course identifier, 2) the course title, 3) a description of the intended audience, 4) learning objectives, 5) instruction guidelines, 6 ) instructor-qualification criteria, 7) presentation materials, 8) course notes, and 9) a proficiency test.

5.3.2.3 Certifying the Training Course. The training program owner will ensure that a candidate training course is compiled into a proposed baseline and submitted to configuration management for evaluation and certification.

5.3.2.4 Trainees. Based on the results of the qualification analysis, the work process owner will identify each trainee who must receive specific training to meet the qualification criteria for a work process.

5.3.2.5 Training Administration. The work process owner will designate a trainer to administer a training course and the proficiency test to the trainees.

5.3.2.6 Proficiency Test Documentation. A trainee's proficiency test documentation for a specific training course is a record that includes 1) the trainee's name, 2) the title and identifier of the training course, 3) the completed test, and 4) the test score. Based on the results of the proficiency test, the trainer will certify that the trainee has successfully completed the training course.

5.3.2.7 Training Certification. A training certification is a record that includes 1) the trainee's name, 2) the title and identifier of the training course, and 3) the certification expiration date.

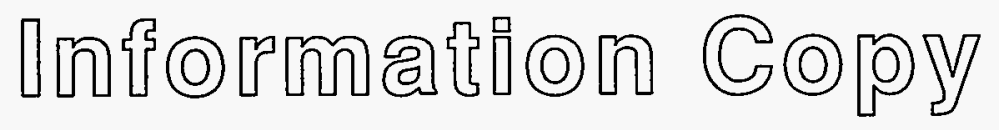




\begin{tabular}{|c|c|c|}
\hline $\begin{array}{l}\text { FOR-001.003 } \\
\text { Page: } 4 \text { of } 37\end{array}$ & Integrated Formal Operations & $\begin{array}{l}\text { Configuration } \\
\text { Management } \\
\\
\text { Office }\end{array}$ \\
\hline
\end{tabular}

\subsection{Deficiencies, Occurrences, and Process Improvement}

This section specifies the requirements for using worker input and objective measurements to identify problems and institute improvements in work processes.

\subsubsection{Deficiencies and Occurrences}

5.4.1.1 Reporting. An initiator formally brings deficiencies or occurrences to the attention of management by preparing a report describing the deficiency or occurrence and submitting it to the work process owner.

5.4.1.1.1 Deficiency Report. A deficiency report is a record that characterizes a deficiency identified in a work process and includes 1 ) a description of the deficient condition, 2) a reference to affected programs or work processes, 3) an indication of severity, and 4) a description of special conditions or restrictions imposed on the affected programs or work processes.

5.4.1.1.2 Occurrence Report. For a description, refer to DOE Order 5000.3B (see Reference 7 in Section 9.0).

5.4.1.2 Impact Analysis. An investigator will use documented plans and procedures, accepted standards and criteria, worker input, and objective measurements to analyze the reported condition's validity and its impact on other items, work processes, the environment, safety, and health; and determine its root cause. The investigator will transmit the analysis results in an impact analysis report to the accountable line manager in a timely manner.

5.4.1.3 Corrective Action. The investigator will use the impact analysis report to create a corrective action plan in accordance with Section 5.1 that specifies how the organization will address the reported condition. The accountable line manager will effectively implement the corrective action plan and will document lessons learned. The lessons learned documentation is a record that includes 1) a reference to the initiating report, 2) a reference to the corrective action plan, and 3) a summary of the lessons learned.

5.4.1.4 Stop Work and Restart. The accountable line manager will ensure that a program plan developed in accordance with Section 5.1 includes the requirements and responsibilities for stopping work on operations involving a deficiency or occurrence that adversely affects the environment, safety, or health, and will ensure that procedures are established in accordance with Section 5.7 for restart of work.

\subsubsection{Process Improvement}

5.4.2.1 Initiation. An advocate identifies a process in need of improvement, suggests improvement strategies, and works with management to implement the improvement.

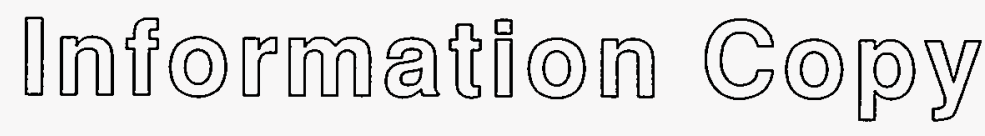




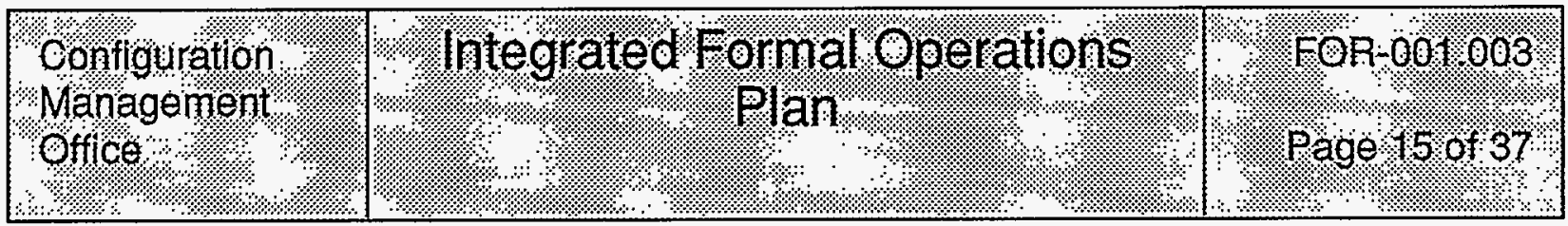

5.4.2.2 Development and Experimentation. The advocate will use documented plans and procedures, lessons learned, accepted standards and criteria, worker input, and objective measurements to develop specific improvements to existing programs, processes, systems, facilities, and work products. The advocate may use pilot programs, continuous quality improvement initiatives, and other innovative approaches to evaluate the effectiveness of potential improvements prior to their implementation.

5.4.2.3 Implementation. The advocate will work with the accountable line manager to incorporate the recommended improvements by updating existing plans (see Section 5.1) and procedures (see Section 5.7.1) and will produce experience documentation for the improvement process. This experience documentation is a record that includes descriptions of the 1) problems identified, 2) strategies utilized, 3) principles and precepts established, 4) results obtained, and 5) lessons learned as a consequence of the process-improvement effort.

\subsection{Records Management}

This section specifies the requirements to identify, gather, track, catalog, store, maintain, and access records produced by the formal operations program. The records management environment is specified by records management standards that enumerate the distinct record types supported, security and protection requirements, retrievability criteria, minimum storage lifetime, and disposal criteria for each record type.

\subsubsection{Records Admission}

This section specifies the requirements for incorporating candidate records into the records management environment.

5.5.1.1 Records Manager. The accountable line manager will designate the records manager responsible for accepting, maintaining, and releasing records within the records management environment.

5.5.1.2 Record Submission. The procedure that governs a record's production will specify the authorized submitter.

5.5.1.3 Record Verification. The records manager will verify that the record is complete and is of a supported record type. The records manager will reject incomplete or unsupported records.

5.5.1.4 Records Catalog. The records manager will maintain a records catalog that includes the following information for each cataloged record: 1) the record identifier, 2) the record-generation date, and 3) a descriptive title.

5.5.1.5 Records Storage. The records manager will store records in a records repository to ensure adequate physical storage, security, protection, and retrievability of archived records.

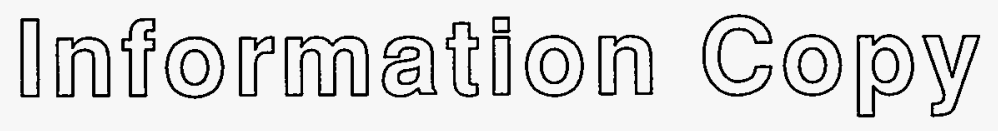




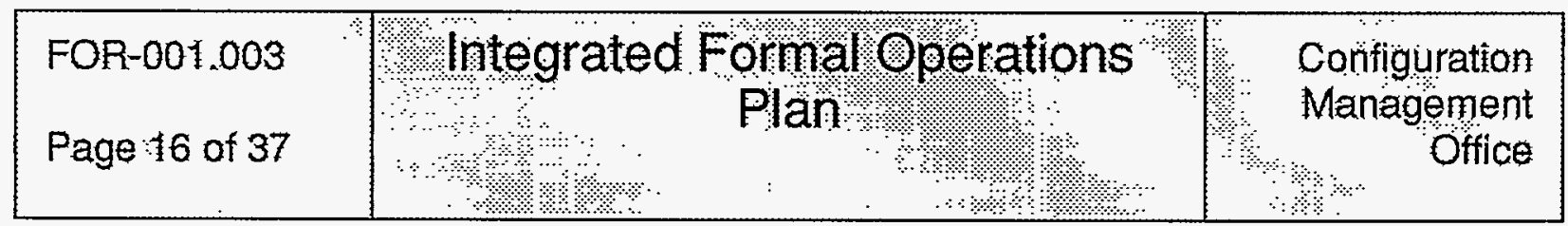

\subsubsection{Obsolete Records}

5.5.2.1 Identification. The records manager will periodically audit the records catalog to identify obsolete records.

5.5.2.2 Disposal. The records manager will ensure that obsolete records are transferred to an external repository or destroyed according to the disposal criteria specified in the records management standards.

5.5.2.3 Catalog Update. The records manager will update the records catalog to reflect the disposition of records.

\subsubsection{Record Release}

This section specifies the requirements for releasing records to an authorized requester.

5.5.3.1 Record Request. The procedure that governs the record's request will specify the authorized requester. The requester submits a record request to the records manager. A record request is a record that includes 1) the date of the request, 2) the record identifier, and 3) the name of the record requester.

5.5.3.2 Request Verification and Disposition. Upon receipt of a record request, the records manager will verify that the request is complete, will reject an incomplete request, and will document the disposition of the request.

5.5.3.3 Record Retrieval. The records manager will determine the accessibility of the requested record, will retrieve it from the records repository, and will make it available to the requester. The records manager will ensure adequate security and protection of released records.

\subsection{Document Control}

This section specifies the requirements to gather, catalog, and store master documents; to maintain the document control environment; and to distribute and track controlled copies of the master documents. The document control environment is specified by document control standards that enumerate the distinct document types supported, the level of security and protection required for each master document, availability criteria, minimum controlled lifetime, and disposal criteria for each document type.

\subsubsection{Document Admission}

This section specifies the requirements for introducing a master document into the document control environment.

5.6.1.1 Document Manager. The accountable line manager will designate the document manager authorized to accept documents into the document control environment and distribute controlled copies of master documents.

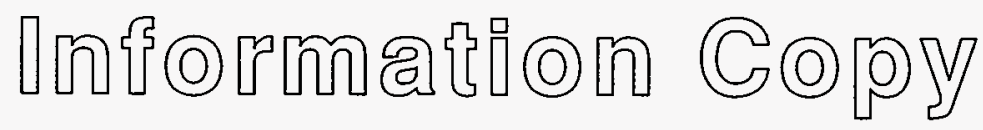




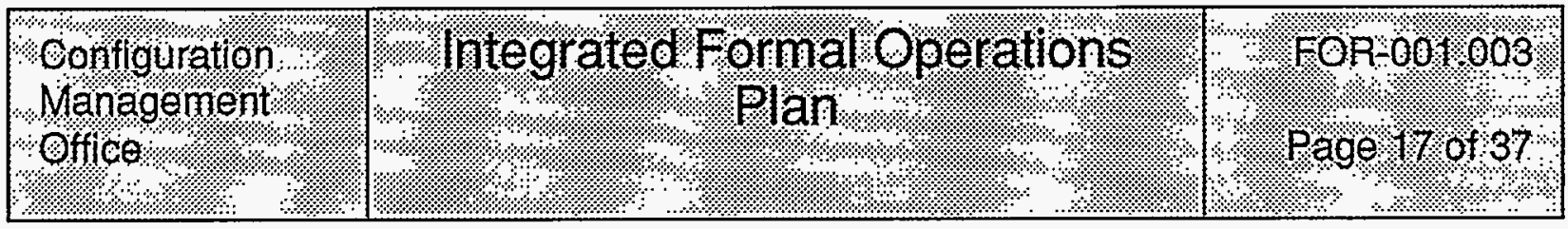

5.6.1.2 Document Source. Only candidate master documents from the configuration management environment will be admitted to the document control environment.

5.6.1.3 Document Verification. The document manager will verify that the candidate master document is complete and is of a supported document type. The document manager will reject incomplete or unsupported documents.

5.6.1.4 Document Catalog. The document manager will maintain a document catalog that includes the following information for each master document: 1 ) the document identifier, 2) the document date, and 3) the document title.

5.6.1.5 Document Storage. The document manager will store master documents in a document repository to ensure adequate physical storage, security, protection, and availability for master documents.

\subsubsection{Obsolete Documents}

5.6.2.1 Identification. The document manager will periodically audit the document catalog to identify obsolete or superseded master documents.

5.6.2.2 Disposal. The document manager will ensure that obsolete and superseded master documents are removed from the document repository and that the catalog is updated accordingly.

\subsubsection{Controlled Distribution}

This section specifies the requirements for producing controlled copies of master documents, labeling the controlled copies, and issuing them to individuals who use them to perform work.

5.6.3.1 Controlled Distribution Request. Responsibility for formally requesting distribution of controlled copies resides with the line manager that is accountable for the work process. A controlled distribution request is a record that includes 1 ) the identifier of the master document, 2) the required number of controlled copies, and 3 ) the name and address of each document custodian.

5.6.3.2 Request Verification. Upon receipt of a controlled distribution request, the document manager will verify that the request is complete and will reject an incomplete request.

5.6.3.3 Preparing Controlled Copies. The document manager will determine the availability of the requested document, will retrieve a copy of the master document from the document repository, and will ensure that only the requested number of controlled copies are made. The document manager will ensure that each controlled copy is assigned a unique control number and is labeled accordingly and that a controlled distribution list is compiled for the distribution. A controlled distribution list is a record that includes 1 ) the identifier of the master

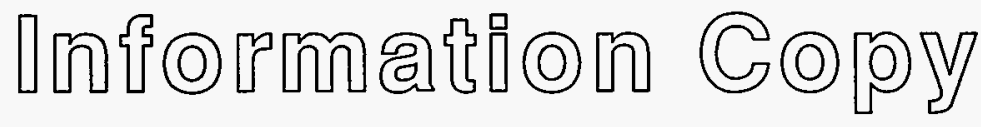




\begin{tabular}{|l|c|c|r|}
\hline FOR-001.003 & Integrated formal Operations : & $\begin{array}{l}\text { Configuration } \\
\text { Management } \\
\text { Page } 18 \text { of } 37\end{array}$ & Office \\
\hline
\end{tabular}

document, 2) a list of controlled copy numbers, and 3) the name and address of each document custodian.

5.6.3.4 Distribution Package. The document manager will ensure that a document distribution package is transmitted to each document custodian on the controlled distribution list.

5.6.3.5 Distribution Verification. The document manager will verify and document that 1) the instructions in the document distribution packages are followed and 2) all controlled copies are accounted for.

\subsection{Work Processes}

This section specifies the requirements for developing and executing the procedures used to perform work processes that implement a certified program plan (or any portion thereof).

\subsubsection{Developing Procedures for a Work Process}

5.7.1.1 Initiating Procedure Development. The program owner (see Section 5.1.1) will designate a work process owner to ensure that procedures, which specify the steps necessary to complete a work process, are defined and documented. The work process owner will initiate procedure development by submitting a change request to, and obtaining a work authorization from configuration management (see Section 5.2.2.2).

5.7.1.2 Developing a Procedure. A procedure is a document that includes 1) the purpose; 2) the scope; 3) a reference to the governing plan;4) definitions;5) a description of special hazards, conditions, limitations, and precautions; 6) qualification criteria; 7) training requirements; 8) roles and responsibilities; 9) procedural steps; and 10) required records. The work process owner will ensure that a procedure is developed in accordance with the governing plan, accepted standards, and good business practices, and that worker input and lessons learned are considered in developing a procedure.

5.7.1.3 Certifying a Procedure. The work process owner will ensure that a candidate procedure is compiled into a proposed baseline and submitted to configuration management for evaluation and certification.

\subsubsection{Executing a Work Process}

5.7.2.1 Worker Qualifications. Before allowing work to begin, the accountable line manager will ensure that workers satisfy the qualification criteria specified in the procedures (see Section 5.3.1). Unqualified workers will not perform any work process that is controlled by a procedure.

5.7.2.2 Controlled Procedures. A worker will follow only controlled copies of procedures. The worker will become familiar with these procedures and will identify the provisions that apply to the worker's tasks.

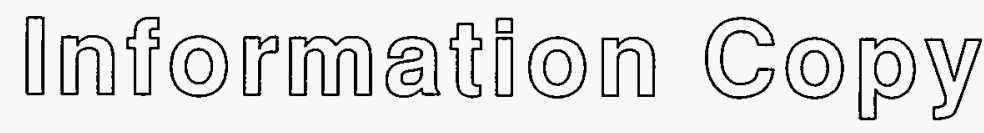




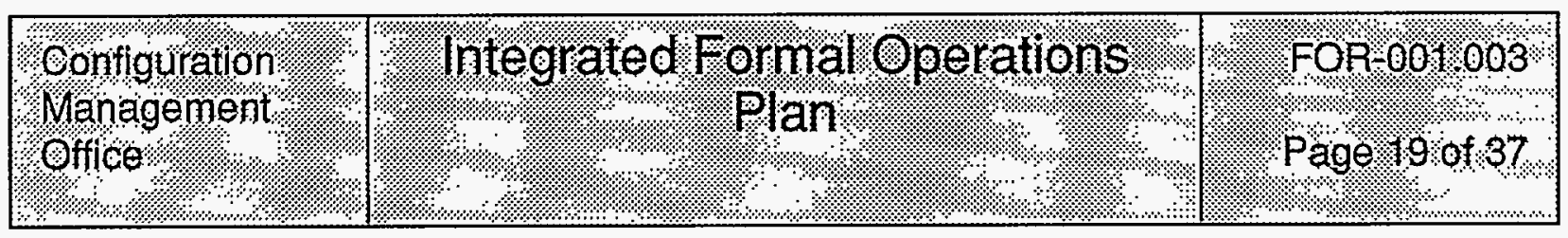

5.7.2.3 Special Conditions and Precautions. The worker will review any hazards, limitations, special conditions, and prescribed precautions identified in the procedures before starting work.

5.7.2.4 Executing a Procedure. The worker will perform work in accordance with the instructions in the procedure, including generating all required records and submitting them to records management in a timely manner.

5.7.2.5 Deficiencies and Process Improvement. The worker will identify and document any deficiencies in, and potential improvements to the work process in accordance with Section 5.4 .

\subsection{Design}

This section specifies the requirements for a formal process to ensure that controlled elements are designed using sound engineering and/or scientific principles and appropriate standards.

\subsubsection{Initiating a Design}

A change requester will initiate a design or a design modification by submitting a change request to, and obtaining a work authorization from configuration management (see Section 5.2.2.2). The accountable line manager will designate a design owner to ensure that designs meet all applicable specifications and standards.

\subsubsection{Design Planning}

The accountable line manager will ensure that a design plan (see Section 5.1) is developed that includes 1 ) the applicable design basis, 2) the requirements imposed on the design or modification, 3) the governing specifications, 4) applicable standards, 5) required design records, 6) special validation criteria, and 7) affected interfaces.

\subsubsection{Design Development}

The design owner will develop the design in accordance with a certified design plan.

\subsubsection{Validation Testing}

If validation testing is required by the certified design plan, it will be conducted in accordance with Section 5.10.

\subsubsection{Design Certification}

The design owner will ensure that a proposed design is compiled into a proposed baseline and submitted to configuration management for evaluation and certification.

\subsection{Procurement}

This section specifies the requirements for a cost-effective and expeditious formal process to procure items and services that meet documented requirements.

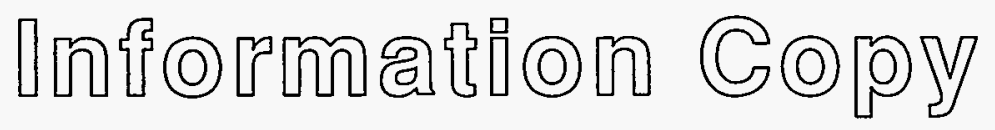




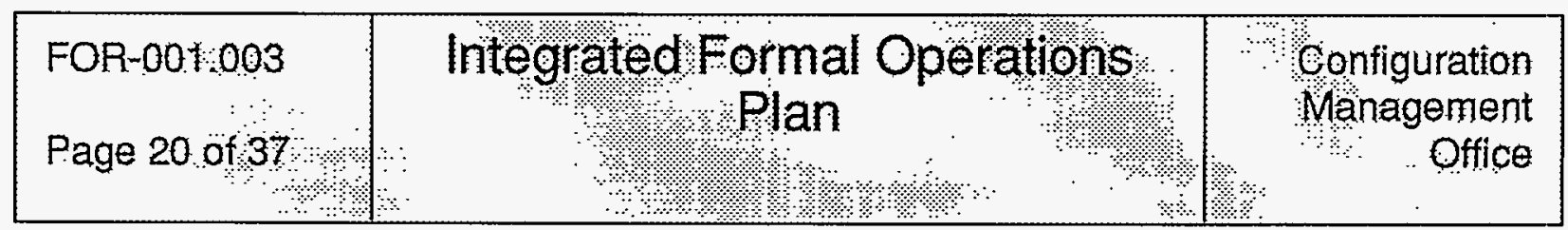

\subsubsection{Initiating a Procurement}

5.9.1.1 Procurement Request. A procurement requester will develop a procurement request, a record that includes 1) a procurement specification of the requirements for the subject items or services, 2) an acceptance plan that details the acceptance criteria (for subject items, an inspection or test plan in accordance with Section 5.10 and for subject services, an assessment plan in accordance with Section 5.11), 3) any special instructions necessary for processing the procurement, and 4) formal notification to the procurement authority to initiate the procurement.

5.9.1.2 Verifying a Procurement Request. Upon receipt of a procurement request, the procurement authority will verify that it is complete and will reject an incomplete request.

5.9.1.3 Vendor Identification and Analysis. The procurement authority will identify candidate vendors for items and services based on input from the procurement requester and vendor information. The procurement authority will ensure that the information provided by the candidate vendor is analyzed to determine the vendor's qualifications to supply the subject items or services. The procurement authority may require a formal assessment of the candidate vendor's operations as part of this analysis (see Section 5.11).

5.9.1.4 Processing a Procurement Request. Based upon the information in a verified procurement request, the procurement authority will issue the necessary documents to obtain the requested items or services from qualified vendors.

5.9.2 Receiving and Acceptance

5.9.2.1 Receipt Certification. The procurement requester will certify the receipt of items or services. A record of receipt is a record that includes 1) a list of the services rendered or the received items and associated quantities and 2) authentication by the procurement requester.

5.9.2.2 Acceptance and Rejection of Items and Services. The procurement requester will certify the acceptability of items and services in accordance with the acceptance plan. The procurement requester will reject deficient items or services and will notify the procurement authority.

5.9.2.3 Deficiency Resolution. The procurement authority will resolve deficiencies in procured items or services in a manner satisfactory to the procurement requester.

\subsubsection{Procurement Documentation.}

The procurement requester and procurement authority will ensure that procurement documentation is assembled for procured items or services. Procurement documentation is a collection of records that includes 1) the authorized procurement request, 2) information relevant to the selection of a supplier, 3) contractual information, 4) supplier-provided information, 5) receipt and acceptance information, and 6) related correspondence.

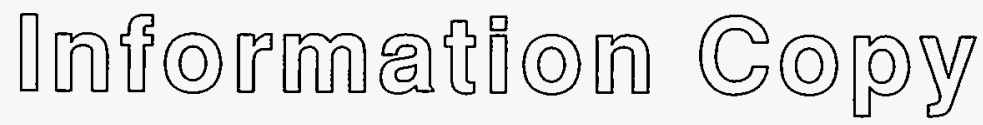




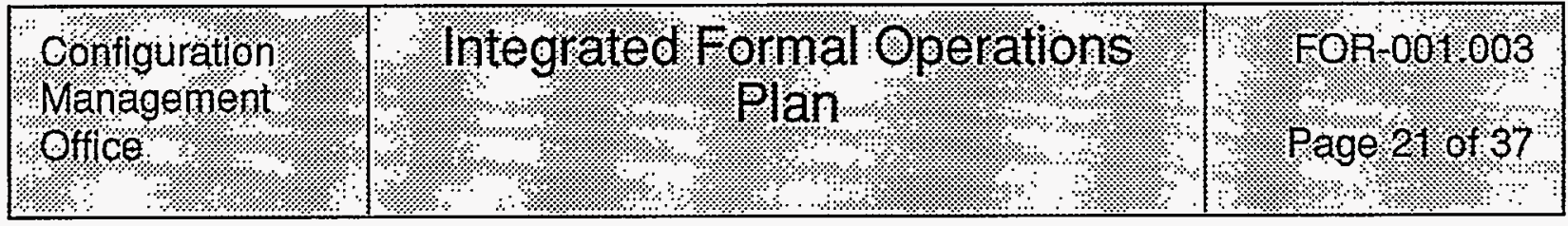

\subsection{Inspection and Testing}

This section specifies the requirements for formal validation and verification activities.

\subsubsection{Planning}

An inspection/test sponsor will develop a formal plan for the inspection or test (see Section 5.1).

5.10.1.1 Inspection Plan. An inspection plan includes 1) the purpose of the inspection, 2) the items to be inspected, 3) inspection criteria, 4) a description of sampling methodologies to be used, and 5) applicable calibration criteria.

5.10.1.2 Test Plan. A test plan includes 1) the purpose of the test, 2) the items to be tested, 3) testing criteria, 4) a description of sampling methodologies to be used,5) a description of special test configurations, and 6) applicable calibration criteria.

\subsubsection{Procedures}

The inspection/test sponsor will ensure that procedures (see Section 5.7) exist to govern the inspection or test and will use these procedures to perform the inspection or test.

\subsubsection{Analyzing Results}

A verifier will analyze the results of the inspection or test, document nonconformances, and transmit resulting nonconformance reports to the inspection/test sponsor. A nonconformance report is a record that includes 1 ) information that identifies the item, 2) a description of the nonconformance, 3) a reference to the governing inspection or test plan and associated procedures, and 4) the name of the verifier.

\subsubsection{Impact Analysis}

The inspection/test sponsor will use documented plans, procedures, baselines, accepted standards and criteria, worker input, and objective measurements to analyze the validity of each nonconformance, and its impact on other items, work processes, the environment, safety, and health; and determine its root cause. The inspection/test sponsor will transmit the analysis results in an impact analysis report to the accountable line manager in a timely manner.

\subsubsection{Corrective Action}

The inspection/test sponsor will use the impact analysis report to create a corrective action plan in accordance with Section 5.1 that specifies how the organization will address the nonconformance. The accountable line manager will effectively implement the corrective action plan and will document lessons learned (see Section 5.4.1.3). The accountable line manager will take immediate corrective action when the nonconformance presents an immediate and serious threat to critical operations, the environment, safety, or health.

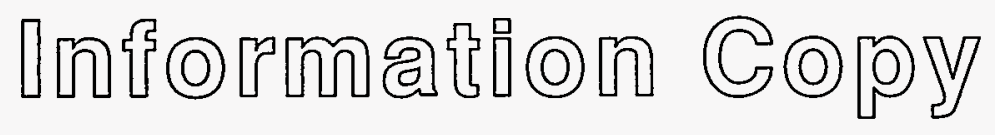




\begin{tabular}{|c|c|c|}
\hline $\begin{array}{l}\text { FOR-001.003 } \\
\text { Page } 22 \text { of } 37\end{array}$ & $\begin{array}{l}\text { Integrated Formal Operations } \\
\text { Plan }\end{array}$ & $\begin{array}{l}\text { Configuration } \\
\text { Management } \\
\text { Office }\end{array}$ \\
\hline
\end{tabular}

\subsubsection{Certification Documentation}

The verifier will formally document the results of the inspection or test. Inspection/test certification documentation is a record that includes 1 ) information that identifies the inspected or tested items, 2) the results of any measurements, 3 ) the date and time of the inspection or test, 4) a reference to the governing inspection or test plan and associated procedures, and 5) the name of the verifier.

\subsubsection{Process Improvement}

Based on the contents of the inspection/test certification documentation and any nonconformance reports, the inspection/test sponsor will, in accordance with Section 5.4 , initiate development and implementation of substantive, measurable improvements to the processes used to produce the subject items.

\subsection{Assessments}

This section specifies the requirements for a formal process that promotes improvement by conducting planned, periodic independent assessments that measure the quality and effectiveness of programs, processes, systems, and facilities.

\subsubsection{Assessment Plan}

An assessment sponsor will plan and implement the assessment and will develop a formal assessment plan in accordance with Section 5.1.

5.11.1.1 Assessment Scope. The assessment plan will identify any existing plans, procedures, records, controlled elements, and other information subject to assessment and will specify the period of performance covered by the assessment.

5.11.1.2 Assessment Criteria. The assessment plan will specify the objective criteria that will be used to evaluate the elements in the assessment scope and will incorporate these criteria into one or more assessment checklists. An assessment checklist is a record that includes 1 ) the identifier of the assessment plan, 2) the date of the assessment, and 3) a list of assessment criteria.

\subsubsection{Procedures}

The assessment sponsor will ensure that procedures (see Section 5.7) exist to govern the assessment. An assessor will use the procedures and checklists to assess the performance of the programs, processes, systems, or facilities in accordance with the assessment plan.

\subsubsection{Documenting Findings and Observations}

The assessor will document findings and observations resulting from the assessment and will initiate corrective action in accordance with Section 5.4.

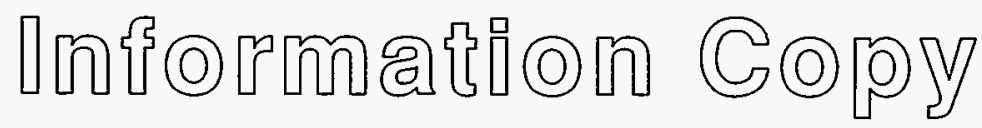




\begin{tabular}{|l} 
Configurtion \\
Management \\
office
\end{tabular}

5.11.3.1 Findings. A finding is documentation of noncompliance with a specified requirement. A finding is a record that includes 1) the identifier of the assessment plan; 2) the date of the assessment; 3 ) the name and identifier of the item, program, process, system, or facility against which the finding is logged; 4) a description of the noncompliance (including a reference to the requirement); and 5) the assessor who logged the finding.

5.11.3.2 Observations. An observation is documentation of a condition to which the assessor wants to call attention, although it fully complies with requirements. An observation is a record that includes 1 ) the identifier of the assessment plan; 2 ) the date of the assessment; 3 ) the name and identifier of the item, program, process, system, or facility against which the observation is logged; 4) a description of the condition; and 5) the name of the assessor who logged the observation.

\subsubsection{Documenting the Assessment}

The assessor will document the results of the assessment in an assessment report, a record that includes 1 ) the purpose of the assessment; 2) the assessment dates; 3) a list of assessment team members; 4 ) references to the assessment plan, procedures, and checklists; 5) a summary of assessment activities; 6) a list of findings and observations; and 7) a schedule of follow-up assessments or measurements, if any, that will be required. The assessor will provide a copy of the assessment report to the assessment sponsor.

\subsubsection{Improvement of Operations}

Based on the contents of the assessment report, the assessment sponsor will, in accordance with Section 5.4, initiate development and implementation of substantive, measurable improvements to programs, processes, systems, or facilities.

\subsection{RESPONSIBILITIES}

\subsection{Accountable Line Manager}

The accountable line manager will

- $\quad$ specify the items, processes, and information, i.e., controlled elements, to which the formal operations program specified in this document applies;

- ensure that each controlled element receives a distinct grade that indicates its level of importance and therefore an indication of the level of configuration management necessary to maintain it;

- develop configuration definitions to specify strategies for grouping related controlled elements into baselines;

- ensure that a candidate configuration definition is compiled into a proposed baseline and is submitted to configuration management for evaluation and certification;

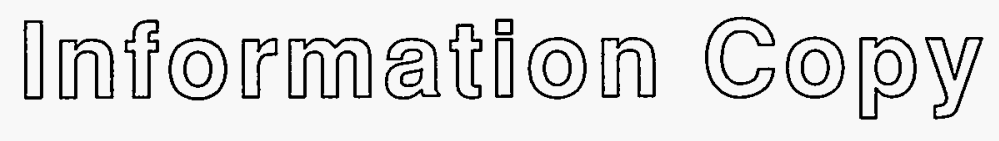




\begin{tabular}{|c|c|c|}
\hline $\begin{array}{l}\text { FOR-00t.003 } \\
\text { Page } 24 \text { of } 37\end{array}$ & $\begin{array}{c}\text { Integrated Formal Operations } \\
\text { Plan }\end{array}$ & $\begin{array}{r}\text { Configuration } \\
\text { Management } \\
\text { Office }\end{array}$ \\
\hline
\end{tabular}

- designate a configuration manager to serve as the line manager's agent in configuration management tasks;

- appoint one or more configuration management liaisons to serve as an interface between requesters and configuration control boards;

- establish one or more configuration control boards and document the scope, authority and reporting structure of each;

- designate a training program owner for every training program to ensure that the program meets all applicable requirements and standards;

- $\quad$ effectively implement corrective action plans and document lessons learned;

- take immediate corrective action when a nonconformance presents an immediate and serious threat to critical operations, the environment, safety, or health;

- define the requirements and responsibilities for stopping work on operations involving a deficiency or occurrence that adversely affects the environment, safety, or health, and establish procedures for restart of work;

- work with an advocate to incorporate recommended improvements by updating existing plans and procedures;

- $\quad$ ensure that controlled distributions of documents that specify work processes are formally requested;

- $\quad$ ensure that workers satisfy the qualification criteria specified in the applicable procedures before allowing work to begin;

- designate one or more design owners to ensure that designs meet all applicable specifications and standards;

- ensure the collection, storage, and analysis of the metrics described in Section 7.0 and use the results of the metrics analyses to actively improve the performance of the formal operations program;

- $\quad$ encourage users of this planning document to complete and return the document improvement questionnaire and will use the contents of the responses to evaluate the performance of this planning document and to aid in the development of future documents;

- $\quad$ track and analyze formal requests for change (such as enhancement requests and discrepancy reports) to this planning document to evaluate its performance; and

- perform periodic assessments to determine the level of performance of the overall formal operations program.

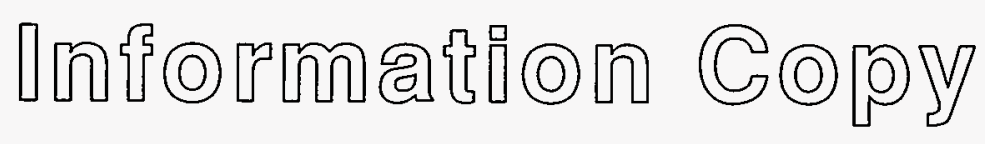




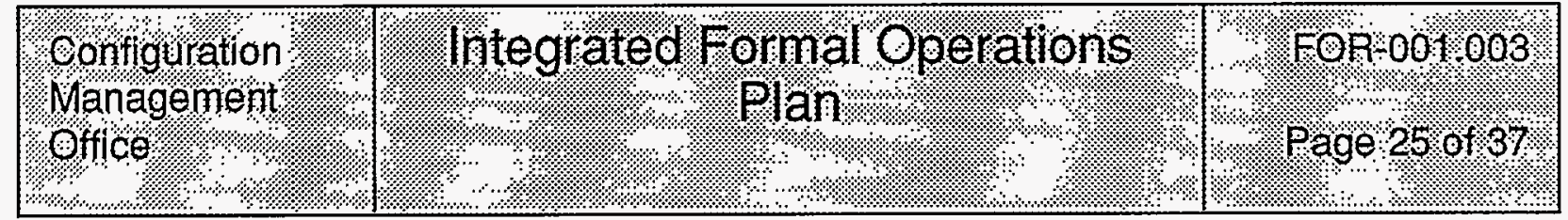

\subsection{Advocate}

The advocate

- will identify processes in need of improvement, suggest improvement strategies, and work with management to implement improvements;

- will use documented plans and procedures, lessons learned, accepted standards and criteria, worker input, and objective measurements to develop specific improvements to existing programs, processes, systems, facilities and work products;

- may use pilot programs, continuous quality improvement initiative, and other innovative approaches to evaluate the effectiveness of potential improvements prior to their implementation; and

- will work with the accountable line manager to incorporate recommended improvements by updating existing plans and procedures and will produce experience documentation for improvement processes.

\subsection{Assessment Sponsor}

An assessment sponsor will

- $\quad$ plan and implement assessments and will develop formal assessment plans in accordance with Section 5.1;

- $\quad$ ensure that procedures exist to govern each assessment (see Section 5.7); and

- initiate development and implementation of substantive, measurable improvements in accordance with Section 5.4.

\subsection{Assessor}

An assessor will

- use procedures and checklists to assess the performance of programs, processes, systems, or facilities in accordance with assessment plans;

- document findings and observations resulting from assessments and initiate corrective action in accordance with Section 5.4; and

- document the results of assessments in assessment reports and provide a copy of each assessment report to the assessment sponsor.

\subsection{Candidate for Qualification}

A candidate for qualification must meet the qualification criteria required of personnel to perform work.

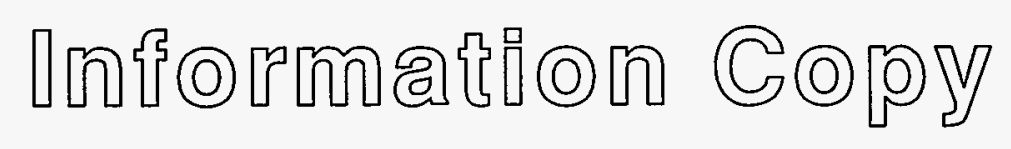




\begin{tabular}{|l|c|c|}
\hline FOR-001.003 & Integrated Formal Operations & $\begin{array}{r}\text { Configuration } \\
\text { Management } \\
\text { Page } 26 \text { of } 37\end{array}$ \\
\hline
\end{tabular}

\subsection{Change Agent}

A change agent will

- change only the controlled elements specified in the applicable work authorization;

- ensure that changes are compiled into a proposed baseline and sent to configuration management for evaluation and certification prior to being placed into service; and

- resolve to the satisfaction of the governing configuration control board all evaluation issues raised during the evaluation of the proposed baseline.

\subsection{Change Requester}

A change requester will submit a request for change to the configuration management liaison.

\subsection{Configuration Control Board}

A configuration control board will

- $\quad$ analyze the merit and expected impact of each change request and variance request;

- $\quad$ amend proposed changes and variances as necessary to ensure technical feasibility and positive impact;

- approve or reject change requests and variance requests and document these decisions;

- $\quad$ issue a work authorization to the change agent assigned to implement a change;

- evaluate proposed baselines to ensure that the implemented changes were completed as specified in the work authorization;

- identify and document evaluation issues and ensure that the change agent satisfactorily resolves each evaluation issue;

- approve or reject proposed baselines based on the results of their evaluations;

- document approved variances and request their distribution in accordance with Section 5.6; and

- define obsolete baselines and direct the configuration manager to designate them as such in the baseline catalog and baseline repository.

\subsection{Configuration Management Liaison}

A configuration management liaison will

- serve as an interface between requesters and configuration control boards;

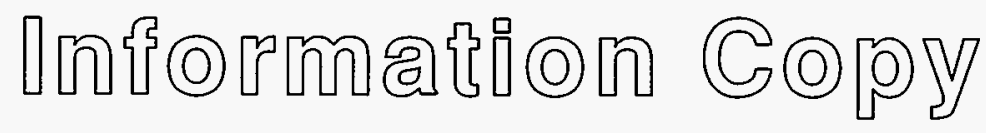




Sonfiguation
Management

- verify that change requests and variance requests are complete before submitting them to the governing configuration control board(s);

- reject incomplete change requests and incomplete variance requests;

- $\quad$ accept proposed baselines from change requests;

- $\quad$ ensure that 1) a work authorization exists for each proposed baseline and 2) each proposed baseline is consistent with its configuration definition;

- $\quad$ reject proposed baselines that do not have associated work authorizations or configuration definitions or that do not conform to their associated work authorizations or configuration definitions;

- $\quad$ accept requests for configuration status reports;

- verify that a report request is complete and reasonable;

- $\quad$ reject an incomplete or unreasonable report request; and

- distribute requested reports in accordance with the distribution list in the report request and submit a copy of each requested report to records management.

\subsection{Configuration Manager}

The configuration manager will

- $\quad$ serve as the line manager's agent in executing configuration management tasks;

- $\quad$ ensure that each controlled element is described and is labeled with a unique identifier that distinguishes it from every other controlled element;

- develop and maintain a document that lists each controlled element, its description, and its identifier;

- assign an identifier to, and document certification of, an approved baseline; authenticate the work authorization to confirm task completion; and authenticate all related change requests to confirm change implementation;

- maintain a catalog of certified baselines;

- $\quad$ store certified baseline documents in the baseline repository;

- ensure that the baseline repository provides adequate physical storage, security, protection, and retrievability for certified baselines;

- periodically audit the baseline catalog to identify obsolete baselines (as defined by the governing configuration control board) and

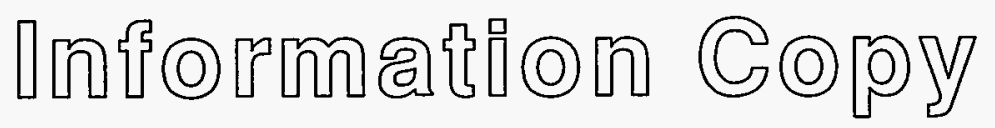




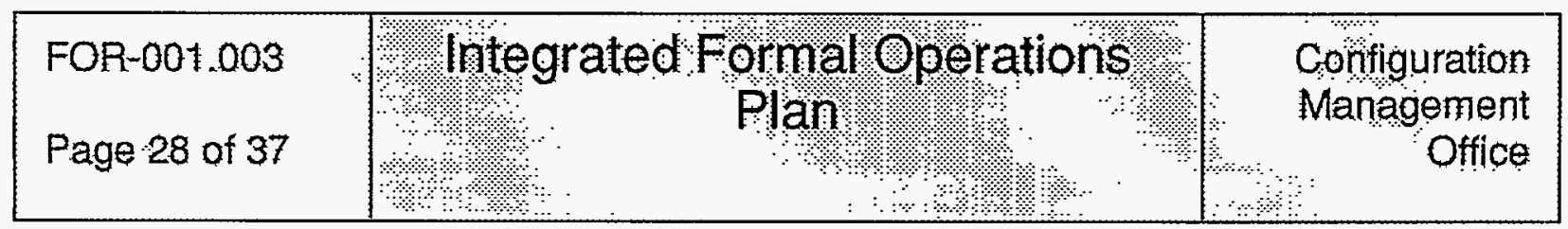

- remove obsolete baselines from the baseline repository and update the baseline catalog;

- reject unreasonable requests for configuration status reports;

- on a best-effort basis, generate requested reports as described in the verified report request;

- analyze issues originating from configuration control board evaluation of any configuration management process element (such as a change implementation or a proposed baseline) and issue reports to management that characterize the performance of the formal operations program;

- $\quad$ perform periodic assessments to determine the level of consistency between the actual items, processes, and information essential to successful operation and those specified as controlled elements;

- $\quad$ assess the consistency between controlled elements and their corresponding configuration definitions;

- track, archive, analyze, and report to management any findings or observations resulting from internal and external assessments; and

- track, store, and analyze the number of variance requests submitted, rejected, amended, and approved, and use the analysis results to characterize the performance of the related procedures in reports to management;

- collect, store, and analyze the dates of records produced during the life of processes documented in this formal operations plan and use the date analysis results to identify and report to the accountable line manager the average response time from initiation to completion of each of the processes;

- endeavor to characterize the costs associated with developing, implementing, administering, and maintaining the formal operations program specified in this planning document; and

- endeavor to characterize schedule-related issues throughout the development, implementation, administration, and maintenance of the formal operations program specified in this planning document.

\subsection{Design Owner}

\section{A design owner will}

- $\quad$ ensure that designs meet all applicable specifications and standards;

- develop a design in accordance with a certified design plan; and

- $\quad$ ensure that a proposed design is compiled into a proposed baseline and submitted to configuration management for evaluation and certification;

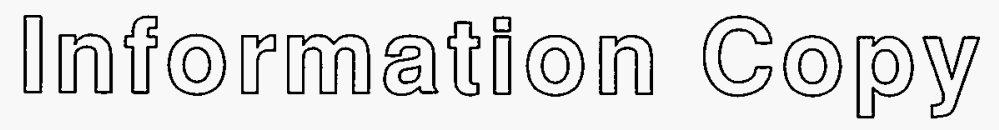




\begin{tabular}{|c|c|c|c|c|c|}
\hline Configurationt \\
Management \\
Office
\end{tabular}

\subsection{Document Custodian}

A document custodian will

- follow all instructions specified in a controlled document distribution package; and

- protect all copies of controlled documents assigned to the document custodian.

\subsection{Document Manager}

The document manager will

- accept candidate master documents into the document control environment;

- verify that a candidate master document is complete and is of a supported type;

- reject incomplete or unsupported documents;

- maintain a document catalog;

- store master documents in a document repository to ensure adequate physical storage, security, protection, and availability for master documents;

- periodically audit the document catalog to identify obsolete or superseded master documents;

- ensure that obsolete and superseded master documents are removed from the document repository and that the catalog is updated accordingly;

- verify that a controlled distribution request is complete;

- reject an incomplete controlled distribution request;

- determine the availability of a requested document, retrieve a copy of the master document from the document repository, and ensure that only the requested number of distribution copies are made;

- ensure that each distribution copy is assigned a unique control number and is labeled accordingly and that a controlled distribution list is compiled for the controlled distribution;

- ensure that a document distribution package is transmitted to each document custodian on the controlled distribution list; and

- verify and document that 1) the instructions in document distribution packages are followed and 2) all controlled copies are accounted for.

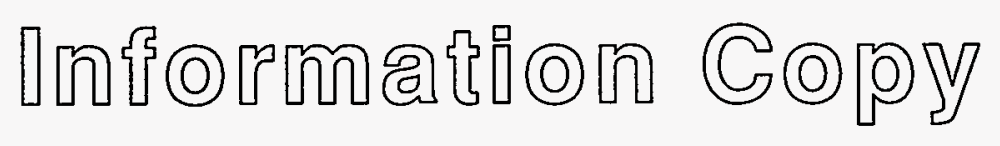




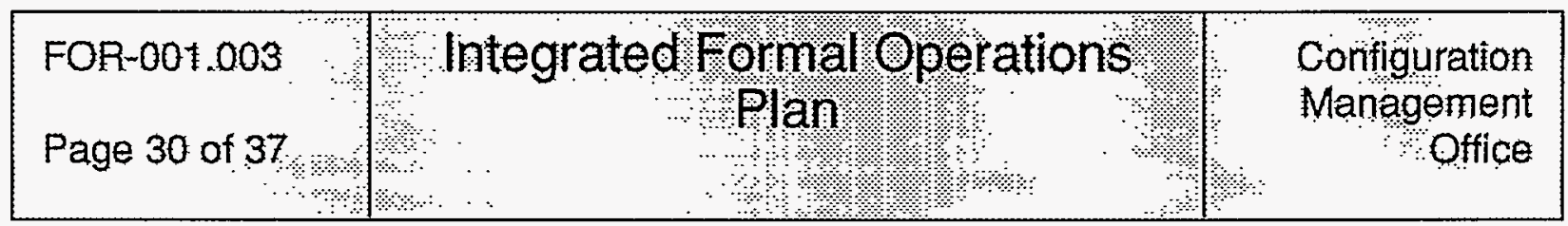

\subsection{Initiator}

An initiator will formally bring deficiencies or occurrences to the attention of management by preparing a report describing the deficiency or occurrence and submitting it to the work process owner.

\subsection{Inspection/Test Sponsor}

An inspection/test sponsor will

- develop a formal plan for an inspection or test;

- $\quad$ ensure that procedures exist to govern an inspection or test and use these procedures to perform the inspection or test;

- $\quad$ use documented plans, procedures, baselines, accepted standards and criteria, worker input, and objective measurements to analyze a nonconformance's validity, its impact on other items, work processes, the environment, safety, and health, and determine its root cause;

- transmit impact analysis results in an impact analysis report to the accountable line manager in a timely manner;

- $\quad$ use an impact analysis report to create a corrective action plan in accordance with Section 5.1 that specifies how the organization will address the nonconformance; and

- in accordance with Section 5.4, initiate development and implementation of substantive, measurable improvements to the processes used to produce inspected or tested items.

\subsection{Investigator}

\section{An investigator will}

- use documented plans and procedures, accepted standards and criteria, worker input, and objective measurements to analyze a deficiency's or occurrence's validity and its impact on other items, work processes, the environment, safety, and health; and determine its root cause;

- transmit impact analysis results in an impact analysis report to the accountable line manager in a timely manner; and

- use an impact analysis report to create a corrective action plan in accordance with Section 5.1 that specifies how the organization will address the deficiency or occurrence.

\subsection{Procurement Authority}

The procurement authority will

- verify that a procurement request is complete;

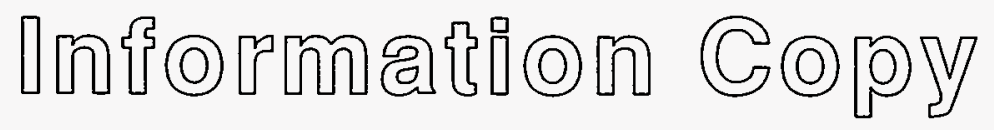




\begin{tabular}{|c|c|c|}
\hline $\begin{array}{l}\text { Qonfiguration } \\
\text { Management? } \\
\text { Office }\end{array}$ & Imegrated Fornal Operations & 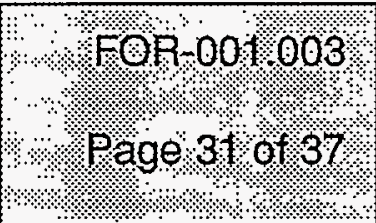 \\
\hline
\end{tabular}

- $\quad$ reject an incomplete procurement request;

- identify candidate vendors for items and services based on input from the procurement requester and vendor information;

- analyze information provided by a candidate vendor to determine the vendor's suitability to supply the subject items or services, including formal assessments as necessary;

- $\quad$ issue the necessary documents to obtain requested items or services from qualified vendor(s) based upon the information in a verified procurement request;

- resolve deficiencies in procured items or services in a manner satisfactory to the procurement requester; and

- ensure that procurement documentation is assembled for procured items or services.

\subsection{Procurement Requester}

A procurement requester will

- develop a procurement request and submit it to the procurement authority;

- $\quad$ certify the receipt of items or services;

- certify the acceptability of items and services in accordance with the acceptance plan;

- reject deficient items or services and notify the procurement authority; and

- ensure that procurement documentation is assembled for procured items or services.

\subsection{Program Owner}

A program owner will

- mandate a program's creation and ensure that a formal plan is developed to describe it;

- designate a work process owner to ensure that procedures, which specify the steps necessary to complete a work process, are defined and documented;

- initiate a program plan by submitting a change request to, and obtaining an approved work authorization from, configuration management;

- ensure that a candidate program plan is compiled into a proposed baseline and is submitted to configuration management for evaluation and certification; and

- designate a work process owner to ensure that procedures, which specify the steps necessary to complete a work process, are defined and documented.

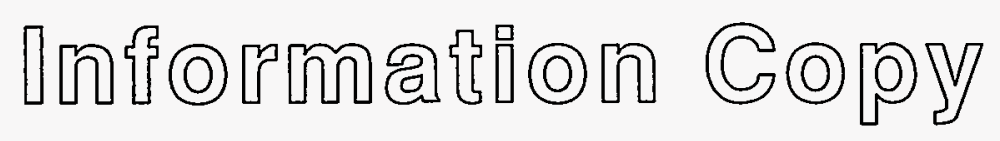




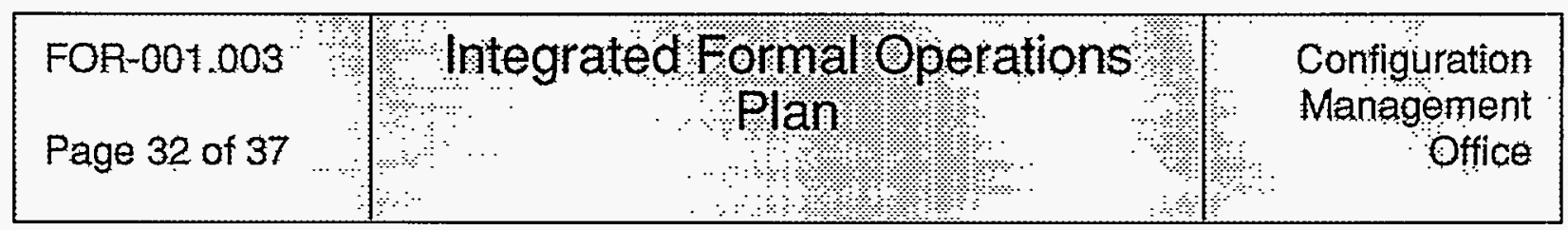

\subsection{Record Requester}

A record requester will submit a record request to the records manager.

\subsection{Records Manager}

The records manager will

- $\quad$ accept candidate records from authorized submitters;

- verify that a record is complete and is of a supported record type;

- $\quad$ reject incomplete or unsupported records;

- maintain a records catalog;

- store records in a records repository to ensure adequate physical storage, security, protection, and retrievability of archived records;

- $\quad$ periodically audit the records catalog to identify obsolete records;

- $\quad$ ensure that obsolete records are transferred to an external repository or destroyed according to the disposal criteria specified in the records management standards;

- update the records catalog to reflect the disposition of records;

- $\quad$ accept a record request from a requester;

- verify that a record request is complete, reject an incomplete request, and document the disposition of the request;

- determine the accessibility of a requested record, retrieve it from the records repository, and make it available to the requester; and

- $\quad$ ensure adequate security and protection of released records.

\subsection{Report Requester}

A report requester will submit a request for a configuration status report to the configuration management liaison.

\subsection{Trainee}

A trainee will receive specific training to meet the qualification criteria for a work process and will take a proficiency test to demonstrate that the training has been effective.

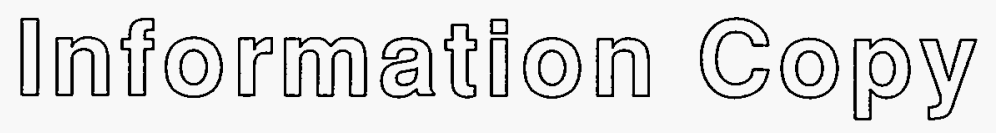




\begin{tabular}{|c|c|c|}
\hline 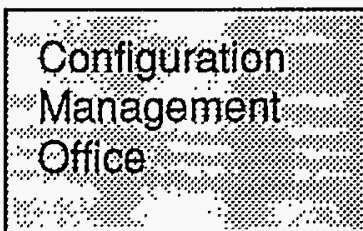 & 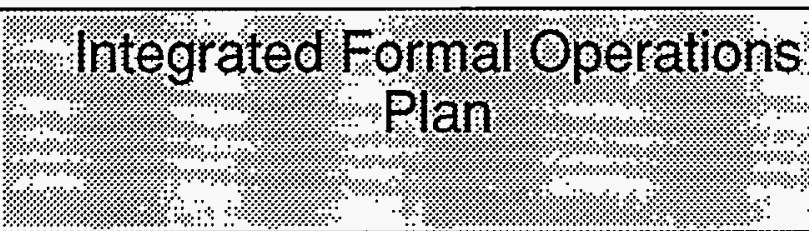 & 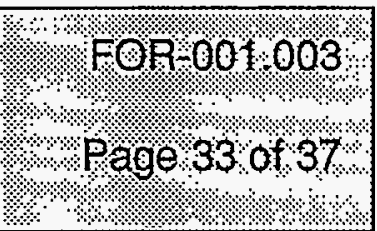 \\
\hline
\end{tabular}

\subsection{Trainer}

A trainer will administer a training course, including a proficiency test, to trainees, and will certify trainees that successfully complete the training course.

\subsection{Training Course Developer}

A training course developer will create a training course in accordance with a certified training plan.

\subsection{Training Program Owner}

A training program owner will

- designate a training course developer to create a training course; and

- ensure that a candidate training course is compiled into a proposed baseline and is submitted to configuration management for evaluation and certification.

6.27 Variance Requester

A variance requester will submit a variance request to the configuration management liaison.

\subsection{Verifier}

A verifier will

- analyze the results of an inspection or test, document nonconformances, and transmit resulting nonconformance reports to the inspection/test sponsor; and

- document the results of an inspection or test.

\subsection{Work Process Owner}

A work process owner will

- designate candidates for qualification who must meet the qualification criteria required of personnel to perform work;

- $\quad$ compare each candidate's qualifications against the criteria for the work process;

- $\quad$ certify each candidate who meets the qualification criteria;

- identify trainees who must receive specific training to meet the qualification criteria for a work process;

- designate a trainer to administer a training course and proficiency test to trainees;

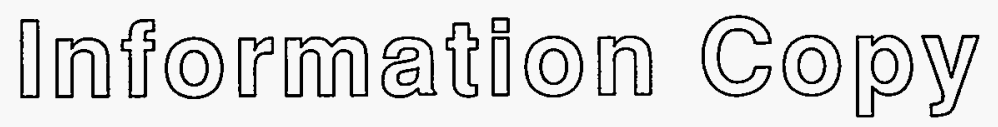




\begin{tabular}{|c|c|c|}
\hline $\begin{array}{l}\text { FOR-001.003: } \\
\text { Page } 34 \text { of } 37\end{array}$ & $\begin{array}{l}\text { Integrated Formal Operations } \\
\text { Plan }\end{array}$ & $\begin{array}{r}\text { Configuration } \\
\text { Management } \\
\therefore \quad \text { Office }\end{array}$ \\
\hline
\end{tabular}

- ensure that procedures, which specify the steps necessary to complete a work process, are defined and documented;

- initiate procedure development by submitting a change request and obtaining a work authorization from configuration management; and

- ensure that a candidate procedure is compiled into a proposed baseline and is submitted to configuration management for evaluation.

6.30 Worker

A worker will

- perform work in accordance with the instructions in controlled copies of procedures;

- become familiar with procedures and identify the provisions that apply to the worker's tasks;

- review any hazards, limitations, special conditions, and prescribed precautions identified in the procedures before starting work;

- be certified and qualified before performing work that is controlled by a procedure;

- generate all records required by the procedures and submit them to records management in a timely manner;

- identify and document any deficiencies in, and potential improvements to work processes; and

- provide input to the analysis of noconformances and deficiencies, and the development of procedures.

\subsection{MEASURES OF PERFORMANCE}

To objectively measure the performance of this planning document and the formal operations program developed from its specifications, the accountable line manager will ensure the collection, storage, and analysis of the metrics described in this section. The accountable line manager will use the results of the metrics analyses to actively improve the performance of the formal operations program.

\subsection{Primary Metrics}

This section specifies the measurements and analyses that must be used to evaluate the performance of the formal operations program at regular intervals during its active life.

\subsubsection{Document Improvement Questionnaire}

A document improvement questionnaire for this planning document is contained in Attachment 1, Document Improvement Questionnaire. The accountable line manager

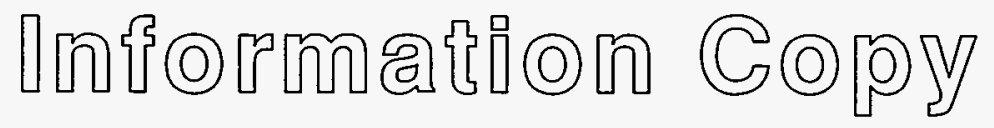




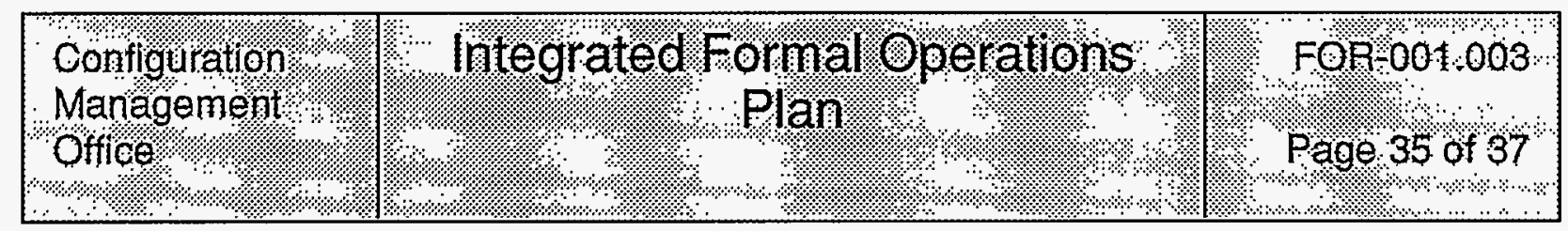

will encourage users of this planning document to complete and return the document improvement questionnaire. The accountable line manager will use the contents of the responses to evaluate the performance of this planning document and to aid in the development of future documents.

\subsubsection{Formal Requests for Planning Document Change}

The accountable line manager will track and analyze formal requests for change (such as enhancement requests and problem reports) to this planning document to evaluate the performance of this document.

\subsubsection{Evaluation Issues}

The configuration manager will analyze issues originating from configuration control board evaluations (such as a change implementation evaluation) and will issue reports to the accountable line manager that characterize the performance of the formal operations program.

\subsubsection{Assessment Findings}

7.1.4.1 External Assessment Findings. The Department of Energy or other authorized external entities may assess the formal operations program, or any part thereof. The configuration manager will track, archive, analyze and report to the accountable line manager any findings or observations originating from such external assessments.

7.1.4.2 Internal Assessment Findings. The configuration manager will perform periodic assessments to determine the level of consistency between the actual items, processes, and information essential to successful operation and those specified as controlled elements (see Section 5.2). The configuration manager will also assess the consistency between controlled elements and their corresponding configuration definitions (see Section 5.2.1.3). The configuration manager will report any findings or observations resulting from such internal assessments to the accountable line manager.

7.1.4.3 Management Assessments. The accountable line manager will perform periodic assessments to determine the level of performance of the overall formal operations program.

\subsubsection{Variance Requests}

The configuration manager will track, store, and analyze the number of variance requests submitted, rejected, amended, and approved, and will use the analysis results to characterize the performance of the related procedures in reports to the accountable line manager.

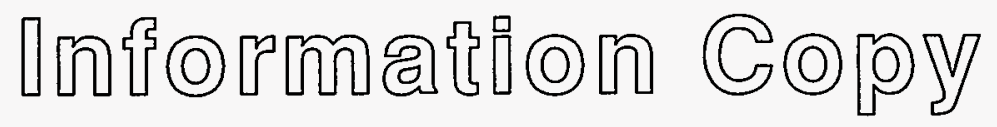




\begin{tabular}{|l|c|c|c|c|}
\hline FOR-001.003 & Integrated Formal Operations & Configuration \\
Page 36 of 37 & Plan & Management \\
office
\end{tabular}

\subsubsection{Process Response}

The configuration manager will collect, store, and analyze the dates of records produced during the life of processes documented in this formal operations plan. The configuration manager will use the date analysis results to identify and report to the accountable line manager the average response time from initiation to completion of each of the processes.

\subsection{Auxiliary Metrics}

This section specifies optional measurements and analyses to be made on the performance of the formal operations program on a best-effort basis.

\subsubsection{Cost}

The configuration manager will endeavor to characterize the costs associated with developing, implementing, administering, and maintaining the formal operations program specified in this planning document.

\subsubsection{Schedule}

The configuration manager will endeavor to characterize schedule-related issues throughout the development, implementation, administration, and maintenance of the formal operations program specified in this planning document.

\subsection{BUDGET AND SCHEDULE}

Because this plan is intended for use by multiple implementing organizations, budget and schedule information will be provided in separate documents by each implementing organization. Refer to Appendix B, Tailoring Guide, for further information.

\subsection{REFERENCES}

1. ASME NQA-1-1989, Quality Assurance Program Requirements for Nuclear Facilities.

2. Bersoff, E. H., V. D. Henderson, and S. G. Siegel, Software Configuration Management. Englewood Cliffs, N.J.: Prentice-Hall, Inc., 1980.

3. LA-UR-93-3760, Glossary of Formal Operations.

4. DOE Order 1324.5A, Records Management Program.

5. DOE Order 4330.4A, Maintenance Management Program.

6. DOE Order 4700.1, Project Management System.

7. DOE Order 5000.3B, Occurrence Reporting and Processing of Operations Information.

8. DOE Order 5480.5, Safety of Nuclear Facilities.

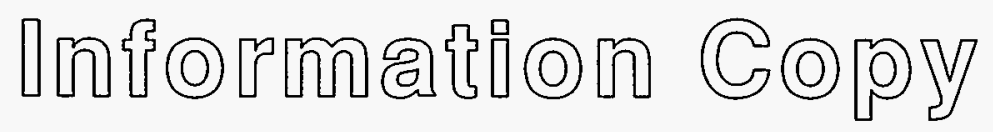




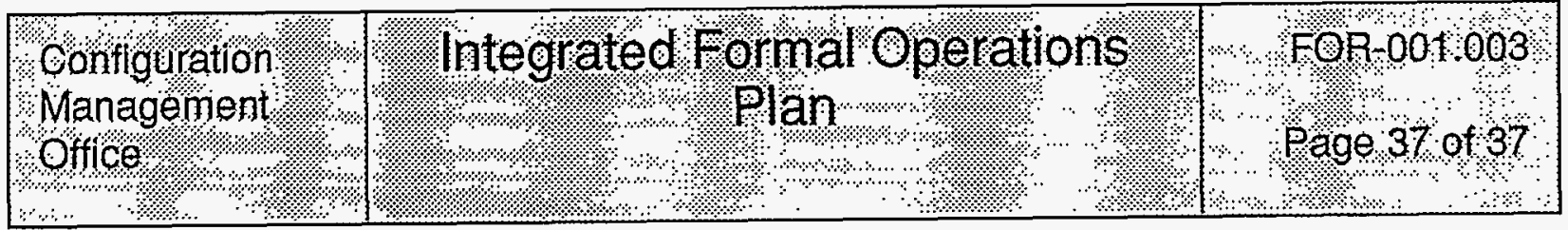

9. DOE Order 5480.19, Conduct of Operations Requirements for DOE Facilities.

10. DOE Order 5480.20, Personnel Selection, Qualification, Training, and Staffing Requirements at DOE Reactor and Non-Reactor Nuclear Facilities.

11. DOE Order 5480.23, Nuclear Safety Analysis Reports.

12. DOE Order 5700.6C, Quality Assurance.

13. LANL-YMP-QP-17.4, Records Preparation.

14. LANL-YMP-QP-18.1, Audits.

\subsection{APPENDIXES}

Appendix A, Process Flow Diagrams

Appendix B, Tailoring Guide

Appendix $\mathrm{C}$, Index

\subsection{ATTACHMENTS}

Attachment 1, Document Improvement Questionnaire 


\begin{tabular}{|c|c|c|}
\hline $\begin{array}{l}\text { Qonfliguration } \\
\text { Management } \\
\text { Qfflce } \\
\%\end{array}$ & Imegrated formal Operations & 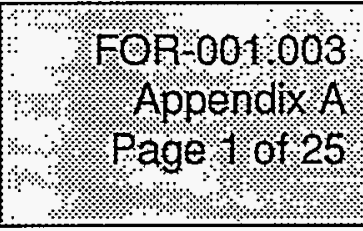 \\
\hline
\end{tabular}

\section{PROCESS FLOW DIAGRAMS}

This appendix contains the process flow diagrams that result from the structured analysis described in the introduction to the Integrated Formal Operations Plan. The following table lists the symbols used in the diagrams along with their meanings.

Table 1: Diagram Symbols

\begin{tabular}{|l|l|}
\hline Symbol & \multicolumn{1}{|c|}{ Meaning } \\
\hline $\begin{array}{l}\text { External Entity. Indicates information flowing into or out of the pro- } \\
\text { cess from an outside entity. The name of the entity is specified within } \\
\text { the white box. }\end{array}$ \\
\hline $\begin{array}{l}\text { Process. Indicates an operation performed on the incoming informa- } \\
\text { tion that results in the outgoing information. The name of the process } \\
\text { is specified within the circle, along with the corresponding section } \\
\text { number from the plan. }\end{array}$ \\
\hline $\begin{array}{l}\text { Interface. Indicates an interface to a process on another page of the } \\
\text { diagram. The name of the process is specified within the symbol. }\end{array}$ \\
\hline $\begin{array}{l}\text { Repository. Indicates a repository where information is stored that can } \\
\text { be used by any process with access to that repository. The name of the } \\
\text { repository is specified within the symbol. }\end{array}$ \\
\hline $\begin{array}{l}\text { Process Flow. Indicates the flow of information from one symbol to } \\
\text { another (from any symbol except other process flows). Only single } \\
\text { direction process flows are depicted in these diagrams. The name of } \\
\text { the information item is specified next to the arrow. }\end{array}$ \\
\hline
\end{tabular}




\begin{tabular}{|l|c|c|r|}
\hline FOR-001.003 & integrated Formal Operations & Configuration \\
Appendix A & Management \\
Page 2 of 25 & & Plan & Office \\
\hline
\end{tabular}

\subsection{Program}

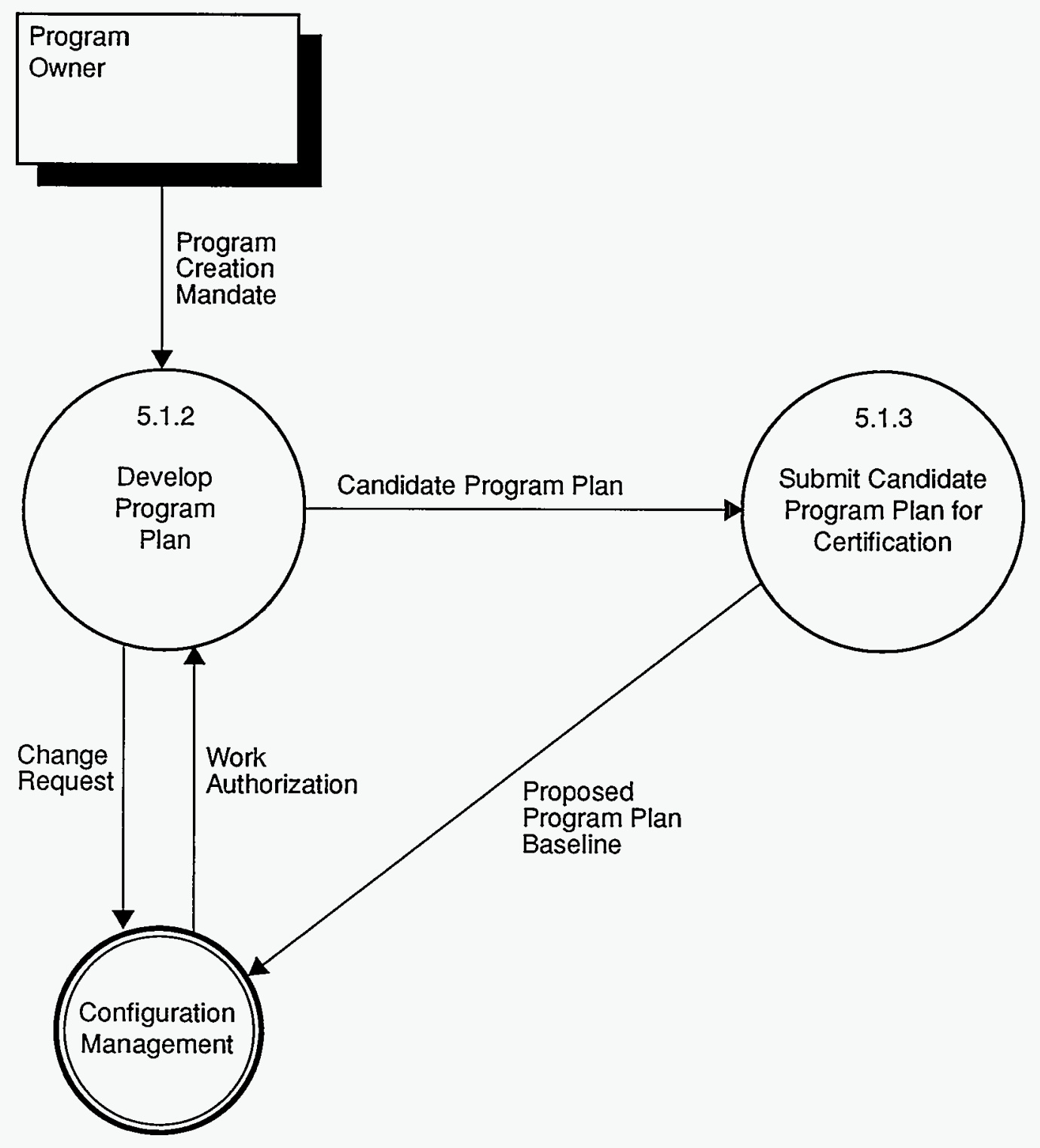

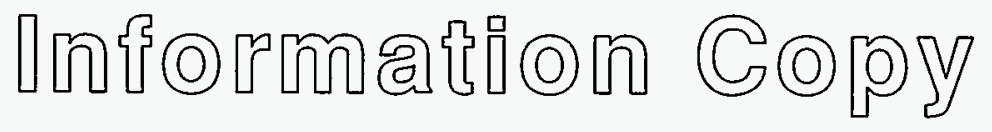




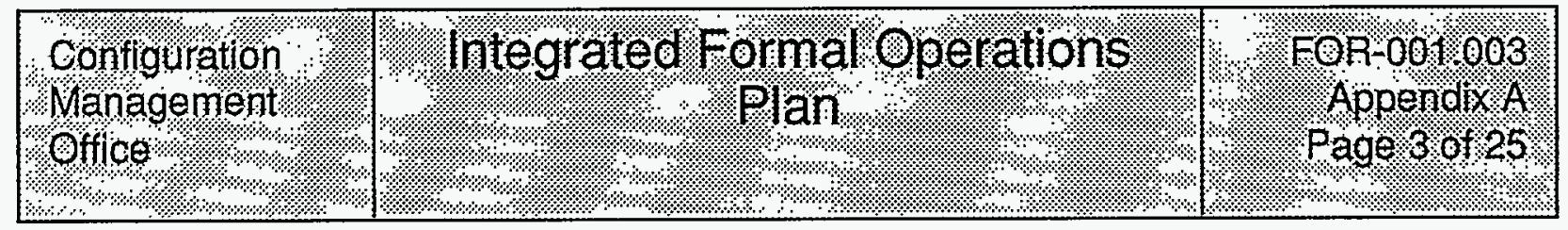

\subsubsection{Configuration Identification}

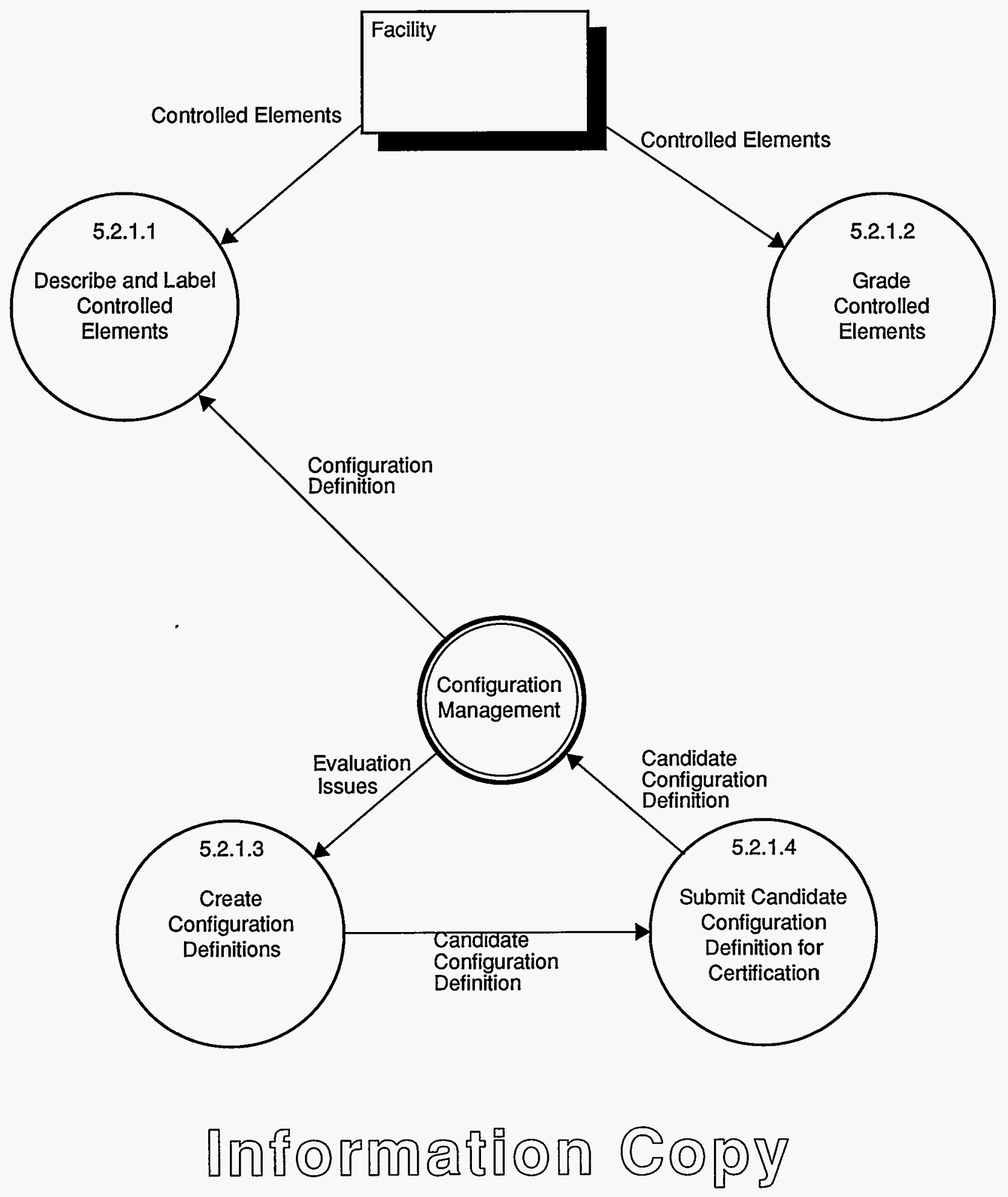




\begin{tabular}{|c|c|c|}
\hline $\begin{array}{l}\text { FOR } 00 \text { t:003 } \\
\text { Appendix A } \\
\text { Page } 4 \text { of } 25\end{array}$ & $\begin{array}{c}\text { Integrated Formal Operations } \\
\text { Plan }\end{array}$ & $\begin{array}{c}\text { Configuration } \\
\text { Management } \\
\vdots\end{array}$ \\
\hline
\end{tabular}

\subsubsection{Initiating Changes}

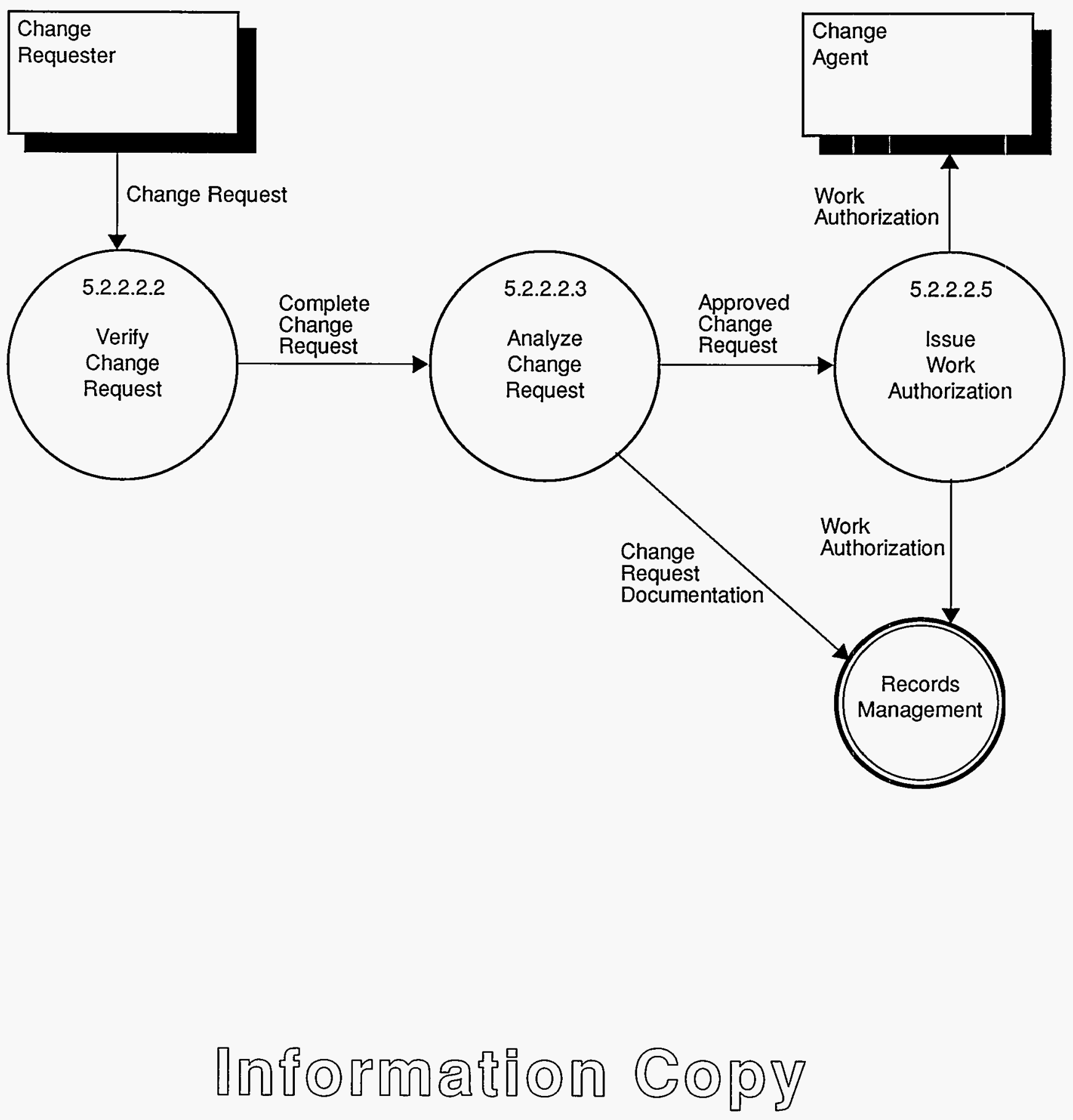




\subsubsection{Implementing Changes}

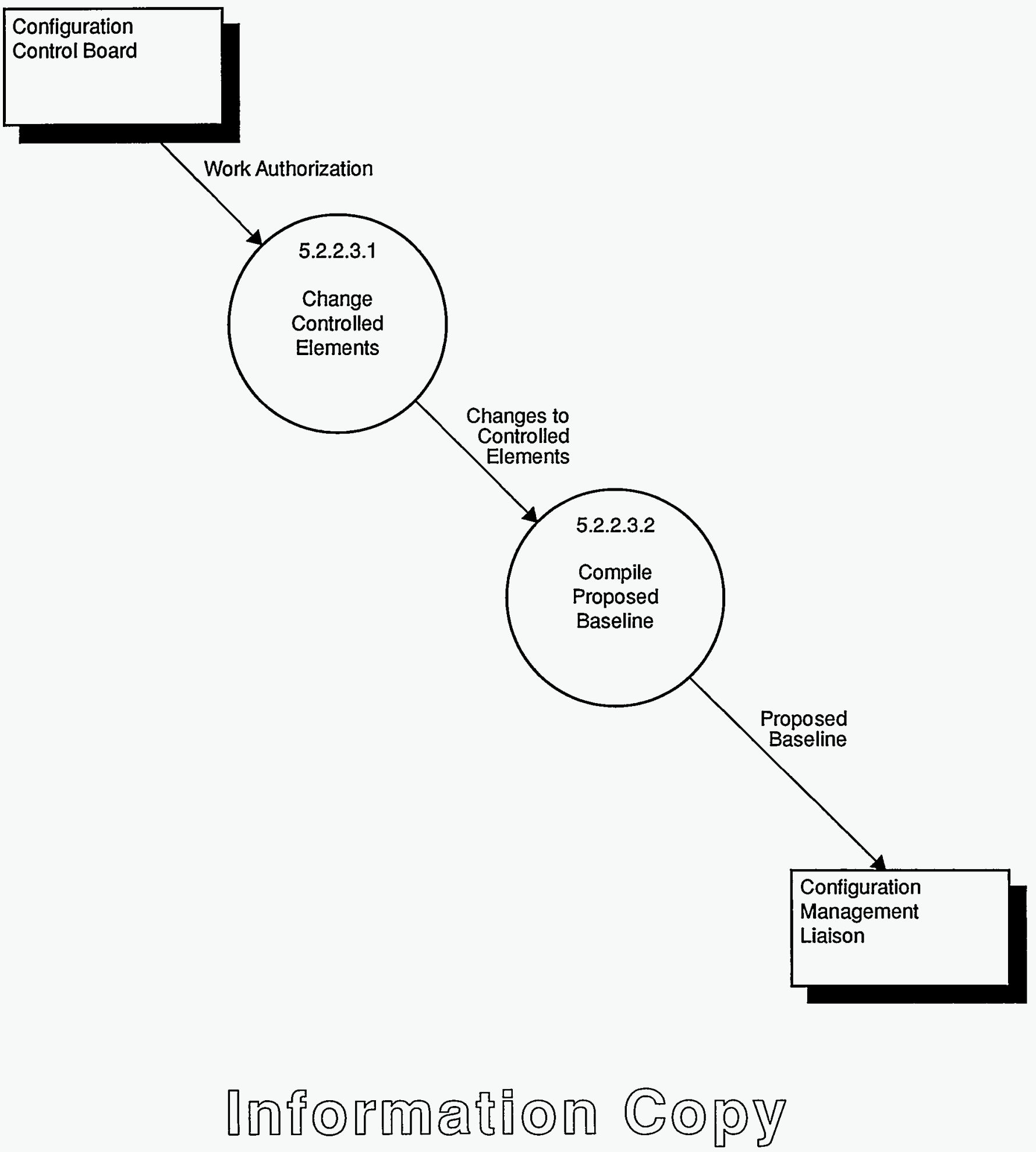




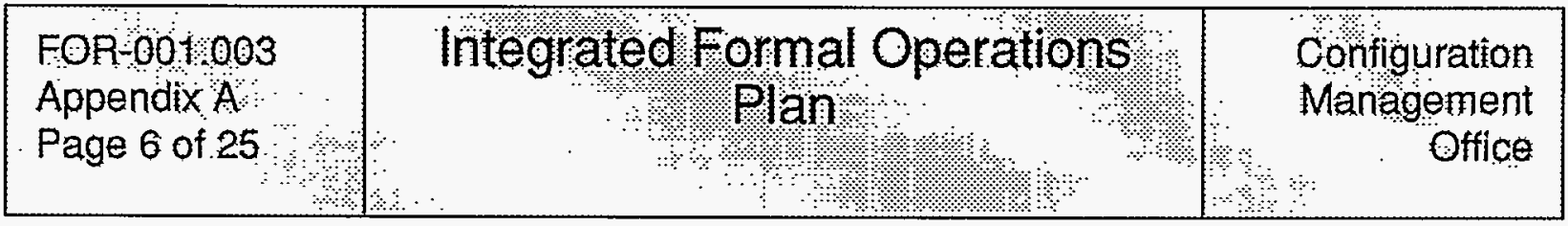

\subsubsection{Baselines}

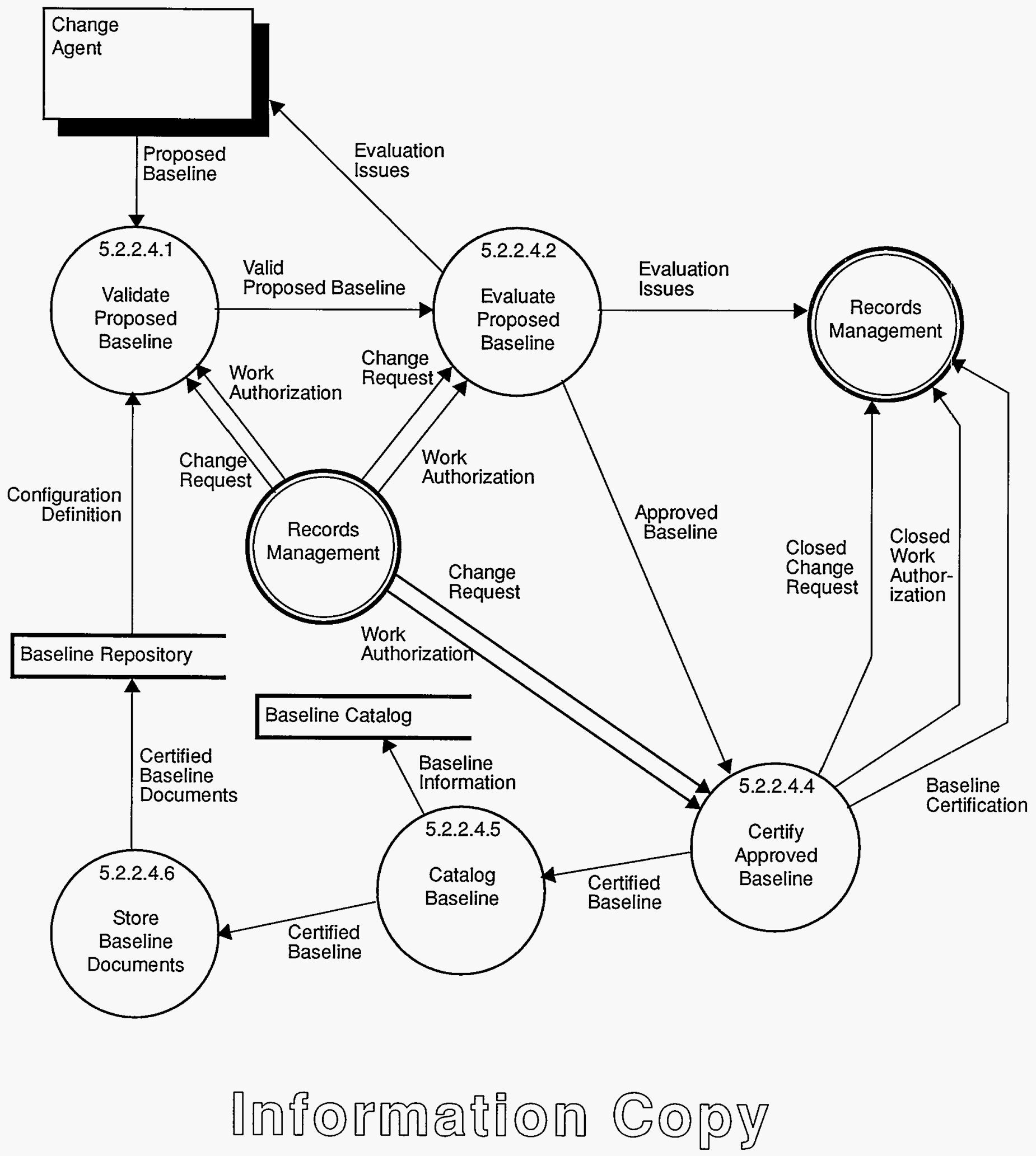




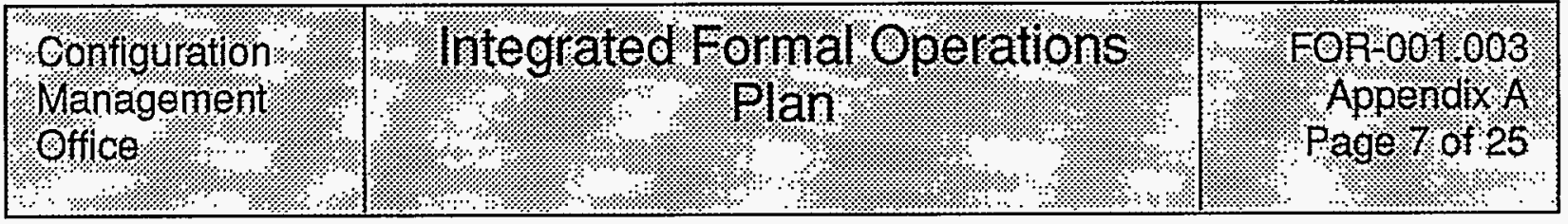

\subsubsection{Variances}

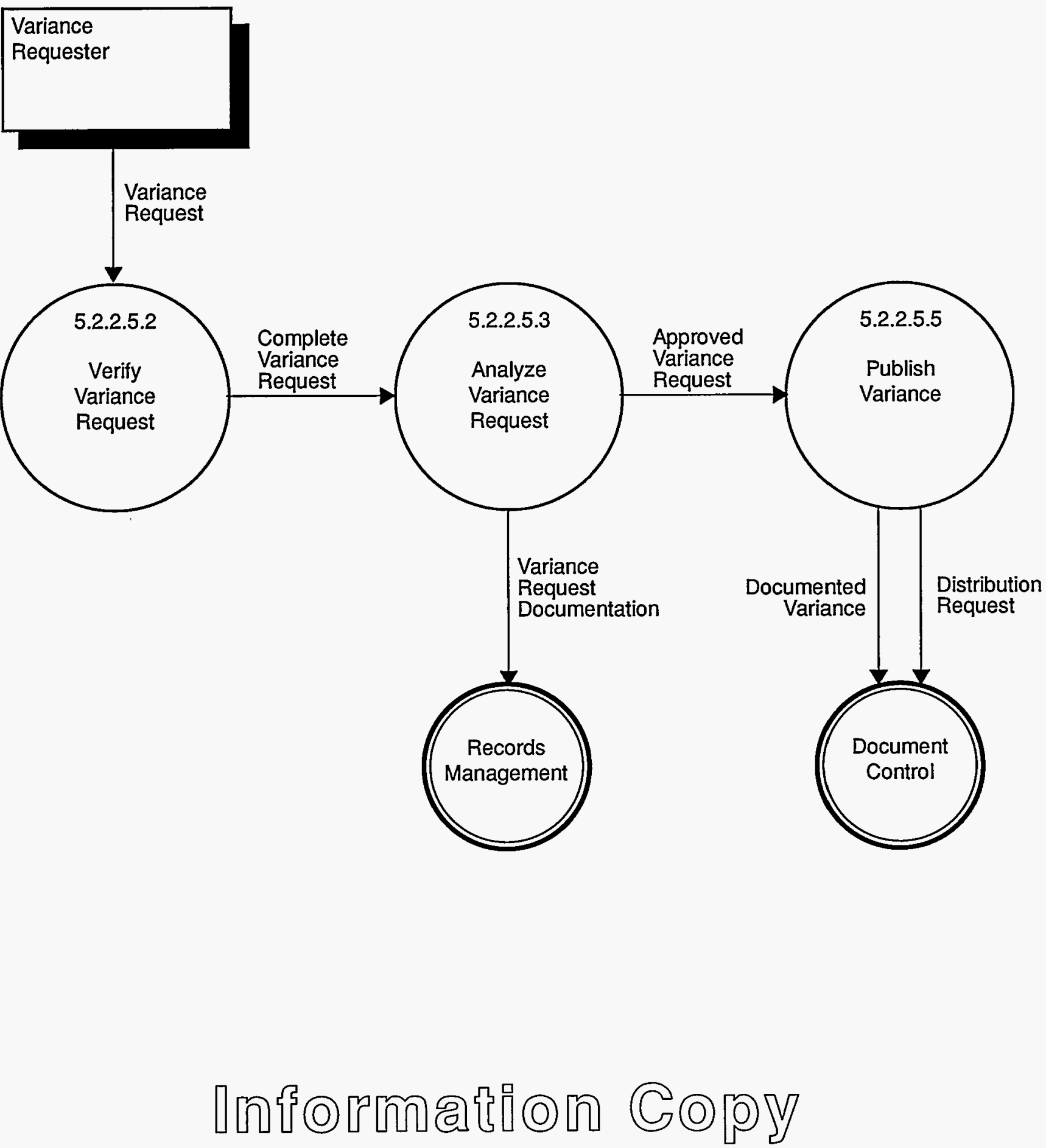




\begin{tabular}{|c|c|c|}
\hline $\begin{array}{l}\text { FOR-001.003 } \\
\text { Appendix A } \\
\text { Page } 8 \text { of } 25\end{array}$ & $\begin{array}{l}\text { Integrated Formal Operations } \\
\text { Plan }\end{array}$ & $\begin{array}{r}\text { Configuration } \\
\text { Management } \\
\text { Office }\end{array}$ \\
\hline
\end{tabular}

\subsubsection{Configuration Status Reports}






\subsubsection{Personnel Qualification}

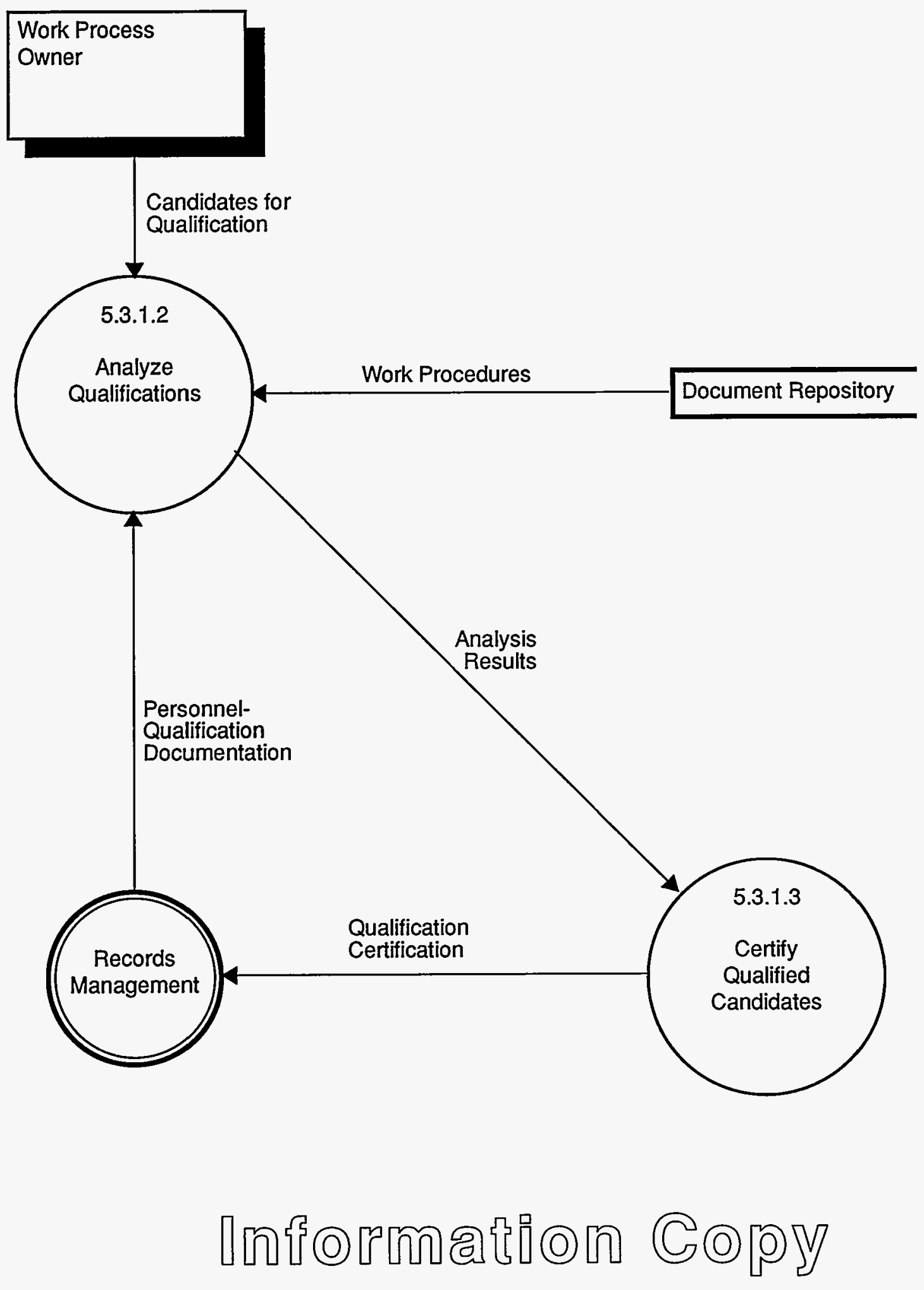




\begin{tabular}{|c|c|c|}
\hline $\begin{array}{l}\text { FOR-001.003 } \\
\text { Appendix A } \\
\text { Pageto: of } 25\end{array}$ & $\begin{array}{l}\text { Integrated Formal Operations } \\
\text { Plan }\end{array}$ & $\begin{array}{r}\text { Configuration } \\
\text { Management } \\
\text { Office }\end{array}$ \\
\hline
\end{tabular}

\subsubsection{Personnel Training}

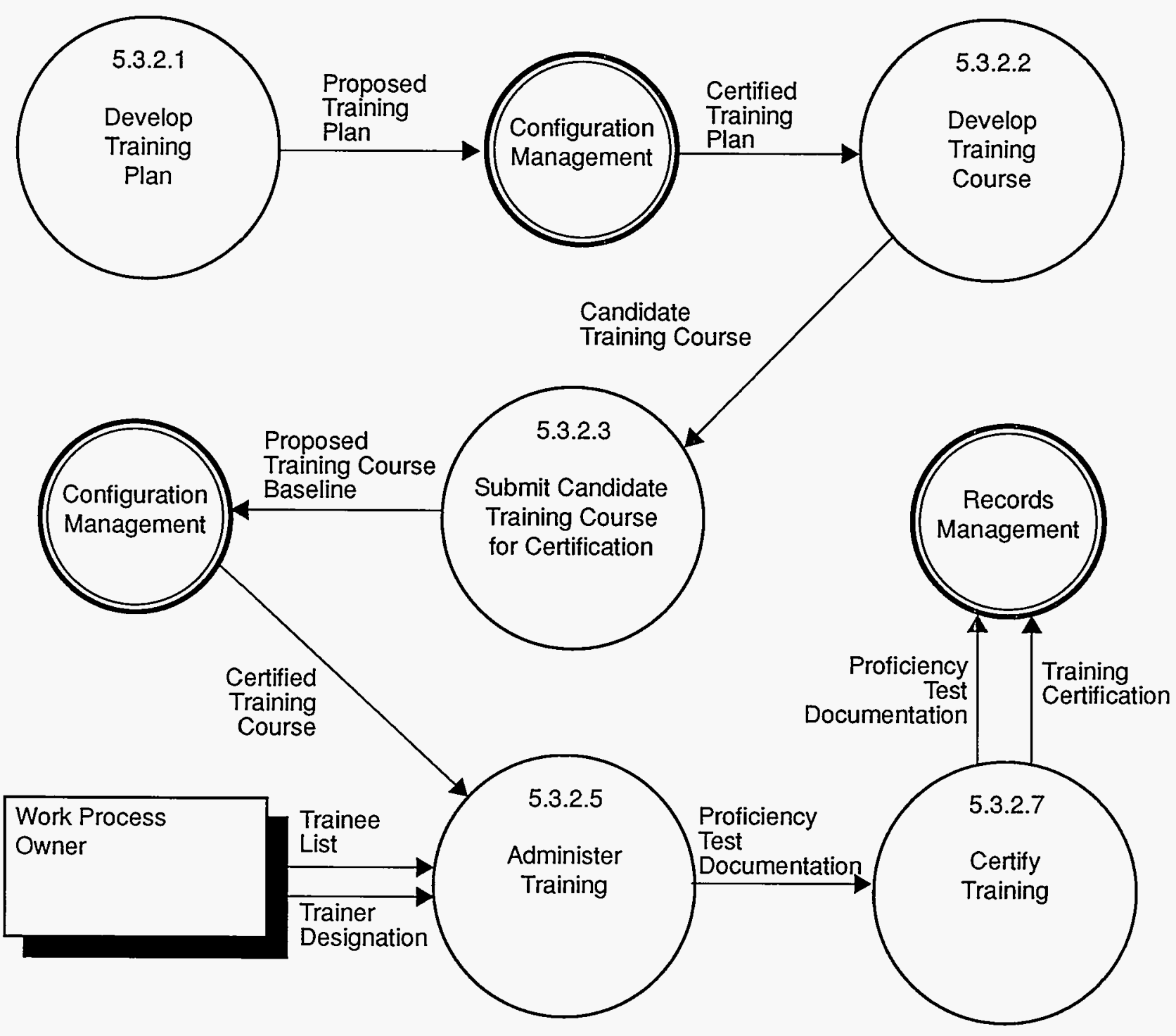

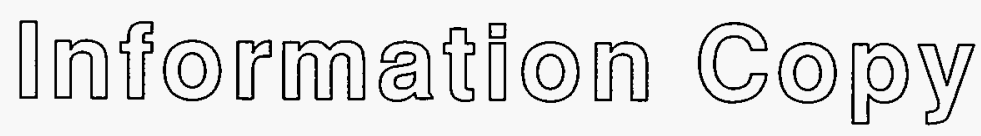




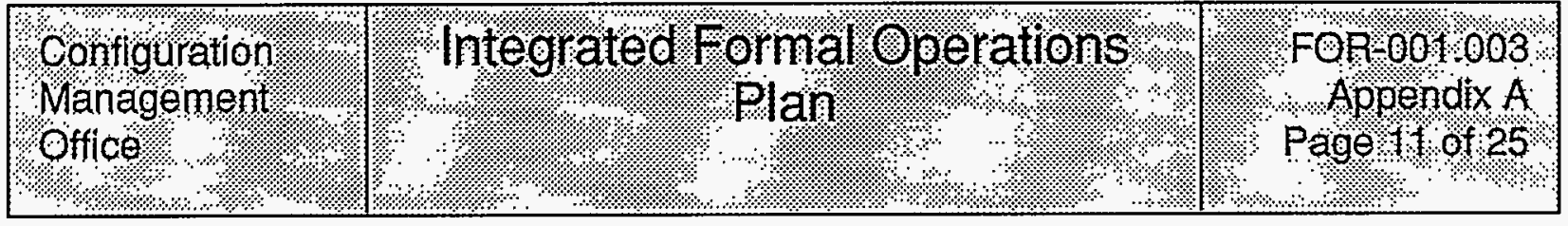

\subsubsection{Deficiencies and Occurrences}

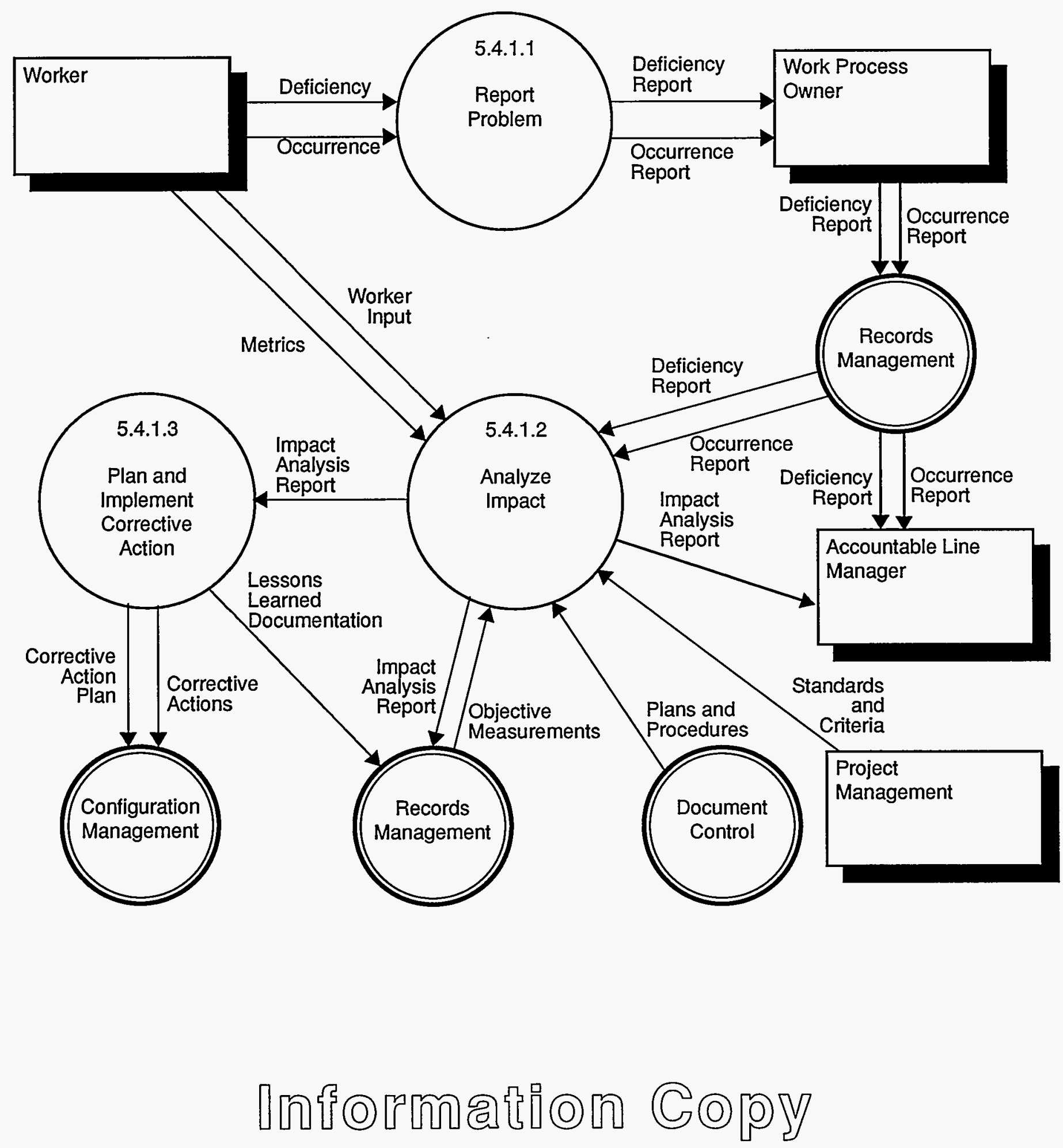




\begin{tabular}{|c|c|c|}
\hline $\begin{array}{l}\text { FOR-001.003 } \\
\text { Appendix A } \\
\text { Page } 12 \text { of } 25\end{array}$ & $\begin{array}{l}\text { Integrated formal Operations } \\
\text { Plan }\end{array}$ & {$\left[\begin{array}{rr}\text { Configuration } \\
\text { Management } \\
0 \quad \text { Office }\end{array}\right.$} \\
\hline
\end{tabular}

\subsubsection{Process Improvement}

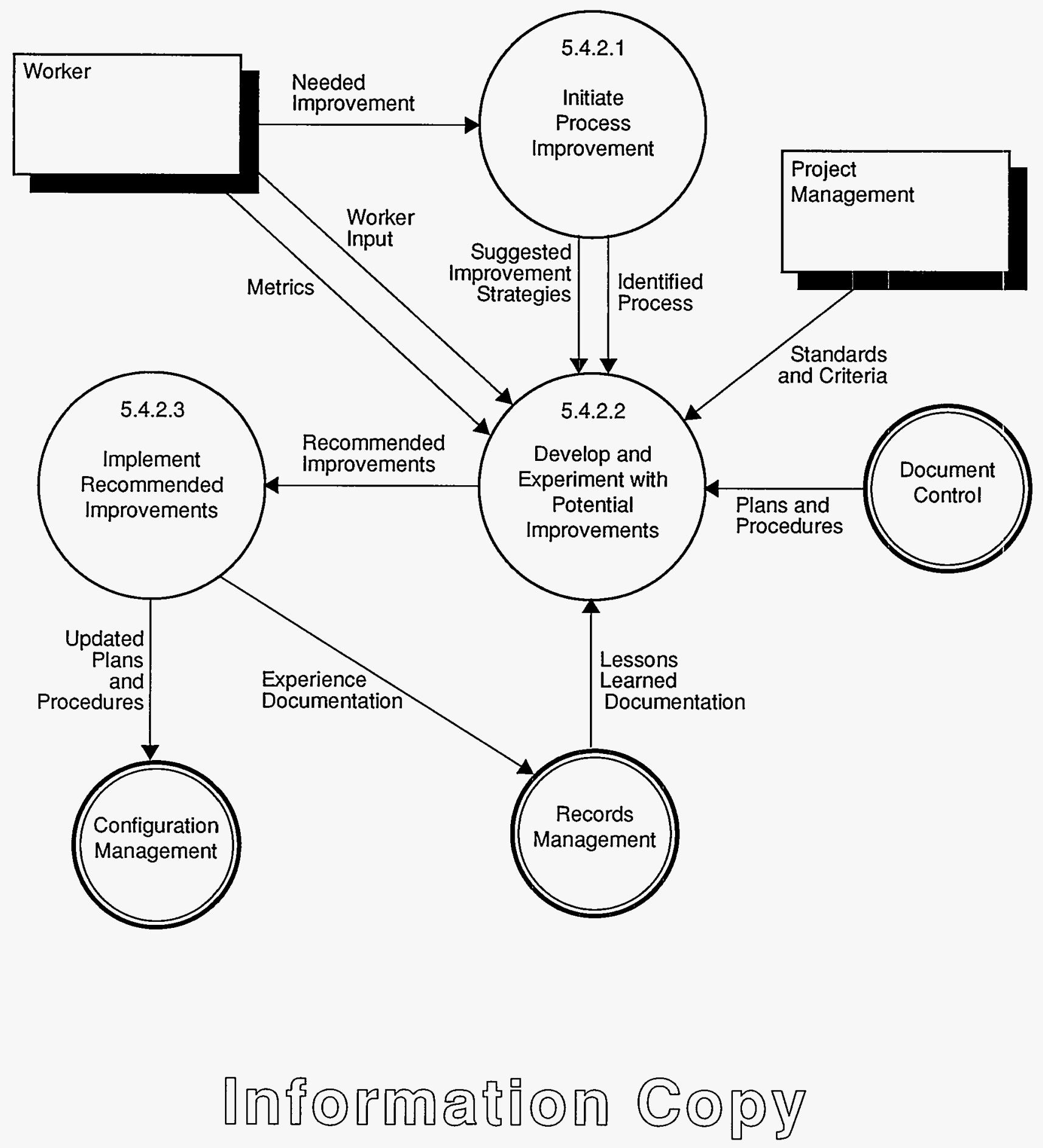




\subsubsection{Records Admission}

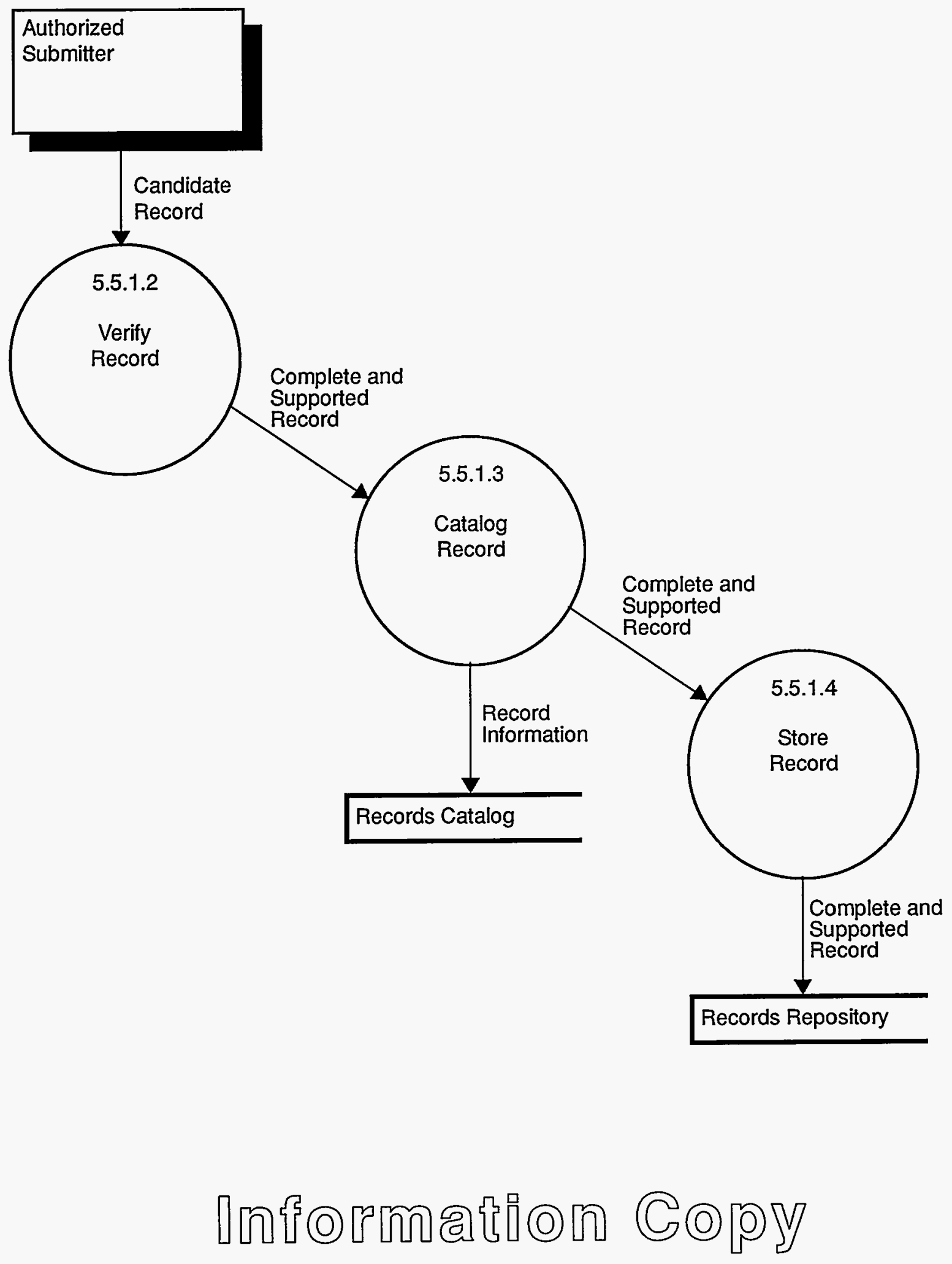




\begin{tabular}{|c|c|c|}
\hline FOR-001.003 & Integrated Formal Operations & Configuratio \\
\hline $\begin{array}{l}\text { Appendix A } \\
\text { Page } 14 \text { of } 25\end{array}$ & $\begin{array}{cc}\text { Plan } \\
0\end{array}$ & $\begin{array}{r}\text { Management } \\
\text { Office }\end{array}$ \\
\hline
\end{tabular}

\subsubsection{Obsolete Records}

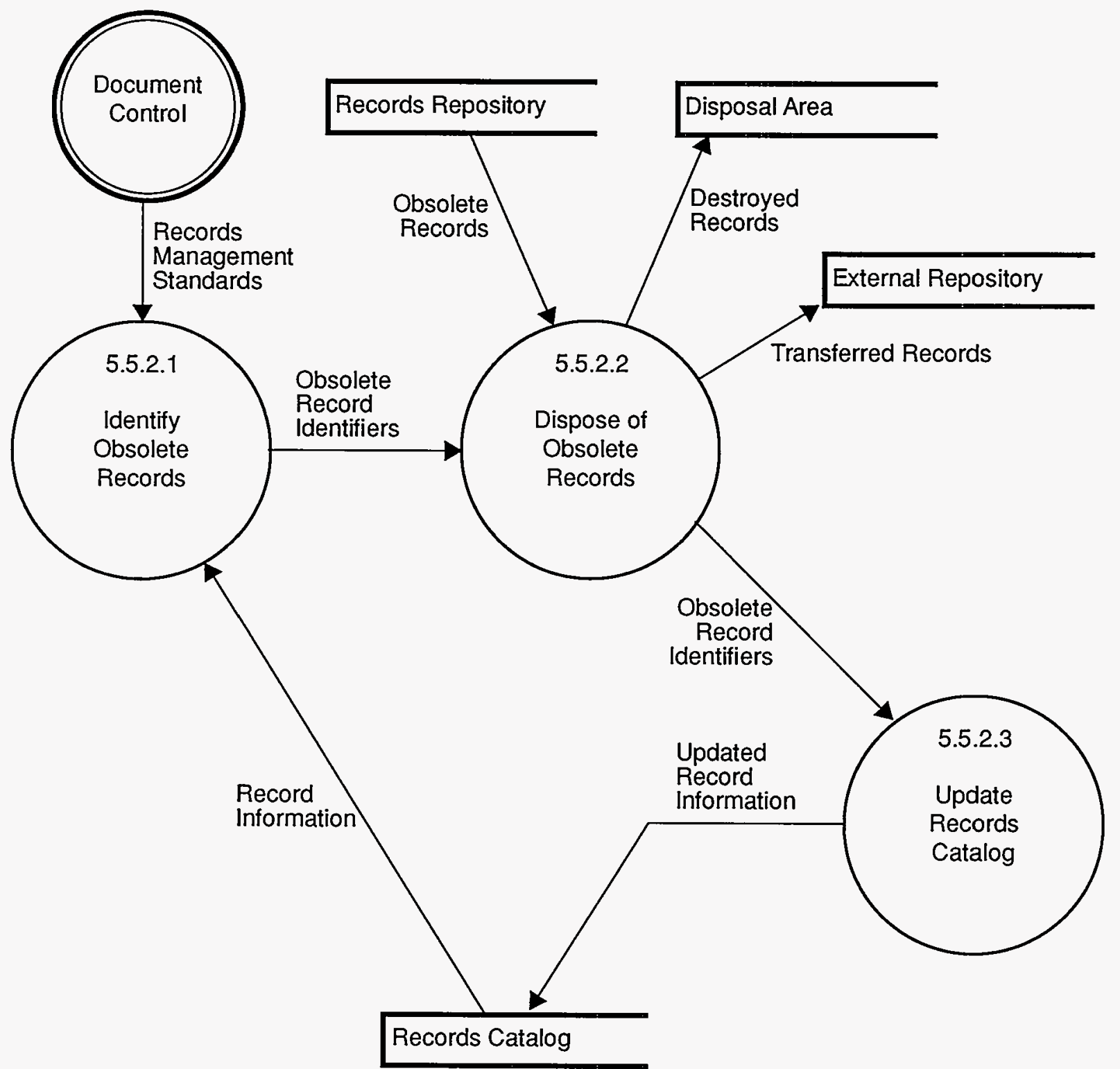

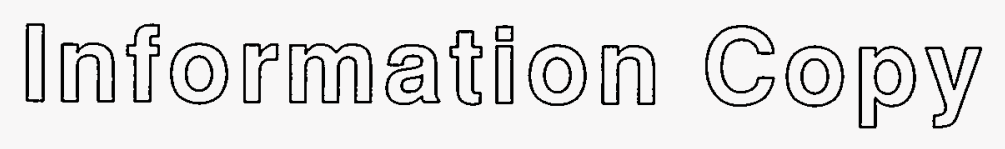




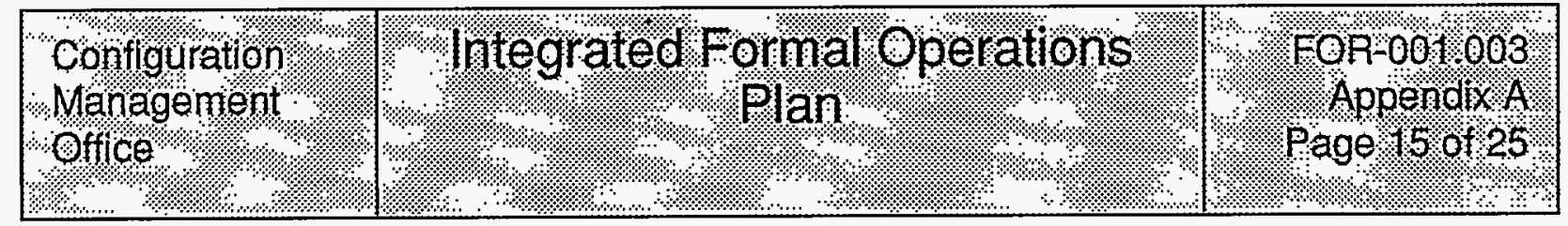

\subsubsection{Record Release}

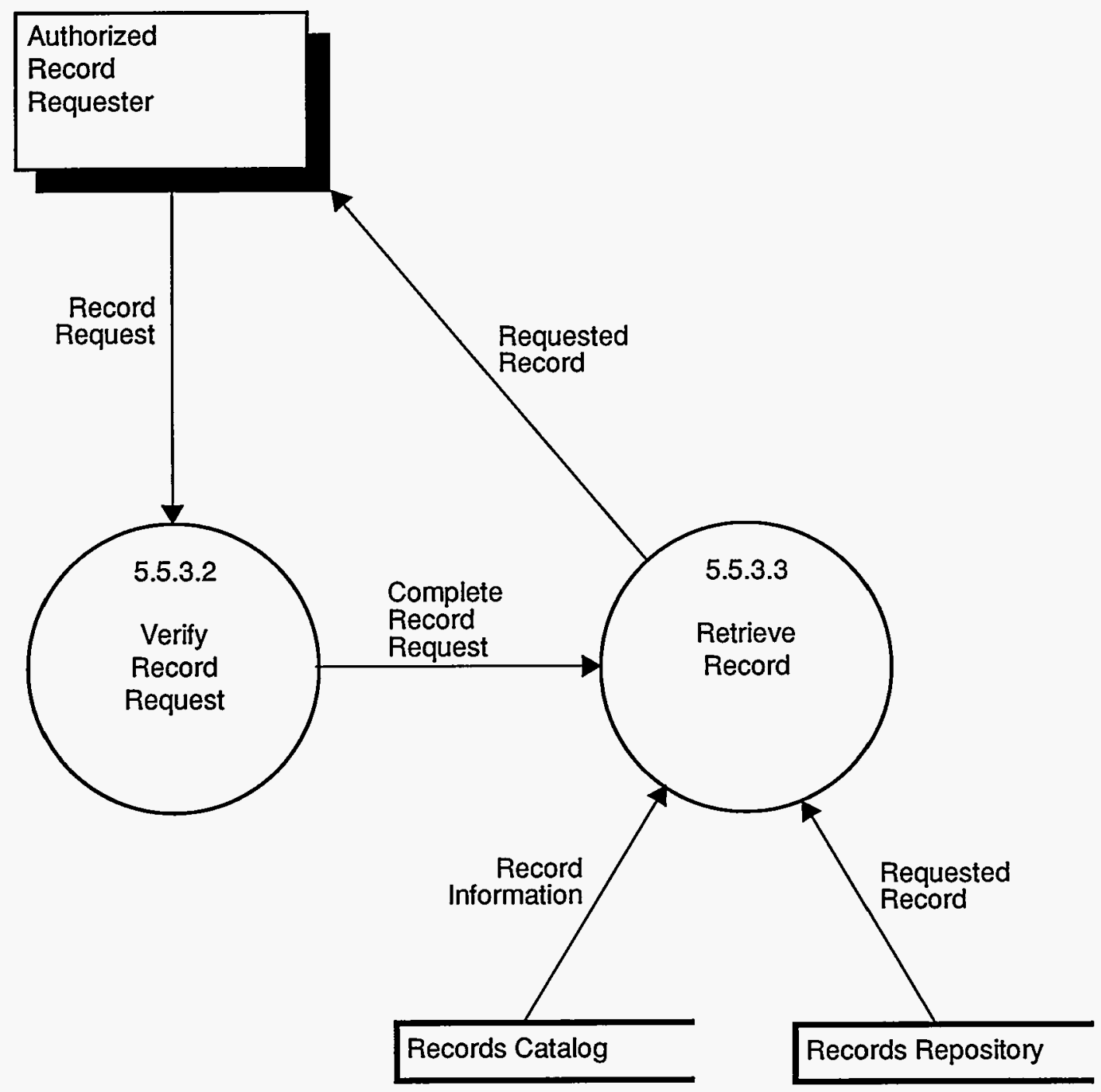

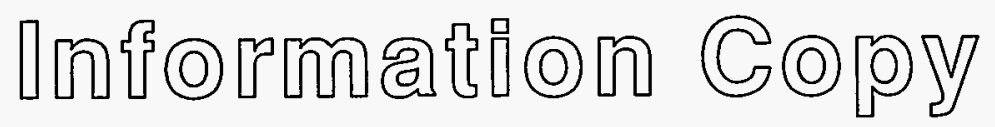




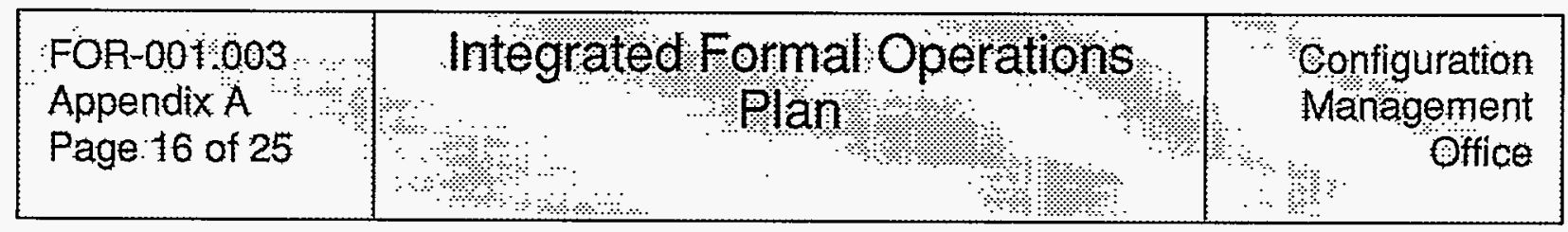

\subsubsection{Document Admission}

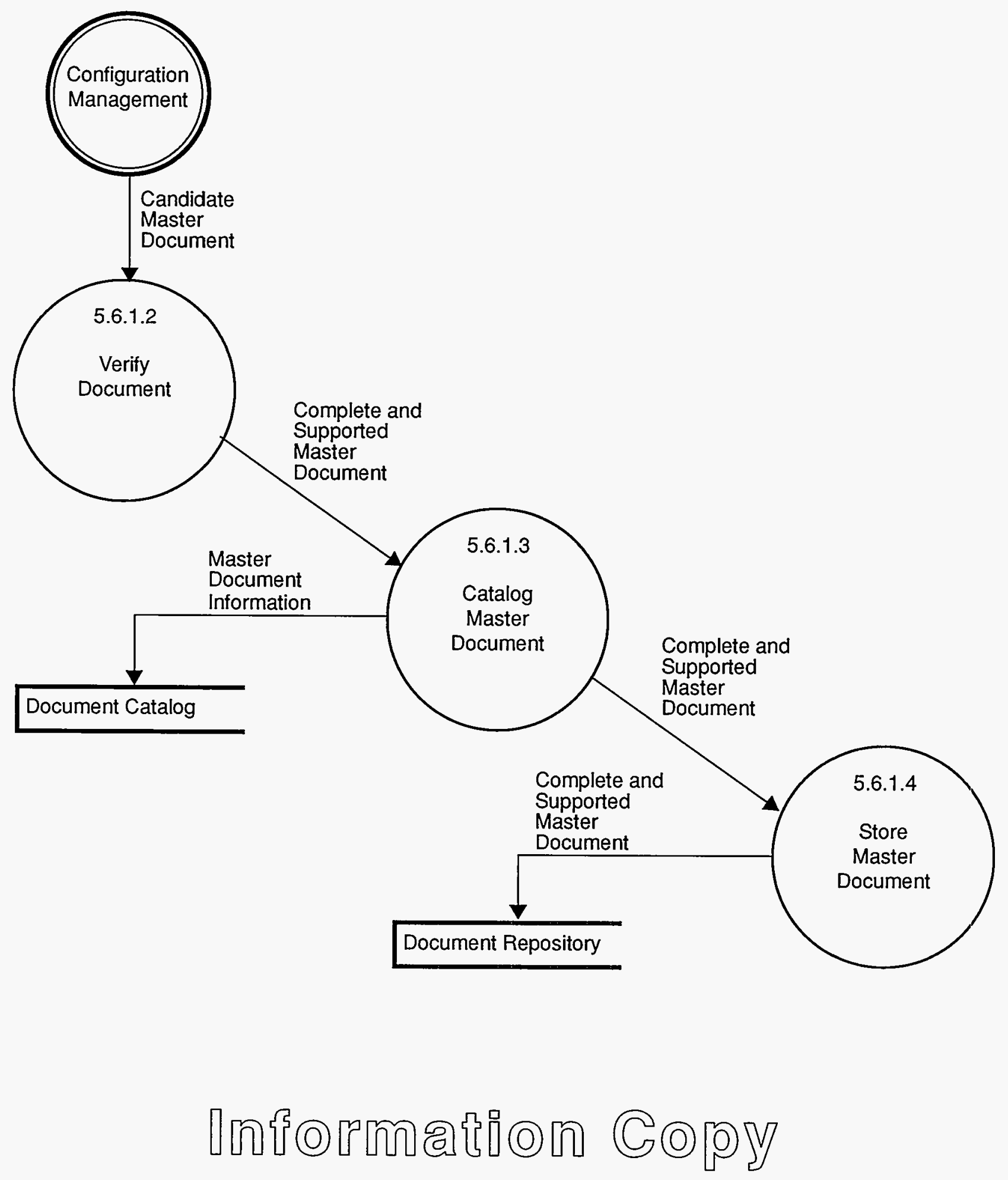




foonfiguration
Management
Office

\subsubsection{Obsolete Documents}

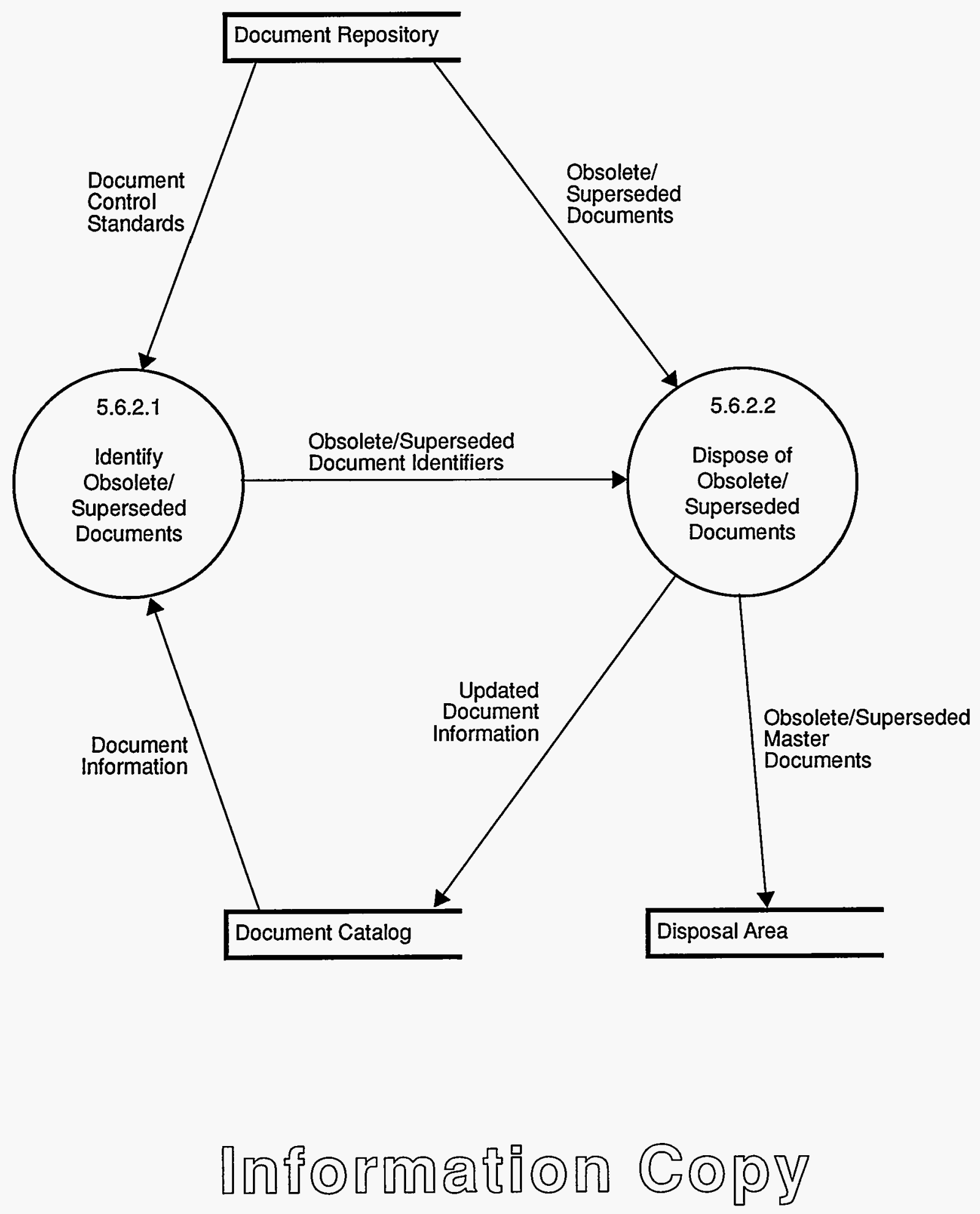




\begin{tabular}{|c|c|c|}
\hline $\begin{array}{l}\text { FOR-001.003 } \\
\text { Appendix A } \\
\text { Page } 18 \text { of } 25\end{array}$ & $\begin{array}{l}\text { Integrated Formal Operations } \\
\text { Plan }\end{array}$ & $\begin{array}{r}\text { Configựration } \\
\text { Management } \\
\text {. Office }\end{array}$ \\
\hline
\end{tabular}

\subsubsection{Controlled Distribution}

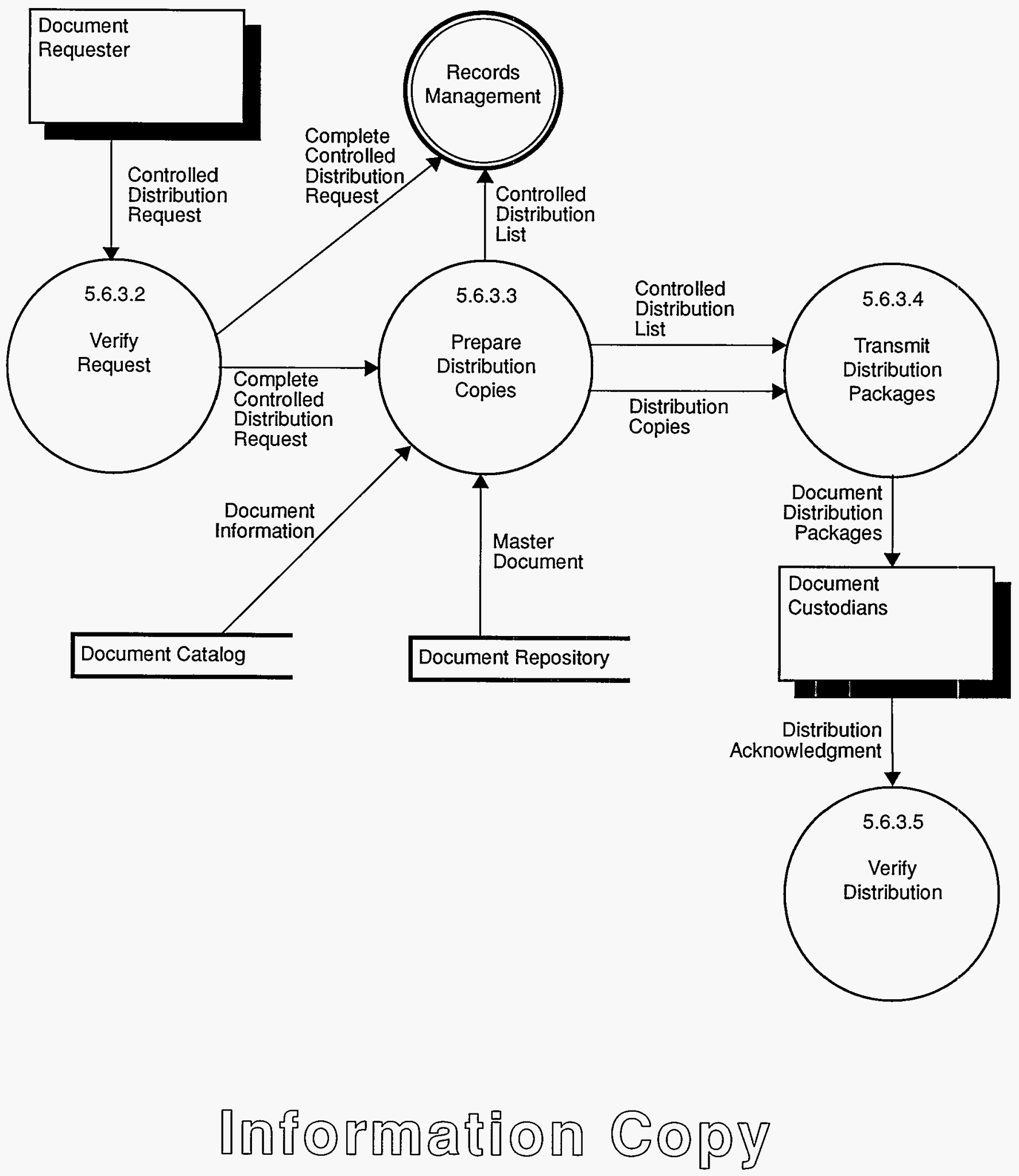




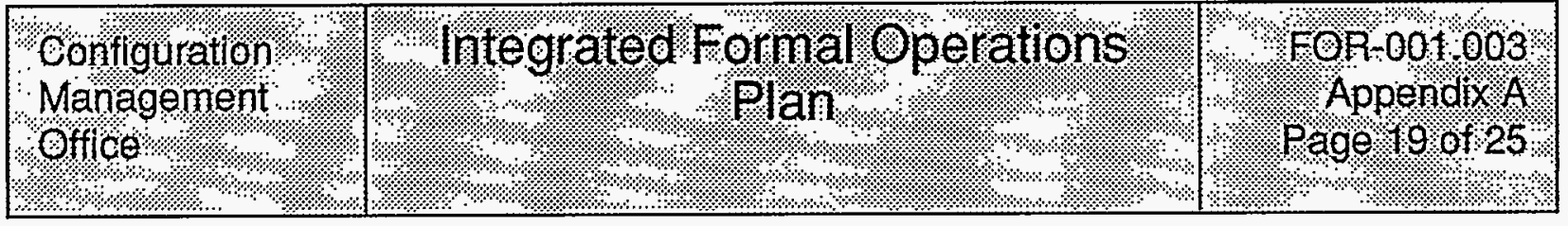

\subsubsection{Developing Procedures for a Work Process}

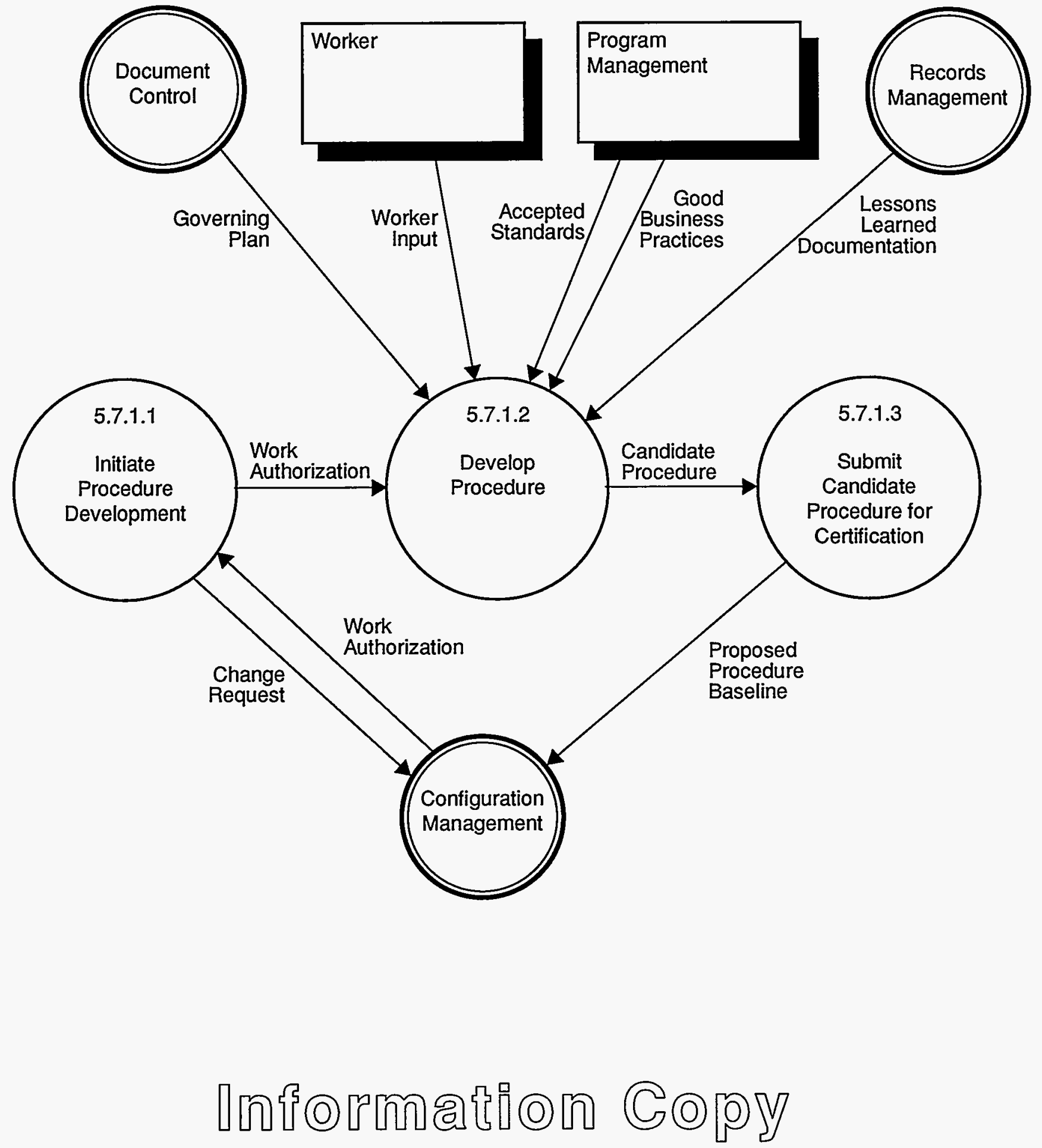




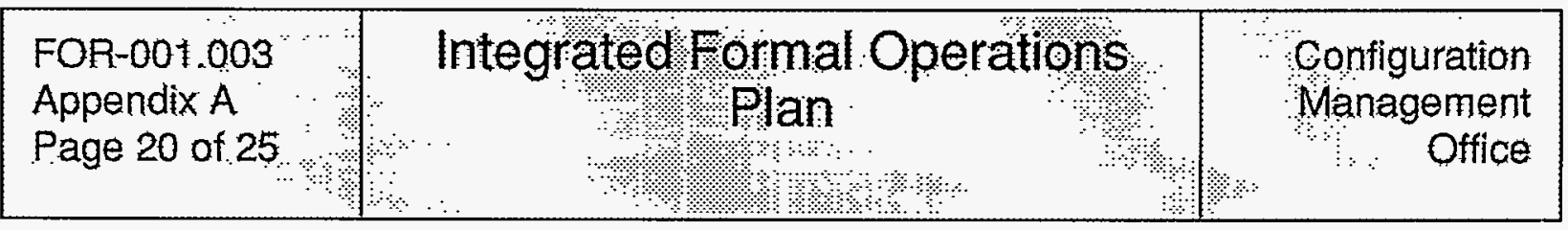

\subsubsection{Executing a Work Process}

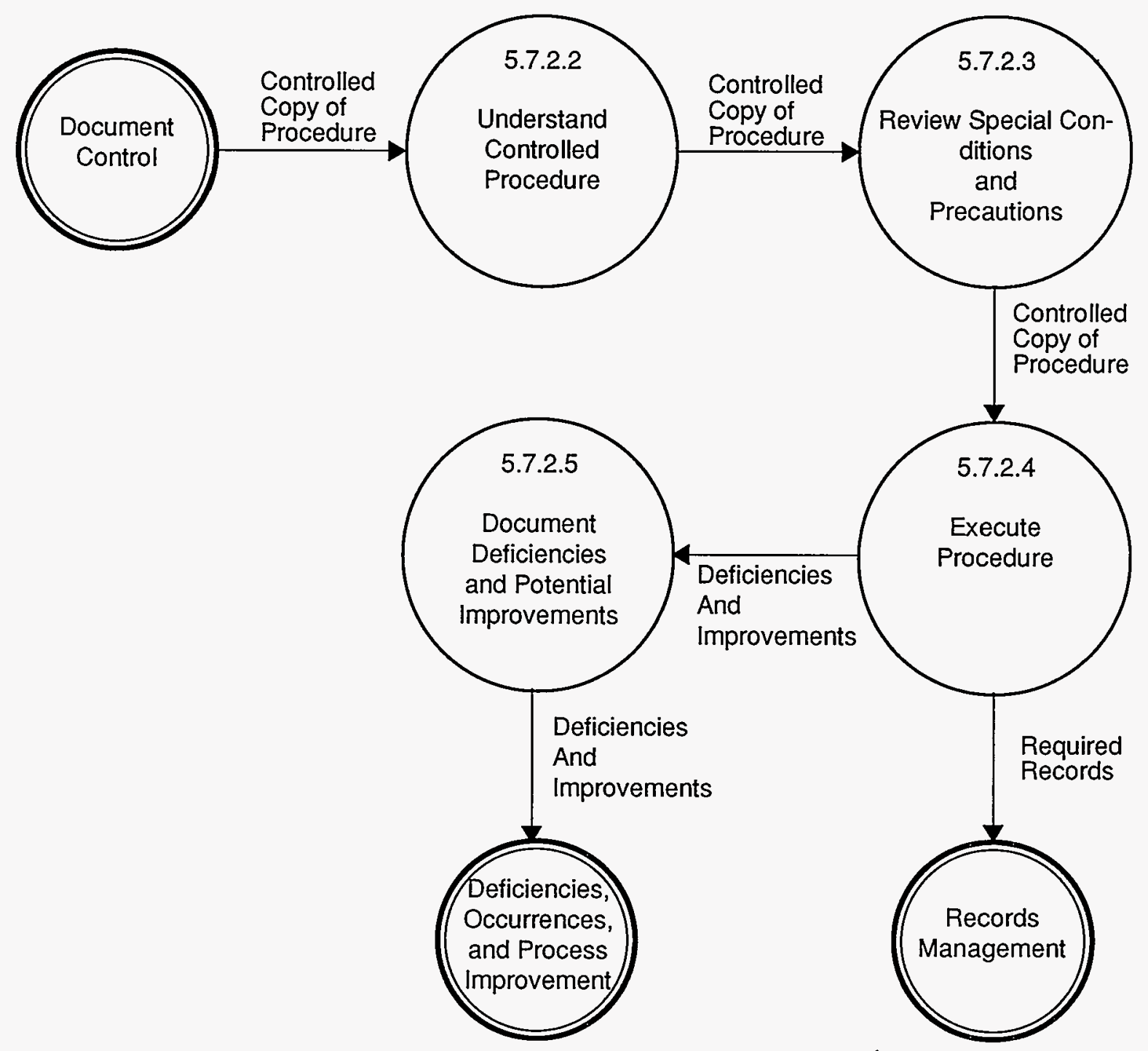




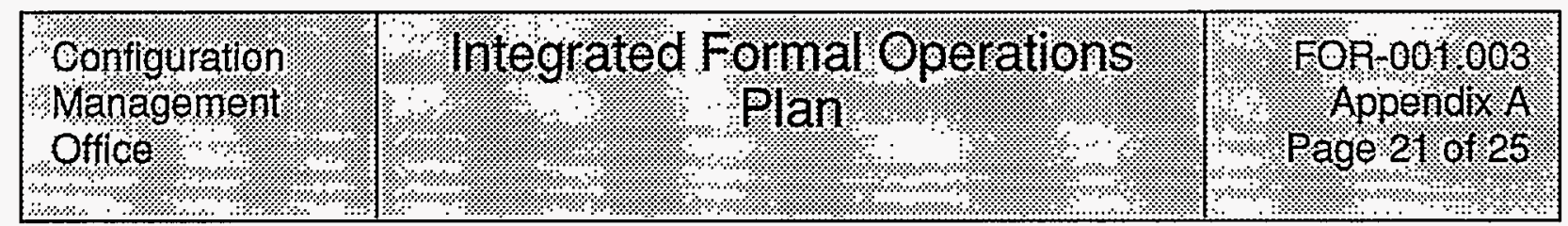

\subsection{Design}

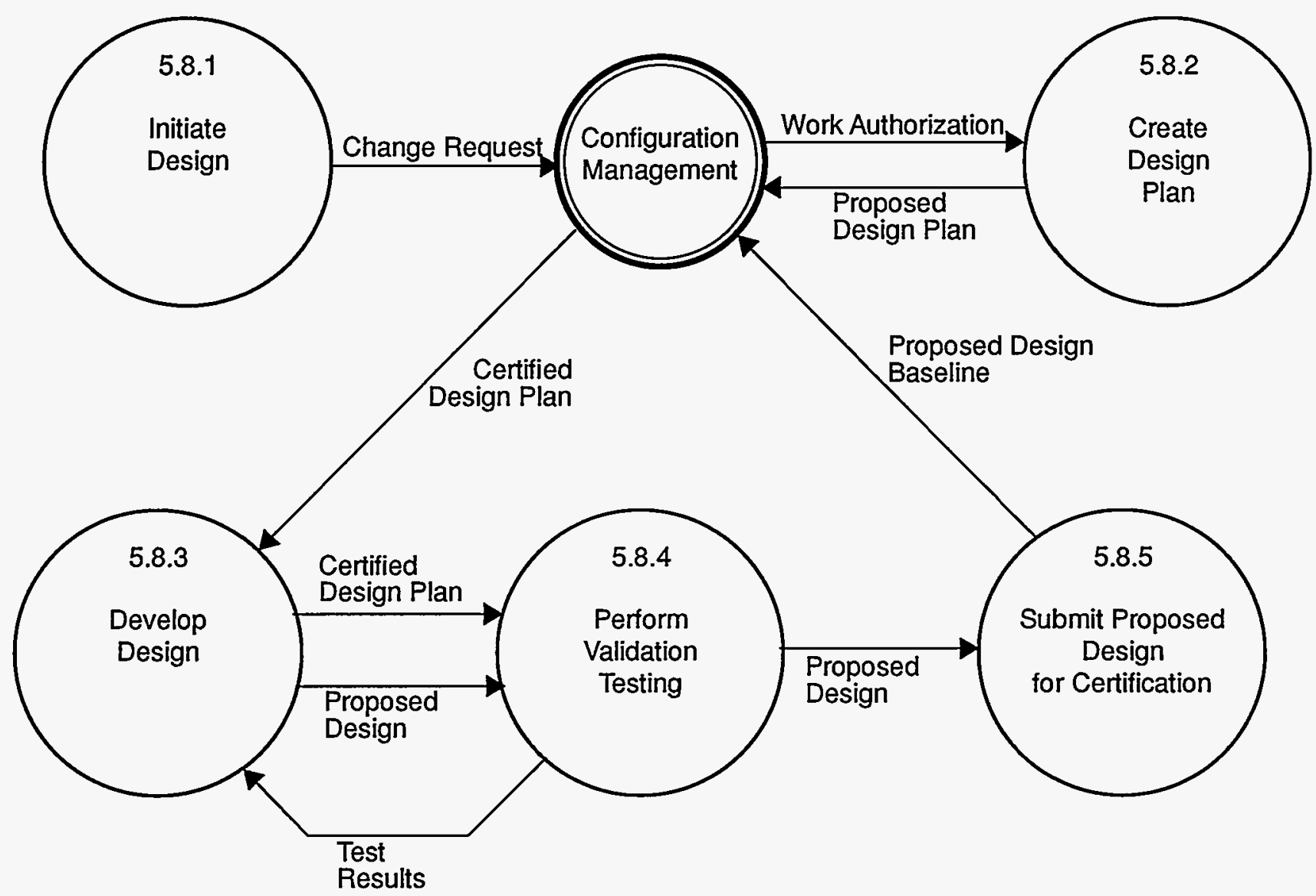

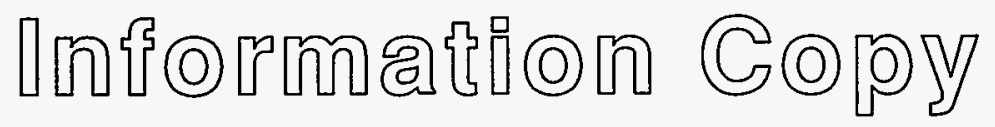




\begin{tabular}{|c|c|c|}
\hline $\begin{array}{l}\text { FOR-001,003 } \\
\text { Appendix A } \\
\text { Page } 22 \text { of } 25\end{array}$ & $\begin{array}{c}\text { Integrated Formal Operations } \\
\text { Plan }\end{array}$ & $\begin{array}{l}\text { Configuration } \\
\text { Management } \\
\text { Office }\end{array}$ \\
\hline
\end{tabular}

\subsubsection{Initiating a Procurement}

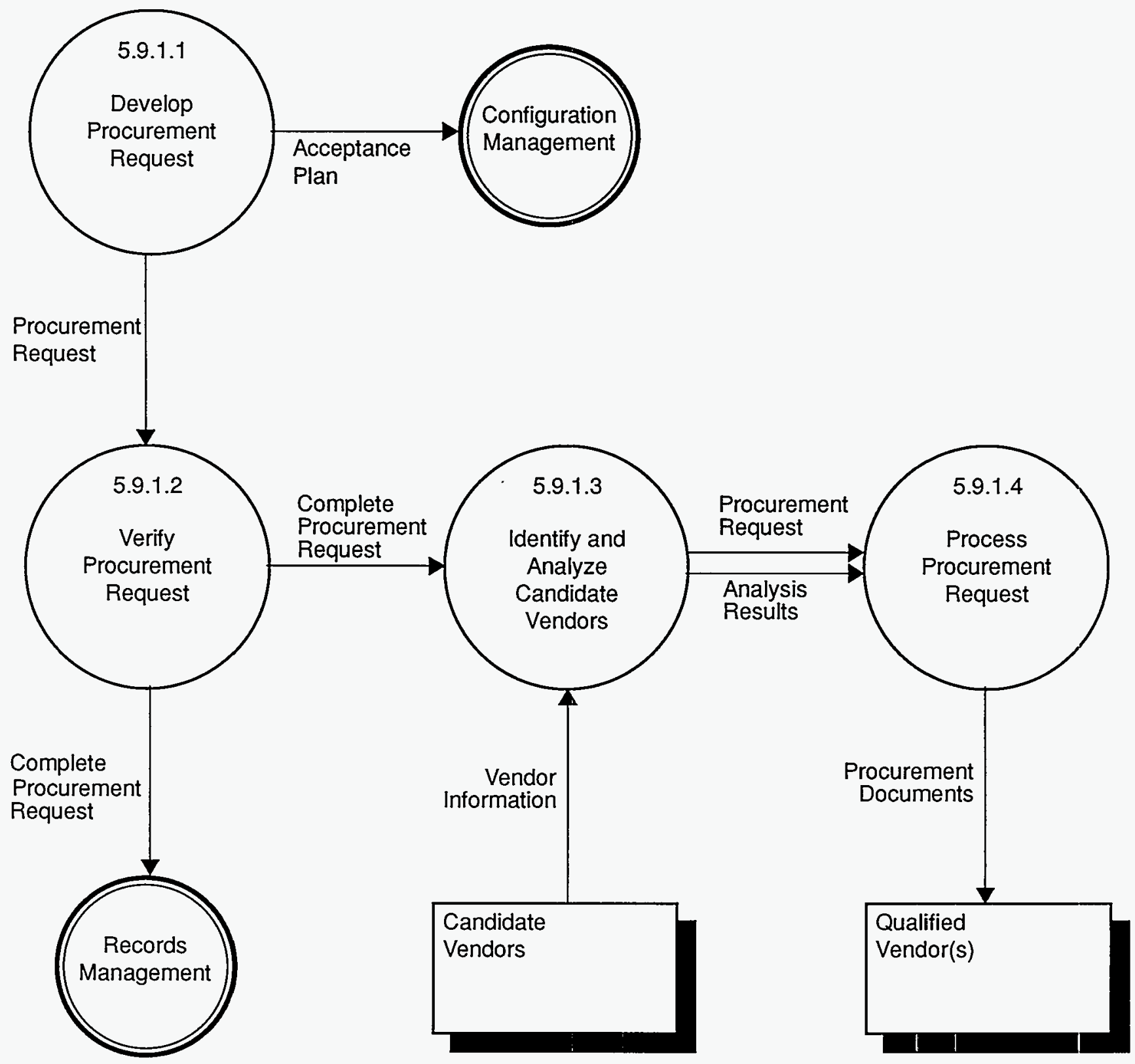




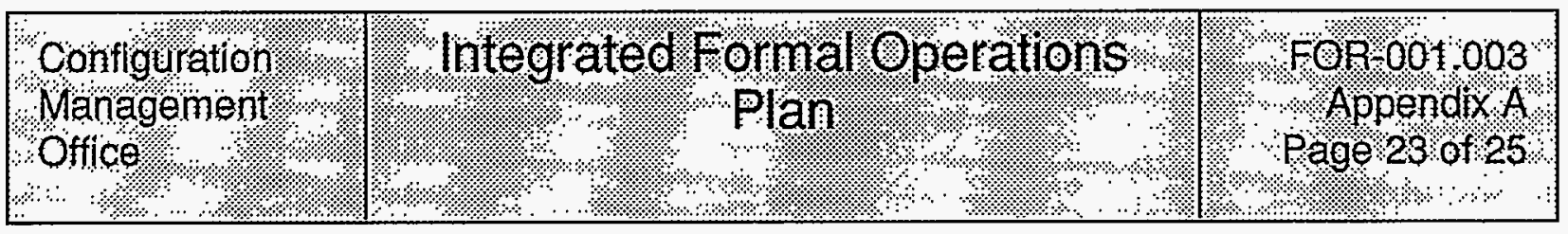

\subsubsection{Receiving and Acceptance}

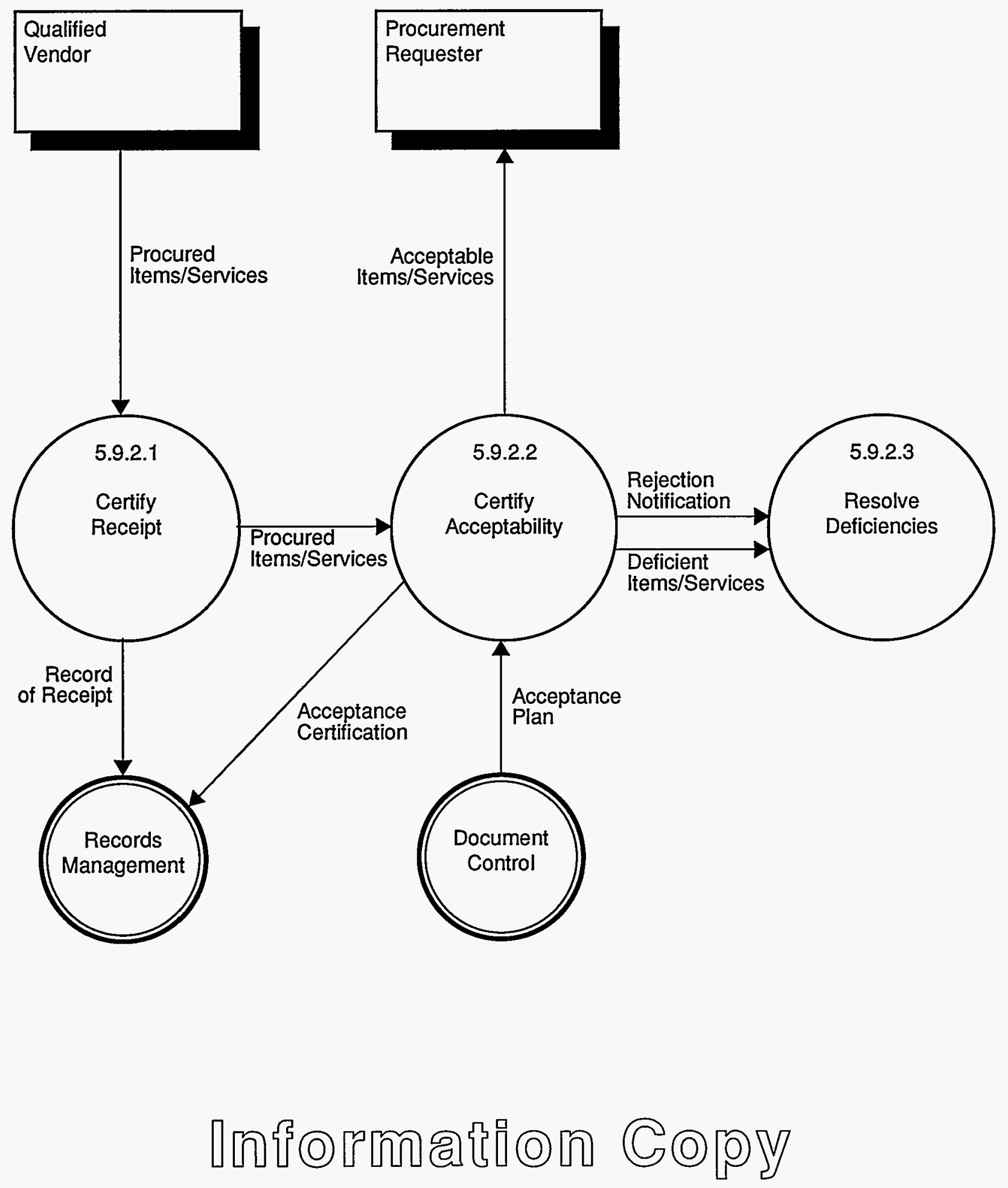




\begin{tabular}{|l|c|c|}
\hline $\begin{array}{l}\text { For-001003 } \\
\text { Appendix }\end{array}$ & Integrated Formal Operations & $\begin{array}{r}\text { Configuration } \\
\text { Management } \\
\text { Page } 24 \text { of } 25\end{array}$ \\
& & Office \\
\hline
\end{tabular}

\subsection{Inspection and Testing}

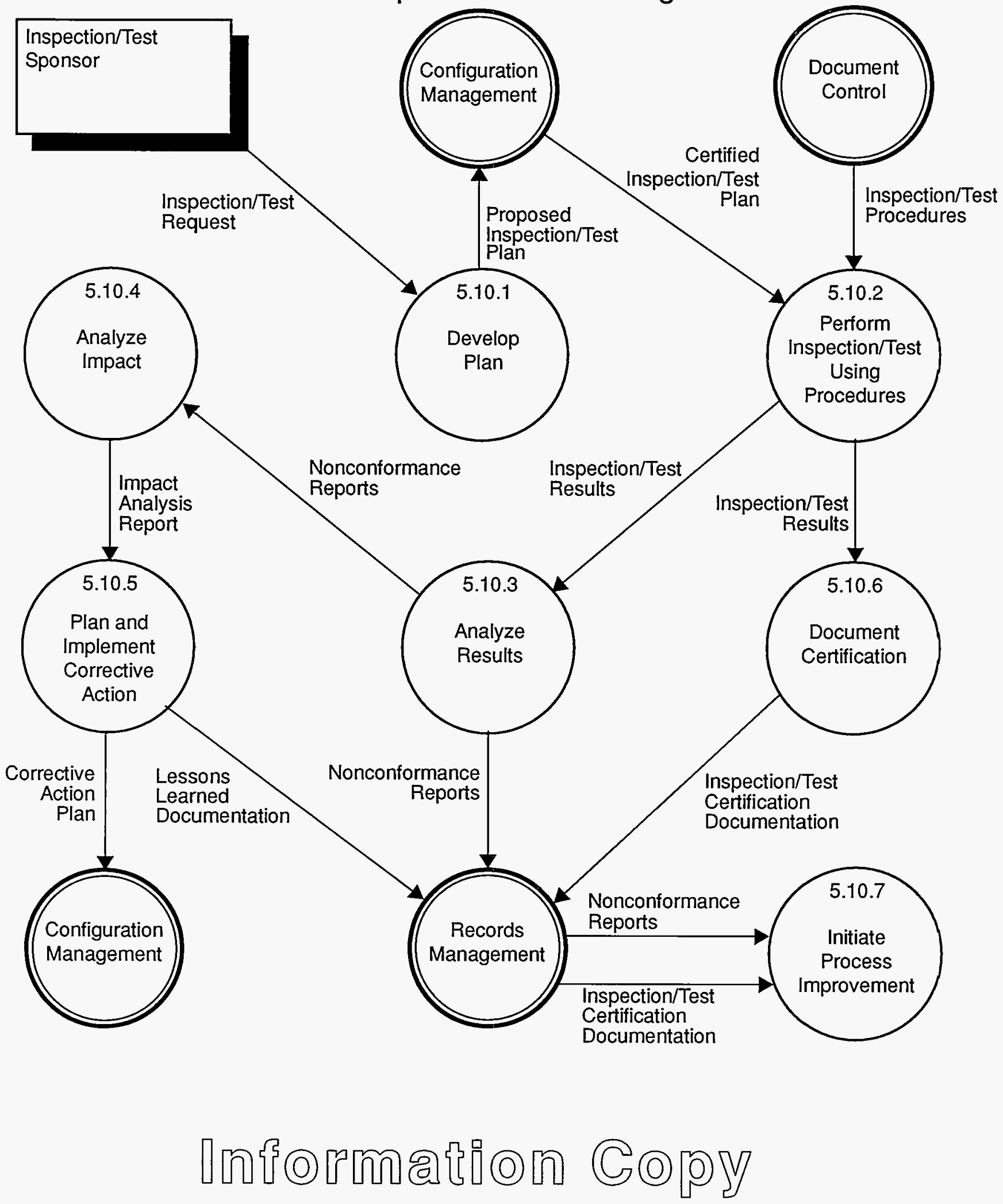




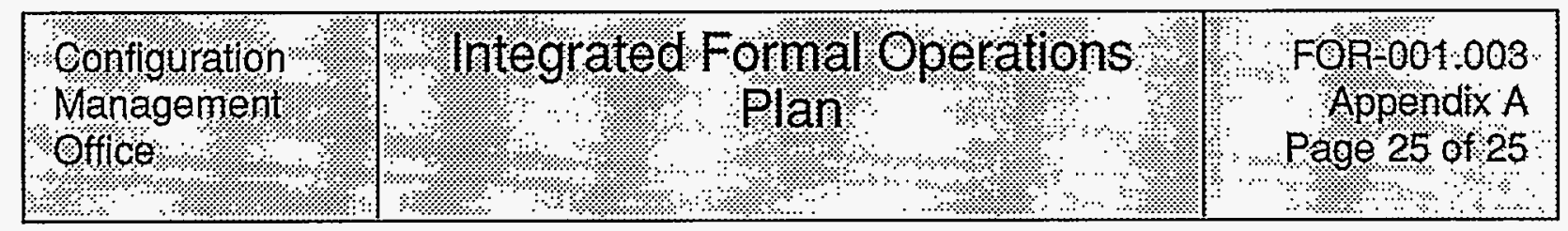

\subsection{Assessments}

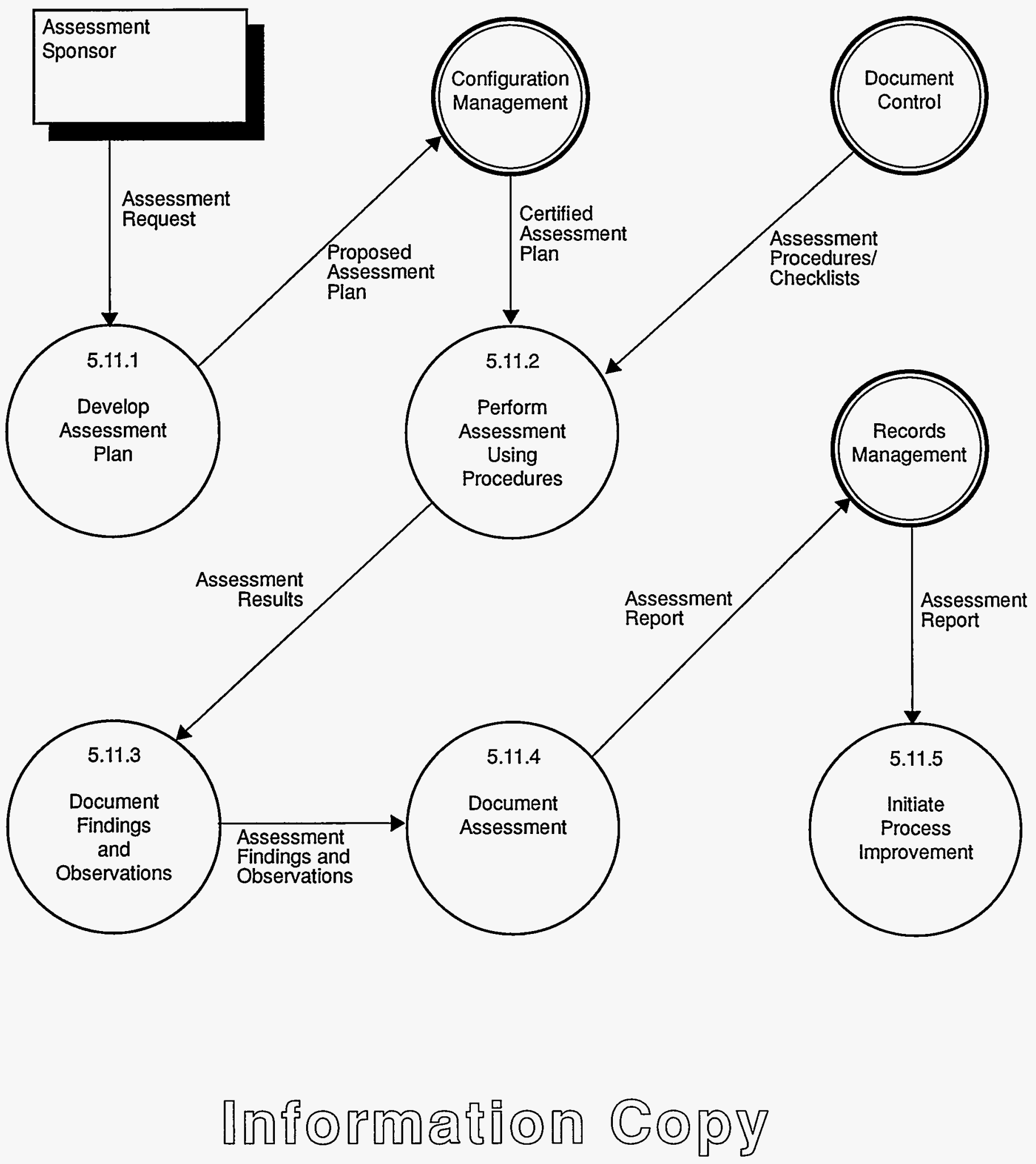




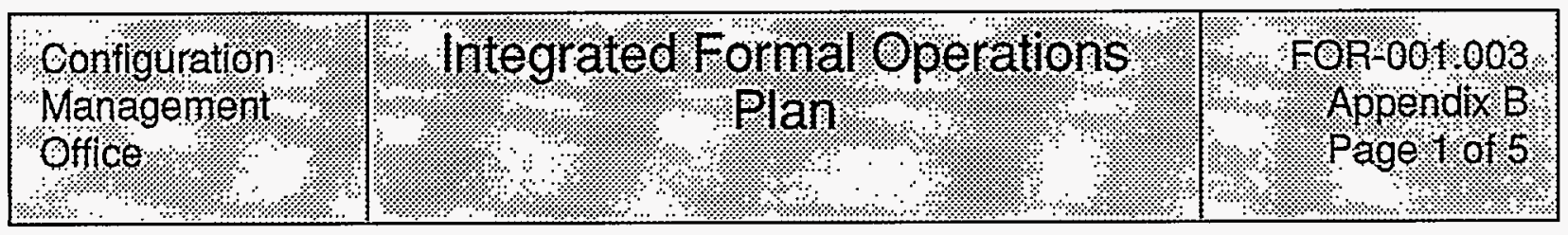

\section{TAILORING GUIDE}

\subsection{OVERVIEW OF THE INTEGRATED FORMAL OPERATIONS PROGRAM}

The integrated formal operations program, of which this plan is a part, provides all of the elements needed to establish a consistent, comprehensive formal operations environment at a Laboratory organization. It specifies overall requirements, furnishes implementing processes in the form of procedures and task lists, defines technical performance criteria, and establishes practical training programs.

Intended to be equally applicable to any Laboratory organization, the program comprises eleven specific elements. It specifies unambiguous requirements and exhaustive implementation and support information for each element. The intent is to furnish a smorgasbord of uniform, consistent, and coherent mini-programs from which an organization can construct a useful, low overhead, formal operations program.

The scope of the integrated formal operations program is not limited to any particular organization, discipline, or function at the Laboratory. It applies equally well across the board. However, achieving this universal applicability has a price: organization-specific information gets replaced by more general references, without compromising the authority of the program. Consequently, when an organization adopts the program, some tailoring is necessary to accommodate its particular role, organization, and operating environment. The tailoring process effectively adds sufficient organization-specific detail to the program without requiring changes to the principal program documents.

An example of this approach is evident in the way we handle roles and responsibilities throughout the program. We wrote all of the requirements and implementation in terms of general work functions rather than specific job positions that an organization must create or maintain. Work functions are closely related to program elements and processes, and the responsibilities associated with them are thoroughly and clearly defined.

However, there is no specification in the integrated program of how a work function maps into an existing organizational structure. Management therefore has the freedom to specify this mapping through the tailoring process. One work function may map into several existing positions, or numerous work functions may all be performed by only one worker. Regardless of the final tailoring, the approach permits the integrated formal operations plans and procedures to clearly spell out roles and responsibilities without imposing artificial structures on implementing organizations.

\subsection{INTEGRATED FORMAL OPERATIONS PROGRAM DOCUMENTATION}

To really understand the integrated formal operations program, one must first gain an appreciation for the hierarchy of documentation that defines it. This is particularly true if one expects to be successful at the tailoring process. We have chosen to organize these documents into three functionally related tiers:

- the integrated formal operations plan;

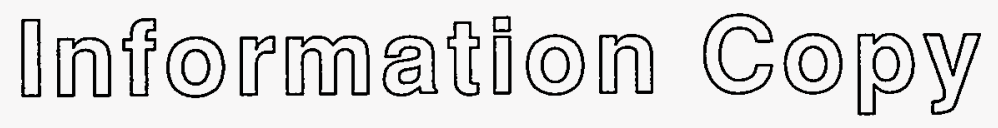




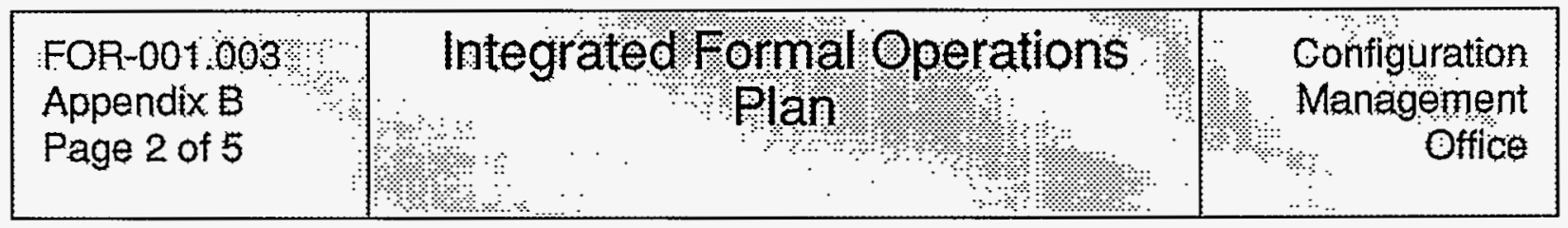

- implementing procedures and task lists; and

- technical standards.

\subsection{Integrated Formal Operations Plan}

The integrated formal operations plan (that is, this document) contains all of the requirements for the program. As the sole requirements document for the program, it provides the basis and authority for all implementations. It also defines the objective criteria that assessors will use to evaluate the performance of an implementation.

The requirements specified in the integrated formal operations plan are the result of an indepth analysis process. The goal of this process was to identify the minimum set of unambiguous requirements necessary to completely define the associated element, to specify formal interfaces between the elements, and to eliminate the implicit dependencies between them.

The result is a set of eleven explicit, indivisible program elements that define the entire formal operations landscape. Unlike other approaches consisting of collections of isolated, interdependent, disembodied requirements, this strategy provides authoritative, internally consistent, high-level building blocks (the program elements) from which to construct an overall program. It further provides well-defined, standard interconnections between elements, thereby vastly simplifying the program development process.

\subsection{Procedures and Task Lists}

The next tier of documents contains task lists and procedures. These documents define the processes that must be performed to satisfy the requirements specified in the integrated formal operations plan. As such, these documents define a particular implementation of the requirements. Under no circumstances may documents in this tier define new or auxiliary requirements.

Typically there is one procedure document for each program element. The procedure defines the overall process associated with the element. It may reference many subordinate task lists that provide the specific implementation details. Task lists must be referenced, either directly or indirectly through other task lists, by a procedure, in order to conform with the requirements levied on procedures in Section 5.7 of the integrated formal operations plan.

The integrated formal operations program is replete with procedures and task lists for the program elements. They are complete with detailed process specifications and supporting information such as forms and checklists. Together they define the recommended (but certainly not the only) implementation of the requirements in the plan.

\subsection{Technical Standards}

Technical standards specify additional criteria with which an implementation must comply. Often such criteria are necessary to define acceptance conditions, specify the attributes or characteristics of a component of the implementation (for example, temperature and humidity

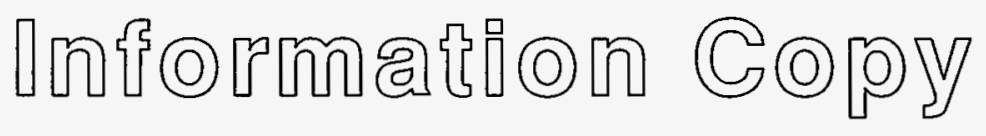




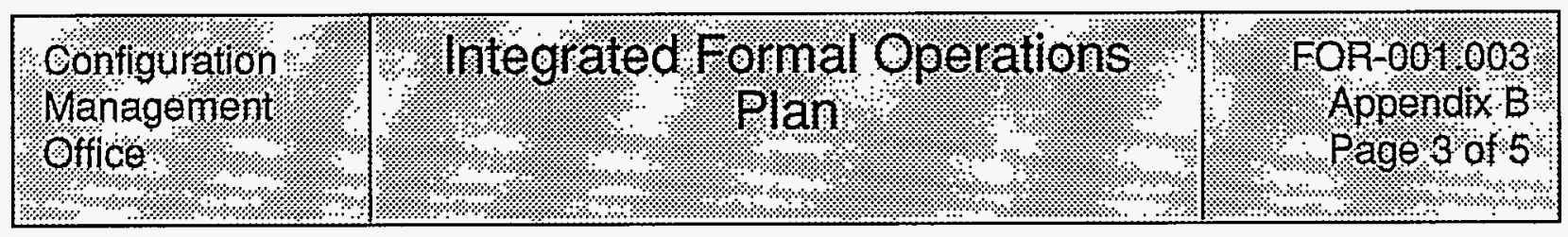

ranges required for storage of computer media), or other implementation-specific issues of a non-procedural nature.

We provide many technical standards with the integrated formal operations program. Although they are suitable for adoption as-is, we intend them to provide practical examples of how to write and use technical standards.

\subsection{TAILORING PHILOSOPHY}

A Laboratory organization has much flexibility in its approach to tailoring the integrated formal operations program to the local environment. Tailoring may occur at many levels, and many factors affect the tailoring approach.

The adopting organization must decide how much of the integrated program to incorporate. The organization may choose to adopt the entire program: plan, procedures, task lists, and technical standards. This is the simplest approach and requires minimal tailoring to map the work functions specified in the plan with local job positions.

Alternatively the organization may decide to adopt only certain elements of the program. In this case, they could grade out the irrelevant or otherwise unneeded elements (and any associated procedures, task lists, and/or standards). They would follow this high level tailoring with the work function mapping described above.

It is also possible to tailor the procedures and task lists, although care must be taken to ensure that the tailored documents still satisfy the program requirements from the plan. In such cases, the organization may modify some or all of the original procedures and task lists, or it might simply use them as resources for developing a customized set.

Almost regardless of the tailoring approach, we expect most organizations will want to modify some or all of the technical standards to ensure a better fit to the local environment. Indeed, we encourage this approach and provide the technical standards for precisely this purpose. That is to say that one of the principal functions of the technical standards is to provide a vehicle and mechanism for adapting the integrated formal operations program without impacting the higher level requirements and implementation documents.

The sections that follow provide specific suggestions for employing the technical standards to complete this necessary tailoring. Using these as a guide and keeping your organization's goals and priorities clearly in mind, you can develop an effective, low-overhead formal operations program rapidly and efficiently.

\subsection{TAILORING GUIDANCE}

\subsection{Technical Standards}

The implementing procedures provided with this plan are written with a Laboratory-wide focus, without specifying the non-procedural information that is dependent on the individual organizations implementing this plan. The organizations will provide this non-procedural information in the form of technical standards documents. In the most formal organizations, the organization's configuration control board will approve the technical standards

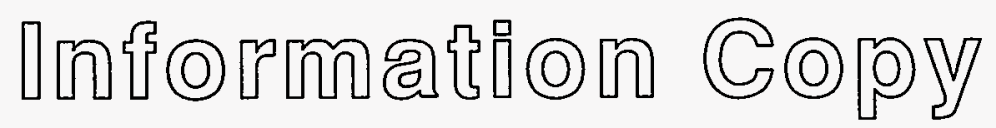




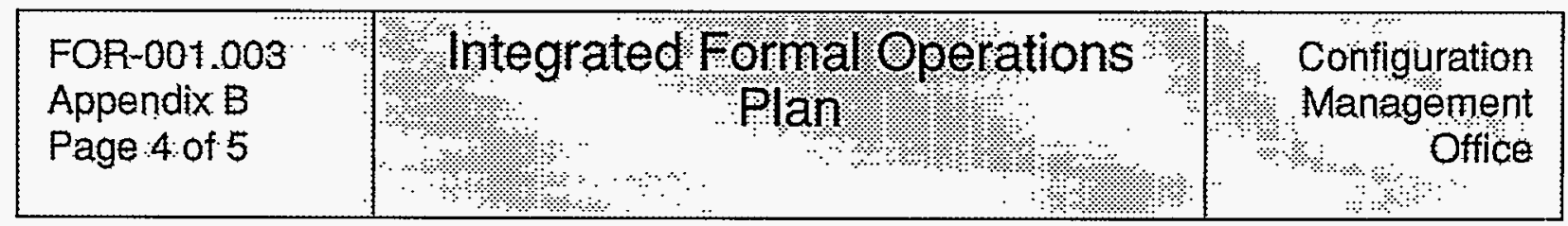

documents. Alternatively, in a less formal operation, a memorandum from a technical standards developer to the accountable line manager will satisfy the requirements.

The organization must decide whether to adopt the technical standards provided with the integrated formal operations program outright, adapt them for their use, or create entirely different standards. For example, the standards for configuration control boards has broad applicability and will be extremely useful to most organizations as is. The standards for records management may need some modification by an organization to more adequately fit its needs. Other areas of operation will be so intimately tied to the specific organization that the organization will have to create the technical to address those environments.

\subsection{Responsibilities}

Another important task is mapping the work functions specified in Section 6.0 of this plan to existing or planned job titles within the organization. The organization should specify it's job descriptions in terms of those work functions and should document them in formal management documents. This task does not necessarily result in a one to one mapping; single individuals could fulfill multiple work functions, and multiple individuals could have responsibility for single work functions. For small organizations this mapping will most likely be the former with a single individual accomplishing the tasks of, for example, records manager and document manager. Large organizations on the other hand will most likely have such a volume of records and documents that these work functions may be assigned to multiple individuals.

When assigning responsibilities, the organization must take into account which plan elements it will implement, and at what level of formality. If, for example, the plan element for design is not implemented, there is no need to assign the design owner work function to an individual within the organization. If such a person is needed on an infrequent basis, the accountable line manager can assign someone on a temporary basis.

The local configuration control board will be the focal point of change control and will provide a strong influence in the formal operations program. Therefore, the CCB should be made up of the individuals with primary responsibility within the organization, for example, the accountable line manager (who should serve as the chair), technical managers such as operations and engineering, and support managers such as configuration management and records management. Refer to the configuration management procedures and technical standards for information about the roles and structure of configuration control boards.

\subsection{Budget and Schedule}

Because this plan is intended for use by multiple implementing organizations, it does not attempt to characterize the budget and schedule information. The implementing organization must develop the budget and schedule for the formal operations program, regardless of whether this plan is being adopted outright or adapted for the special circumstances of the organization. The implementing organizations will provide budget and schedule information in separate documents that should be considered as controlled elements.

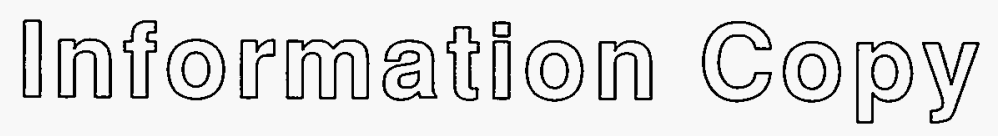




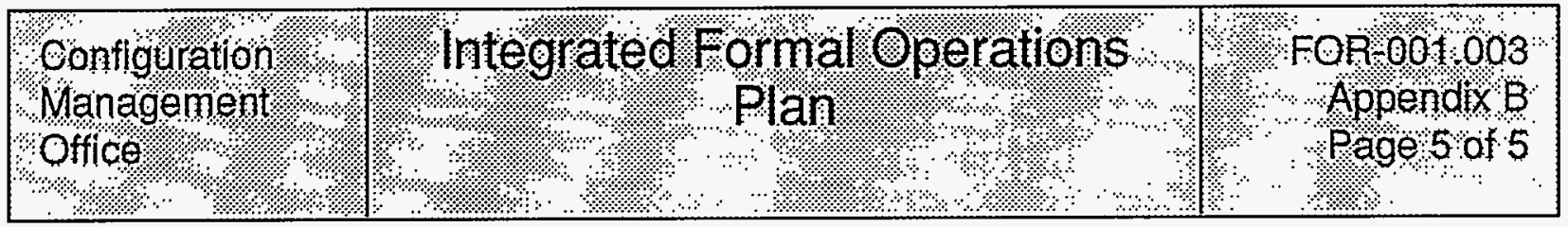

\subsection{Other Issues}

Two other issues must be addressed by the organization tailoring this plan to their operations:

- The organization should change the mailing address for the Document Improvement Questionnaire attached to any document adapted by the organization (no longer controlled by the Configuration Management Office) to be that of the local organization.

- The document identifier for the plan and any implementing procedures adapted by the organization (no longer controlled by the Configuration Management Office) should reflect the labeling methodology specified on the organization's configuration definition for requirements documents. 


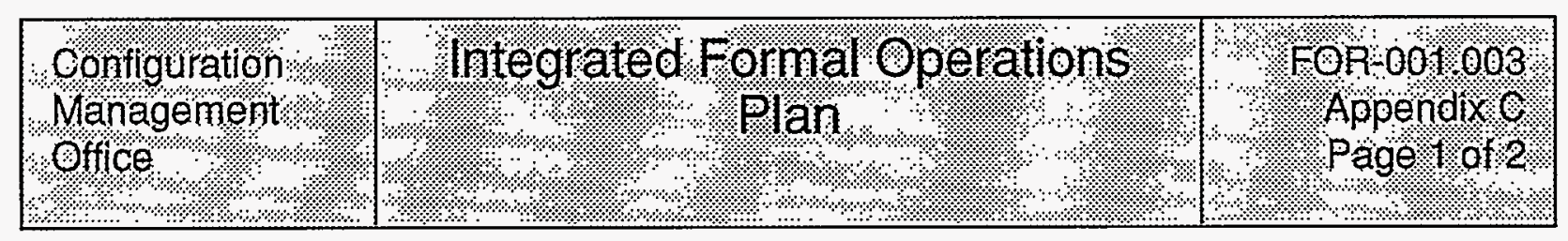

\section{INDEX}

\begin{tabular}{|c|c|c|c|}
\hline A & & document catalog & 17 \\
\hline acceptance plan & 20 & document control standards & 16 \\
\hline advocate & 14 & document custodian & 17 \\
\hline analyzed change request & 9 & document distribution package & 18 \\
\hline analyzed variance request & 12 & document improvement questionnaire & 34 \\
\hline assessment checklist & 22 & document manager & 16 \\
\hline assessment plan & 22 & document repository & 17 \\
\hline assessment report & 23 & & \\
\hline assessment sponsor & 22 & $\mathbf{E}$ & \\
\hline assessor & 22 & evaluation issues & 10 \\
\hline authentication & 10 & experience documentation & 15 \\
\hline B & & $\mathbf{F}$ & \\
\hline baseline & 8 & finding & 23 \\
\hline baseline catalog & 11 & & \\
\hline baseline certification & 11 & I & \\
\hline baseline repository & 11 & impact analysis report & 14 \\
\hline & & initiator & 14 \\
\hline C & & inspection plan & 21 \\
\hline candidate for qualification & 12 & inspection/test certification documente & ation \\
\hline change agent & 10 & 22 & \\
\hline change request & 9 & inspection/test sponsor & 21 \\
\hline change requester & 9 & investigator & 14 \\
\hline configuration control board & 9 & & \\
\hline configuration definition & 6 & $\mathbf{L}$ & \\
\hline configuration management liaison & 9 & lessons learned & 14 \\
\hline configuration manager & 9 & lessons learned documentation & 14 \\
\hline configuration status report & 12 & & \\
\hline controlled distribution list & 17 & $\mathbf{M}$ & \\
\hline $\begin{array}{l}\text { controlled distribution request } \\
\text { controlled elements }\end{array}$ & $\begin{array}{r}17 \\
5\end{array}$ & master document & 16 \\
\hline corrective action plan & 14 & $\mathbf{N}$ & \\
\hline D & & nonconformance & 21 \\
\hline deficiency & 14 & nonconformance report & \\
\hline deficiency report & 14 & $\mathbf{O}$ & \\
\hline $\begin{array}{l}\text { design owner } \\
\text { design plan }\end{array}$ & $\begin{array}{l}19 \\
19\end{array}$ & observation & 23 \\
\hline document & 16 & & \\
\hline
\end{tabular}

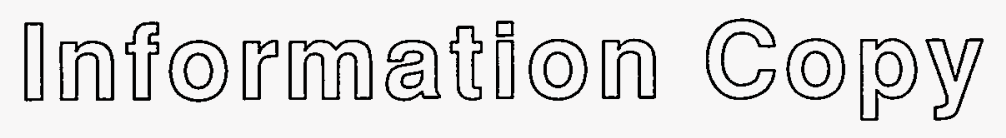



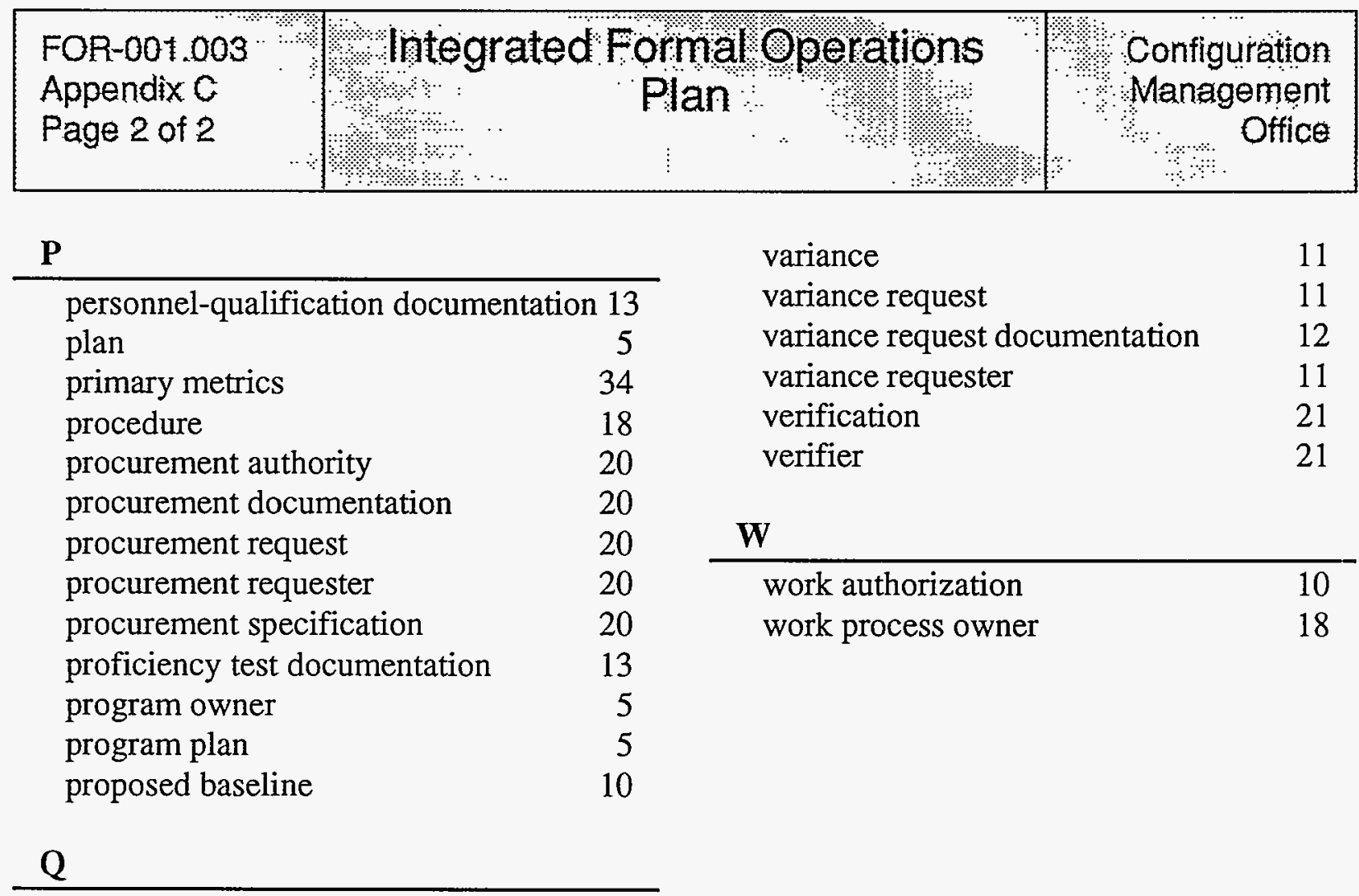

$\underline{Q}$

personnel-qualification documentation 13

plan

primary metrics

34

procedure

18

procurement authority

20

procurement documentation

20

procurement request

20

procurement requester

procurement specification

variance

11

variance request

11

variance request documentation $\quad 12$

variance requester

11

verification

21

verifier

proficiency test documentation

20

20

program owner

13

program plan

proposed baseline

qualification certification

qualification criteria

$\mathbf{R}$

record of receipt

record request

records

15

records catalog

15

records management standards

records manager

15

report request

12

report requester

test plan

21

trainees

13

trainer

13

training certification

13

training course

13

training course developer

13

training plan

13

training program

\section{V}

validation 


\section{DOCUMENT IMPROVEMENT QUESTIONNAIRE}

\begin{tabular}{|c|c|c|c|c|c|}
\hline & Excellent & Good & Fair & Poor & N/A \\
\hline Accuracy & $\square$ & $\square$ & $\square$ & $\square$ & $\square$ \\
\hline Clarity & $\square$ & $\square$ & $\square$ & $\square$ & $\square$ \\
\hline Consistency & $\square$ & $\square$ & $\square$ & $\square$ & $\square$ \\
\hline Completeness & $\square$ & $\square$ & $\square$ & $\square$ & $\square$ \\
\hline Level of Detail & $\square$ & $\square$ & $\square$ & $\square$ & $\square$ \\
\hline Organization & $\square$ & $\square$ & $\square$ & $\square$ & $\square$ \\
\hline Relevance & $\square$ & $\square$ & $\square$ & $\square$ & $\square$ \\
\hline Usefulness & $\square$ & $\square$ & $\square$ & $\square$ & $\square$ \\
\hline Understandability & $\square$ & $\square$ & $\square$ & $\square$ & $\square$ \\
\hline Examples & $\square$ & $\square$ & $\square$ & $\square$ & $\square$ \\
\hline Figures & $\square$ & $\square$ & $\square$ & $\square$ & $\square$ \\
\hline Index & $\square$ & $\square$ & $\square$ & $\square$ & $\square$ \\
\hline Lack of Editorial Errors & $\square$ & $\square$ & $\square$ & $\square$ & $\square$ \\
\hline Page Layout & $\square$ & $\square$ & $\square$ & $\square$ & $\square$ \\
\hline Overall Quality & $\square$ & $\square$ & $\square$ & $\square$ & $\square$ \\
\hline
\end{tabular}

The best feature of this document is

The worst feature of this document is

I found the following errors in this document:

Page Description

Additional comments or suggestions to improve this document:

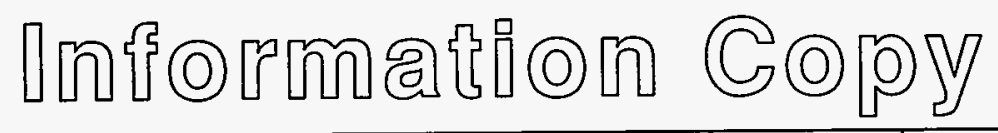

\begin{tabular}{|l|l|}
\hline Organization & Telephone \\
\hline
\end{tabular}

